\title{
F-Area Burning/Rubble Pits (231-F, 231-1F, \& 231-2F) Corrective Measures Study/Feasibility Study
}

by

E. Palmer

Westinghouse Savannah River Company

Savannah River Site

Aiken, South Carolina 29808

DOE Contract No. DE-AC09-89SR18035

This paper was prepared in connection with work done under the above contract number with the U.S.

Department of Energy. By acceptance of this paper, the publisher and/or recipient acknowledges the U.S. Government's right to retain a nonexclusive, royalty-free license in and to any copyright covering this paper, along with the right to reproduce and to authorize others to reproduce all or part of the copyrighted paper.
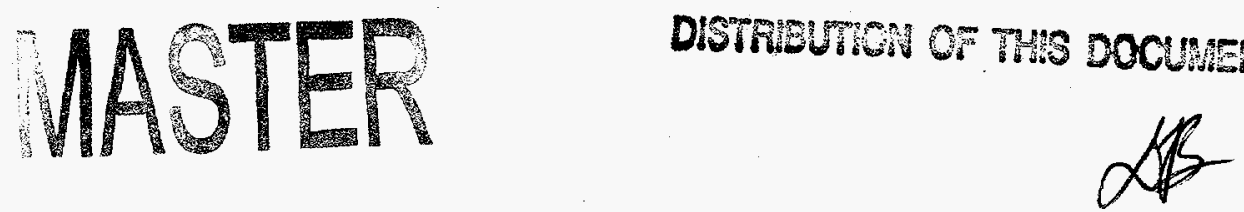
United States Department Of Energy

Savannah River Site

F-Area Burning/Rubble Pits (231-F, 231-1F, \& 231-2F) Corrective Measures Study/Feasibility Study (U)

WSRC-RP-95-660

Revision 1.1

June 17, 1996

Westinghouse Savannah River Company

Savannah River Site

Aiken, SC 29808

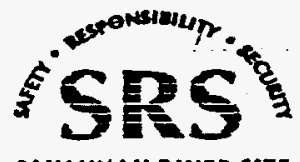

Prepared for the U. S. Department of Energy under Contract No. DE-AC09-89-SR18035 
This page intentionally left blank. 


\section{DISCLAIMER}

This report was prepared as an account of work sponsored by an agency of the United States Government. Neither the United States Government nor any agency thereof, nor any of their employees, makes any warranty, express or implied, or assumes any legal liability or responsibility for the accuracy, completeness, or usefulness of any information, apparatus, product, or process disclosed, or represents that its use would not infringe privately owned rights. Reference herein to any specific commercial product, process, or service by trade name, trademark, manufacturer, or otherwise does not necessarily constitute or imply its endorsement, recommendation, or favoring by the United States Government or any agency thereof. The views and opinions of authors expressed herein do not necessarily state or reflect those of the United States Government or any agency thereof.

This report has been reproduced directly from the best available copy.

Available to DOE and DOE contractors from the Office of Scientific and Technical Information, P.O. Box 62, Oak Ridge, TN 37831; prices available from (615) 576-8401.

Available to the public from the National Technical Information Service, U.S. Department of Commerce, 5285 Port Royal Road, Springfield, VA 22161.

Printed in the United States of America
Prepared for
U.S. Department of Energy
by
Westinghouse Savannah River Company
Aiken, South Carolina




\section{Table of Contents}

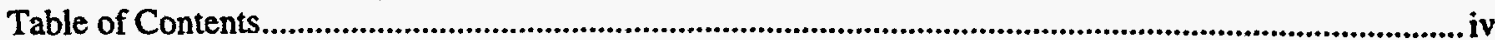

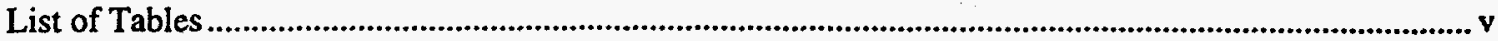

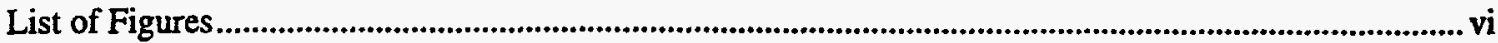

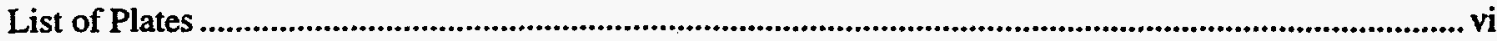

Acronyms and Glossary .................................................................................................................................. vii

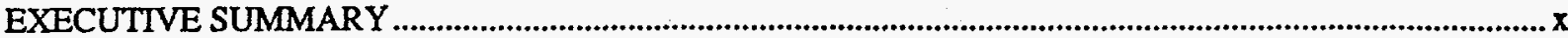

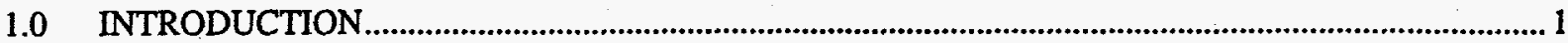

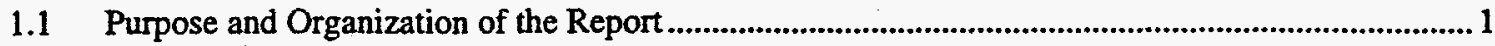

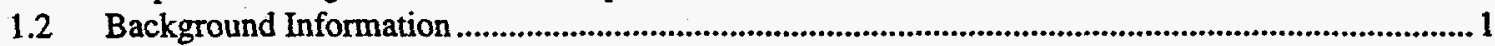

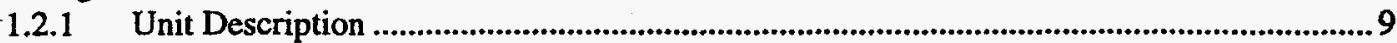

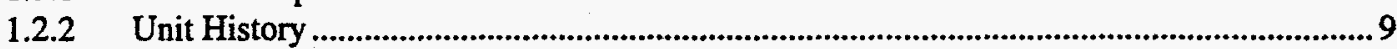

1.2.3 Nature and Extent of the Contamination..................................................................................... 9

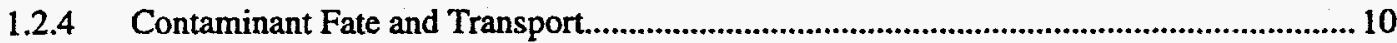

1.2.4.1 Data Collection and Evaluation ......................................................................... 10

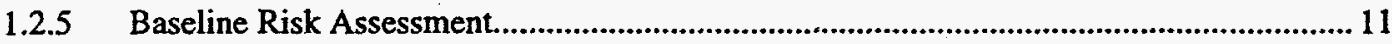

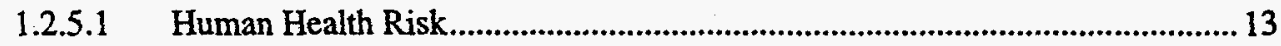

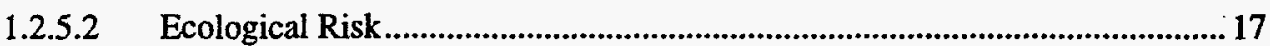

1.2.5.3 Uncertainties from the Baseline Risk Assessment ...........................................2 23

2.0 IDENTIFICATION AND SCREENING OF TECHNOLOGIES .........................................................24

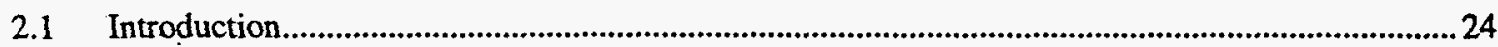

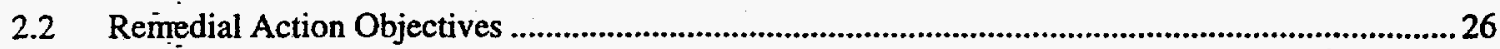

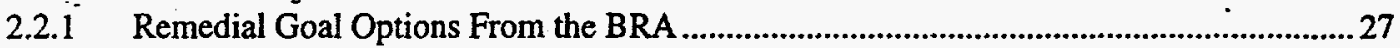

2.2.1 Applicable or Relevant and Appropriate Requirements (ARARs) …................................27

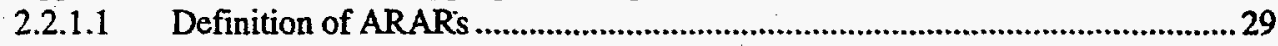

2.2.1.2 To-Be-Considered Information......................................................................29

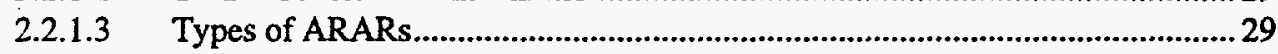

2.2.2 Remedial Action Objectives .....................................................................................................31

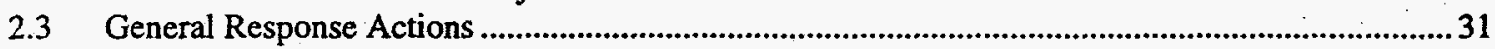

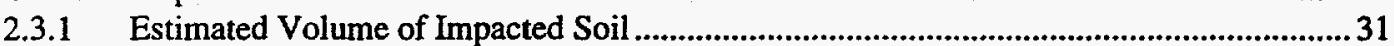

2.4 Identification and Screening of Technology Types and Process Options ........................................32

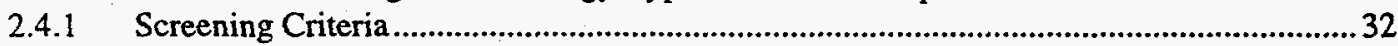

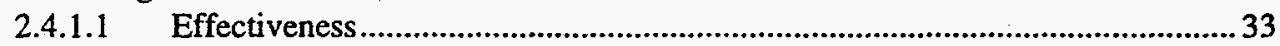

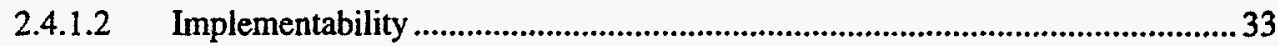

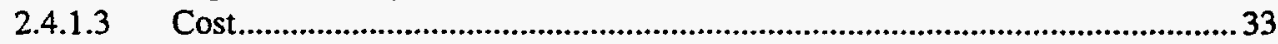

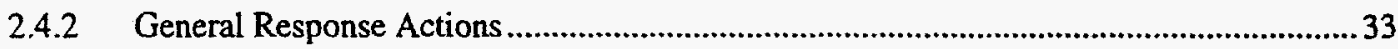

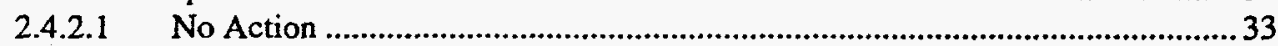

2.4.2.2 Institutional Controls ................................................................................. 34

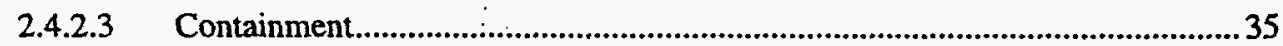

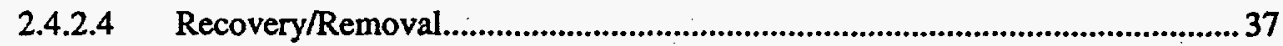

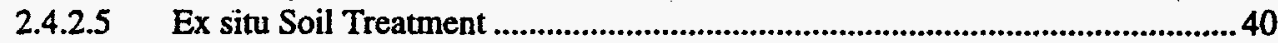

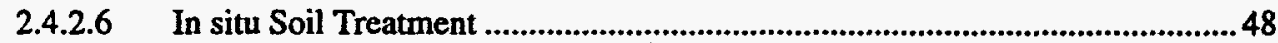

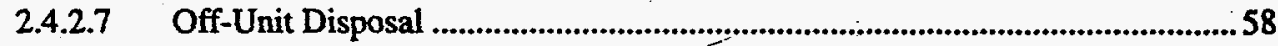

2.4.3 Screening for Effectiveness, Implementability, and Cost ................................................5

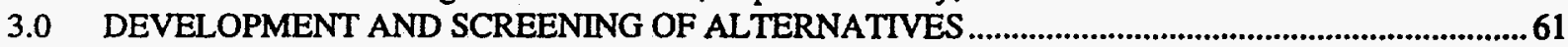

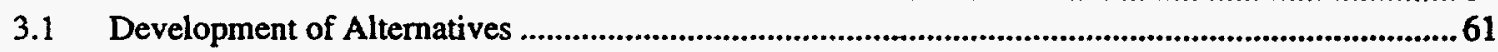

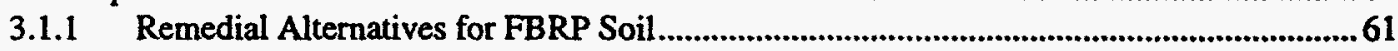

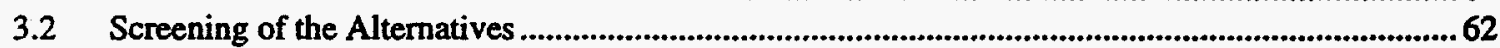

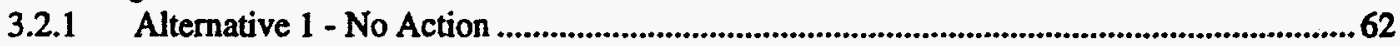

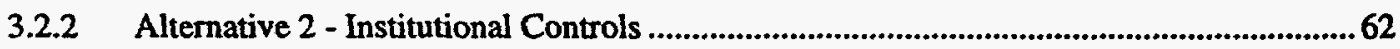

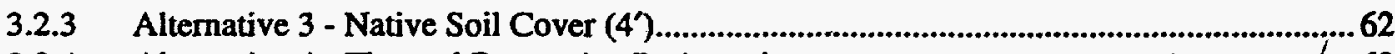

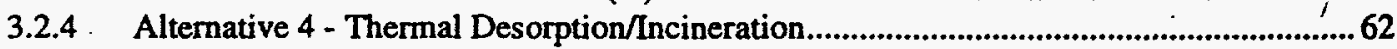

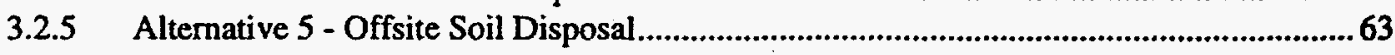




\section{DISCLAIMER}

Portions of this document may be illegible electronic image products. Images are produced from the best available original document. 


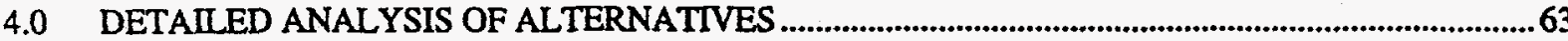

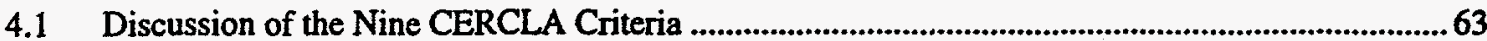

4.2 Evaluation of the Alternatives Under the Nine CERCLA Criteria...................................................66

4.2.1 Alternative 1 - No Action ....................................................................................................6 66

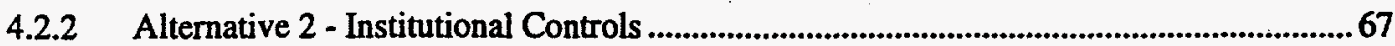

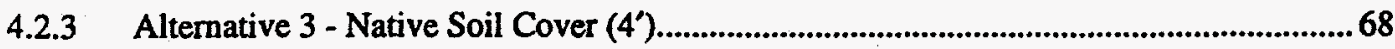

4.2.4 Alternative 4 - Thermal Desorption/Incineration...............................................................69

4.2.5 Alternative 5 - Offsite Soil Disposal..........................................................................70

4.2.6 Summary of the Evaluation of the Alternatives Under the 9 CERCLA Criteria................71

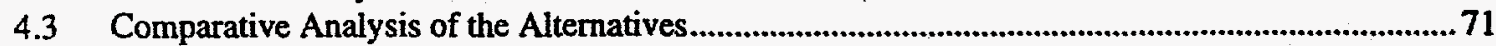

4.3.1 Overall Protection of Human Health and the Environment ...............................................72

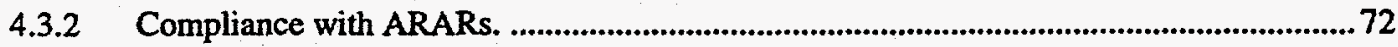

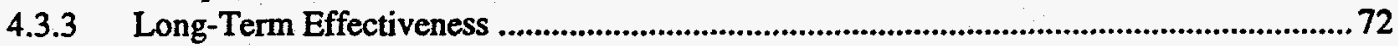

4.3.4 Reduction of Toxicity, Mobility, or Volume ...................................................................... 72

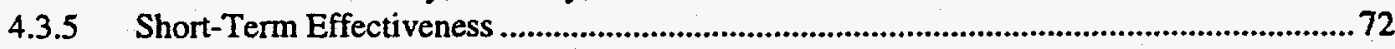

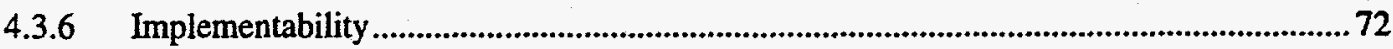

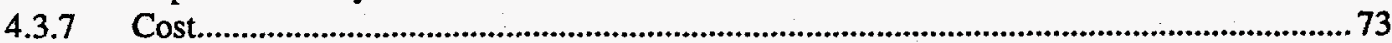

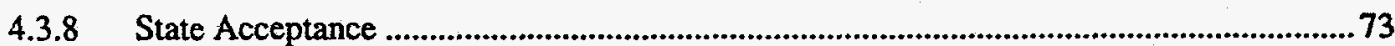

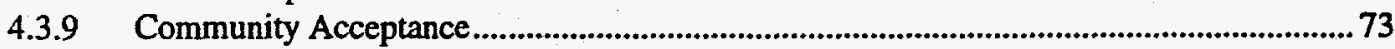

BIBLIOGRAPHY APPENDIX 1

Cost Estimates

\section{List of Tables}

Table 1-1 Summary of Carcinogenic Risk and Noncarcinogenic HI Values for Soil, Current

Visitors; Hypothetical Future Residents and Workers, Burning Rubble Pits 231-F and 231-1F.

Table 1-2 Summary of Carcinogenic Risk and Noncarcinogenic HI Values for Soil, Current

Visitors; Hypothetical Future Residents and Workers, Rubble Pit 231-2F.

Table 1-3 Summary of Carcinogenic Risk and Noncarcinogenic HI Values for Potential On-Unit

Nisitor Exposure Pathways for Burning Rubble Pits 231-F and 231-1F

Table 1-4 Summary of Carcinogenic Risk and Noncarcinogenic HIs for Potential On-Unit/Visitor

Exposure Pathways for Rubble Pit 231-2F.

Table 1-5 Summary of Carcinogenic Risk and Noncarcinogenic HIs for Potential Future On-Unit Resident Exposure Pathways for Burning Rubble Pits 231-F and 231-1F.

Table 1-6 Summary of Carcinogenic Risk and Noncarcinogenic HIs for Potential Future On-Unit Resident Exposure Pathways for Rubble Pit 231-2F

Table 1-7 Summary of Carcinogenic Risk and Noncarcinogenic HIs for Potential On-Unit Commercial/Industrial Worker Exposure Pathways for Burning Rubble Pits 231-F and 231-1F.

Table 1-8 Summary of Carcinogenic Risk and Noncarcinogenic HIs for Potential Future On-Unit

Commercial/Industrial Worker Exposure Pathways for Rubble Pit 23:1-2F

Table 2-1 List of FBRP Risk-Based Chemicals of Concern and the Media in Which They Exist .....................26

Table 2-2 FBRP Intermediate Risk Range Chemicals of Concern and the Media in Which They

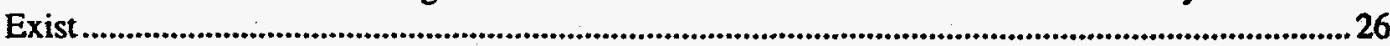

Table 2-3 Remedial Goal Options for Chemicals of Concern by Receptor and Medium for the FArea Burning Rubble Pits (231-F/1F) and Rubble Pit (231-2F)

Table 2-4 Remedial Goal Options for Intermediate Risk Chemicals of Concern for the F-Area Burning/Rubble Pits (231-F/1F) and Rubble Pit (231-2F).

Table 2-5 Potential Location-Specific ARARs for the FBRP

Table 2-6

Applicable, or Relevant and Appropriate Requirements for Soil at the FBRP

Table 2-7

Screening of Technologies for Effectiveness, Implementability, and Cost 
Table 4-1 Evaluation of Alternative 1 - No Action Under the Nine CERCLA Criteria

Table 4-2

Evaluation of Alternative 2 - Institutional Controls Under the Nine CERCLA Criteria

Table 4-3

Evaluation of Alternative 3 - Soil Cover ( $\left.4^{\prime}\right)$ Under the Nine CERCLA Criteria

Table 4-4

Evaluation of Alternative 4 - Thermal Desorption/ncineration Under the Nine CERCLA

Criteria

Table 4-5 Evaluation of Alternative 5 - Offsite Soil Disposal Under the Nine CERCLA Criteria

\section{List of Figures}

Figure 1-1 Location of the Savannah River Site in Relation to Georgia and South Carolina ............................2

Figure 1-2 Location of the Savannah River Site in Relation to the Nearby Area .............................................3

Figure 1-3 F-Area Burning/Rubble Pits (FBRP) in Relation to the F-Area.........................................................4

Figure 1-4 Topographic and Water Table Potentiometric Map of the F-Area Burning/Rubble Pits

(231-F and 231-1F) and Rubble Pit (231-2F)

Figure 1-5 Conceptual Site Risk Model for the F-Area Burning/Rubble Pits ................................................ 16

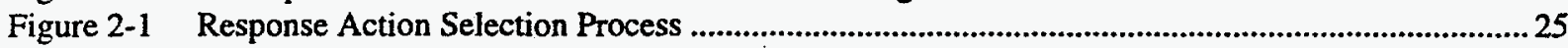

\section{List of Plates}

Plate 1-1 Location of F-Area BRP/RP with respect to F Area. Oblique aerial photograph looking east, the F-Area BRP/RP is the non forested area in the left foreground, the railroad tie pile is in the extreme left foreground, F Area is across the center of the photograph, the Burial Ground Complex and $\mathrm{H}$ Area are in the background. C Road crosses the lower right corner of the photograph and $E$ Road parallels the right margin of the photograph

Plate 1-2 Pits 231-F and 231-1F, while active, circa September 1973. Most of the waste consists of wooden pallets and cardboard boxes. 


\section{Acronyms and Glossary}

ARAR

ATSDR

BRA

BRP

$\mathrm{CAB}$

CERCLA

CMS/FS

$\mathrm{COC}$

COPCs

CPUSs
DOE
EPA
FBRP
FFA
FS
HEAST
HI

HPCDD
HPCDF
HQ

IRIS $^{\mathrm{TM}}$

MCL
Applicable or Relevant and Appropriate Requirements (EPA) are those cleanup standards, standards of control, and other substantive requirements, criteria, or limitations promulgated under federal environmental (RCRA, CWA, and SDWA) or state environmental or facility siting laws that (1) specifically address a hazardous substance, pollutant, contaminant, remedial action, location, or other circumstance found at a CERCLA site or (2) while not applicable to a specific hazardous substance, pollutant, contaminant, remedial action, location, or other circumstance found at a CERCLA site, address problems or situations sufficiently similar to those encountered at the CERCLA site that their use is well suited to the particular site. Only those state standards that are identified by the state in a timely manner and that are more stringent than federal requirements may be applicable or relative and appropriate.

Agency for Toxic Substances and Disease Registry

Baseline Risk Assessment

Burning/Rubble Pit

Citizens Advisory Board

Comprehensive Environmental Response, Compensation, \& Liability Act, 1980

Corrective Measures Study/Feasibility Study

Chemicals of concern are isolated from the list of COPCs by calculating carcinogenic risks and noncarcinogenic hazard indices. COPCs which contribute significantly to a pathway - having a total carcinogenic risk of greater than $1 \times 10^{-4}$ are recognized as carcinogenic COCs. COPCs which contribute significantly to a pathway having a hazard quotient greater than 1.0 are considered noncarcinogenic COCs. A COC typically has a risk exceeding $1 \times 10^{-6}$ or a hazard quotient greater than 0.1 .

Chemicals of potential concern are site- and media-specific, man-made and naturally occurring inorganic and organic chemicals, pesticides, and radionuclides detected at a unit under investigation. The first step in isolating the COPCs is to eliminate all analytes with no detections and data with qualifiers which indicate uncertainty in chemical identification. Nonradionuclide inorganic analytes and naturally occurring radionuclides are recognized as COPCs if the maximum detected concentration is more than twice the mean background concentration in the same medium. Organic chemicals, both natural and anthropogenic, and pesticides are not screened against background, but are identified as COPCs if they are detected at the unit.

Chemicals present in unit samples

United States Department of Energy

Environmental Protection Agency

F-Area Burning/Rubble Pits (231-F, 231-1F, and 231-2F)

Federal Facility Agreement

Feasibility Study (CERCLA)

Health Effects Assessment Summary Tables

Hazard Index - The sum of more than one Hazard Quotient (HQ) for multiple substance and/or multiple exposure pathways; HIs are calculated separately for chronic, subchronic, and shorter duration exposures to non carcinogenic contaminants.

Heptachlorodibenzo-p-dioxin isomers

Heptachlorodibenzo-p-furan isomers

Hazard Quotient - The ratio of a single substance exposure level over a specified time period to a reference dose (RfD) for that substance derived from a similar exposure period for an individual noncarcinogenic contaminant. The $H Q=$ estimated dose/RfD, summed to give the Hazard Index (HI).

Integrated Risk Information System ${ }^{\mathrm{TM}}$

Maximum Contaminant Level established in SDWA, 1974 - The maximum permissible level of a contaminant in water delivered to the outlet of the ultimate user of a public water system. 
NCP

NPL

OCDD

OSHA

OU

PAH

PCB

PCE

RAGS

RAO

RCRA

RDA

RD/RA

RfD

RFI

RGO

RI

RME

ROD

RP
Contaminants added to the water under circumstances controlled by the user are excluded, except corrosion of plumbing. MCLs are enforceable.

National Oil and Hazardous Substances Pollution Contingency Plan, 1990, commonly referred to as the National Contingency Plan

National Priorities List

Octachloro-dibenzo-p-dioxin isomers

Occupational Safety and Health Administration

Operating Unit

Polycyclic Aromatic Hydrocarbons

Polychlorinated Biphenyl

Tetrachloroethylene

Risk Assessment Guidance for Superfund Volume I, Human Health Evaluation Manual (Part A) guidance document used to implement regulations, replaced The Superfund Public Health Evaluation Manual; RAGS Volume II is the Environmental Evaluation Manual

Remedial Action Objectives - medium- and waste site-specific goals for protecting human health and the environment. Term is being replaced by remedial goal options (RGO).

Resource Conservation \& Recovery Act, 1976

Recommended Daily Allowance - the amount of an essential human nutrient that can be ingested for a lifetime (70 years) without deleterious effects. Distinguished from minimum daily requirement of an essential nutrient which must be ingested to maintain health and prevent deficiency disease.

\section{Remedial Design/Remedial Action work plan}

Reference Dose - Estimate of a daily exposure to the human population that is likely to be without appreciable risk of deleterious effects during a lifetime (70 years). RfDs and RfCs are reported with their uncertainty factors (UFs), which usually consist of multiples of 10 ; each factor represents a specific area of uncertainty in the extrapolation from available data. Using UFs reduces the potential for underestimation of adverse noncarcinogenic effects on sensitive subpopulations, during the derivation of RfDs and RfCs.

RCRA Facility Investigation

Remedial Goal Options - based on ARARs, health-based cleanup goals, ecological concerns, and soil values for the protection of groundwater for the chemicals and media of concern and are covered in a separate section in the baseline risk assessment. The RGO Section should contain a table with media cleanup levels for each $\mathrm{COC}$ in each land-use scenario. The table should present one set of RGOs for each media, land use, and receptor type.

Remedial Investigation

Reasonable Maximum Exposure (RAGS) - the highest exposure that is reasonably expected to occur at a site and in practice is estimated by combining upper bound (90 to 95 th percentile)values for some but not all exposure parameters. The general exposure equation is:

$$
\text { Intake }=(C \times \mathbb{R} \times E F \times E D) /(B W \times A T) \text {. }
$$

Concentration (C) is the $95 \%$ upper confidence limit on the arithmetic average of the concentration of the contaminant that is contacted in a given medium over the exposure period for both RME and CT. Intake/contact rates (IR) is the amount of contaminated medium contacted per unit value of time or event; RME ingestion of potable water rate is 2 liters per day for the residential scenario, occupational default has not been determined. The child's (residential) soil and dust ingestion rate is $200 \mathrm{mg} /$ day and the adult soil and dust ingestion rate for both residential and occupational is $100 \mathrm{mg} /$ day, an acute ingestion rate of $480 \mathrm{mg} /$ day may be appropriate for short duration, exposure intensive activities such as excavation or gardening. RME exposure frequencies (EF) are: residential 350 days per year and occupational 250 days per year. RME exposure durations (ED) are: residential 30 years and occupational 25 years. Body weight (BW) is assumed to be $15 \mathrm{~kg}$ for an average child (6 years old) and $70 \mathrm{~kg}$ for an average adult. Averaging time (AT) is equal to actual exposure time for non carcinogens and 70 years for carcinogens.

Record Of Decision

Rubble Pit 
SCDHEC

SMCL

SRS

South Carolina Department Of Health \& Environmental Control

SVOC Secondary Maximum Contaminant Level

TAL Siver Site

TCE

TCL

TCLP

Semi-Volatile Organic Compound

Target Analyte List

Trichloroethylene

TES

Target Compound List

Toxicity Characteristic Leaching Procedure, 40 CFR 261.24 (9/25/90)

Unit Screening

Threatened, Endangered, and Sensitive Species

VOC

Sampling and testing process used to confirm the presence or absence of subsurface hazardous substances above background concentrations and, if confirmed, to determine if hazardous substances have been released at a RCRA/CERCLA unit.

WSRC Volatile Organic Compound

Westinghouse Savannah River Company 


\section{EXECUTIVE SUMMARY}

Two burning/rubble pits (BRPs)(i.e., 231-F \& 231-1F) and one rubble pit (RP)(i.e., 231-2F) in the F-Area of the Savannah River Site have been found to contain levels of contaminants that pose potential risks to human health. The Baseline Risk Assessment (BRA)(WSRC, 1996b) determined that these risks would be for future residents and future workers from exposure to the soil. The purpose of this report is to evaluate alternatives which can be used to reduce the risks to a threshold risk level of $1 \times 10^{-4}$ and, possibly, below a threshold risk level of $1 \times 10^{-6}$, with consideration of ARARs.

The chemicals of concern are: carbon tetrachloride, dichloromethane, and tetrachloroethylene, in the groundwater; and PCB-1254 in the soil at RP 231-2F. The BRA determined that there are no risks exceeding 1 $\times 10^{-6}$ for current on-unit visitors. The total carcinogenic risk for future on-site commercial/industrial workers is $4 \times 10^{-5}$ for all of the pits. The noncarcinogenic hazard index (HI) value is 0.4 for BRPs $231-\mathrm{F} / 1 \mathrm{~F}$ and 0.5 for RP 231-2F for the future workers. The total carcinogenic risk for future on-site residents (adult and child) is $2 x$ $10^{-4}$ for all of the pits. These risks are driven primarily from potential exposure to nonradionuclides in the groundwater. The hazard indices were 3.0 for BRPs $231-\mathrm{F} / 1 \mathrm{~F}$ and 5.0 for RP $231-2 \mathrm{~F}$ for the future residents exposed to both the $0-2 \mathrm{ft}$ and $0-4 \mathrm{ft}$ soil. These increased HIs resulted primarily from potential exposure to chemicals in the groundwater and potential exposure to PCB-1254 in the soil at RP 231-2F. In the ecological assessment, only mercury in soil at BRP $231-F / 1 F$ and in the wetland sediment was identified as having the potential to pose risk to the assessment endpoints for the F-Area Buming/Rubble Pits (FBRP) waste unit. It was concluded that there is essentially no likelihood that any significant impacts to the community of species in the vicinity or the FBRP will occur.

While groundwater has been found to contain levels of carbon tetrachloride, dichloromethane and tetrachloroethylene above MCLs, groundwater contamination will not be dealt with in this report. This CMS/FS will deal only with control of the source operable -unit. Additional groundwater characterization has been proposed which will determine the source of the groundwater contamination. Once this has been determined, the groundwater will be evaluated within the appropriate operable unit.

The only chemical of concern for soil is PCB-1254. The maximum concentration of PCB-1254 found in the FBRP was $2.87 \mathrm{mg} / \mathrm{kg}$ in rubble pit 231-2F. The level of PCBs does not exceed the ARAR of $10 \mathrm{mg} / \mathrm{kg}$ (TSCA). This value does exceed the action level of $1 \mathrm{mg} / \mathrm{kg}$ for residential land use (EPA, 1990), however it is below the action level of $10 \mathrm{mg} / \mathrm{kg}$ for industrial land use. Arsenic, benzo[a]pyrene, Cs-137, heptachlorodibenzo-p-dioxin, K-40, and Sr-90 are not COCs, however, they do contribute to risks in excess of 1 $\times 10^{-6}$.

The universe of possible treatment technologies was considered and screened to a manageable list of potentially applicable technologies for soil remediation at the FBRP. The remaining technologies were assembled into five alternatives which were evaluated for remediation of the soil at all three pits. These are: 1) No action, 2) Institutional Controls, 3) Native Soil Cover, 4) Thermal Desorption/Incineration, and 5) Offsite Soil Disposal.

Estimated costs for the five alternatives which went through detailed analysis within this report are shown below:

Alt. No.
1
2
3
4
5

- Remediation Cost
$\$ 0$
$\$ 10,346$
$\$ 415,164$
$\$ 6,879,536$
$\$ 4,674,817$




\subsection{INTRODUCTION}

\subsection{Purpose and Organization of the Report}

The purpose of this report is to evaluate various technologies that can be used to remediate the soil contamination attributed to the FBRP source unit. While groundwater has been found to contain levels of carbon tetrachloride, dichloromethane and tetrachloroethylene above Maximum Contaminant Levels (MCLs), assessment of groundwater contamination will not be dealt with in this report. The FBRP will be evaluated as a source control operable unit. The source of the groundwater contamination has not yet been determined. The RFI/RI Plan (WSRC-RP-90-486, Revision 2.1, May 1996) has been revised to propose additional groundwater characterization for VOC contamination in the FBRP area. After the characterization, the groundwater will be evaluated within the appropriate operable unit.

Section 1 of this report gives the background of this facility. Section 2 discusses the remedial action objectives (RAOs) and the general response actions for each medium of interest. The technology types and process options are identified and evaluated for each medium of interest. A selection and evaluation of representative technologies is included. Section 3 describes the rationale for combining technologies into alternatives. Section 4 gives a detailed analysis of each alternative as well as a comparative analysis of these alternatives.

\subsection{Background Information}

The Savannah River Site (SRS) is located principally in Barnwell and Aiken Counties near the City of Aiken, South Carolina (Figure 1-1). SRS is owned by the U.S. Department of Energy (DOE). Management and operating services are provided by Westinghouse Savannah River Company (WSRC). SRS has historically produced tritium, plutonium, and other special nuclear materials for national defense. SRS also has provided nuclear materials for the space program and for medical, industrial, and research efforts. Chemical and radioactive wastes are by-products of nuclear material production processes. Hazardous substances, as defined by the Comprehensive Environmental Response, Compensation, and Liability Act, 1980 (CERCLA) and hazardous waste as defined by Resource Conservation \& Recovery Act, 1976 (40 CFR 261.20) (RCRA) are currently present in the environment at SRS.

SRS manages waste materials that are regulated under RCRA. Certain SRS activities have required operating or post-closure permits under RCRA. SRS received a RCRA hazardous waste permit from the South Carolina Department of Health and Environmental Control (SCDHEC) on September 30, 1987. On December 21, 1989, SRS was placed on the National Priorities List (NPL). In accordance with Section 120 of CERCLA, DOE has entered into a Federal Facility Agreement (FFA) with the U.S. Environmental Protection Agency (EPA) Region IV and SCDHEC to coordinate cleanup activities at SRS into one comprehensive strategy that fulfills RCRA and CERCLA assessment, investigation, and response action requirements. Appendix $C$ of the FFA lists the F-Area BRPs as a RCRA/CERCLA unit.

The location of the F-Area BRPs at SRS and their relative locations to other SRS facilities are shown in Figure 1-3. The F-Area BRPs are comprised of two burning/rubble pits, BRPs 231-F and 231-1F, and one rubble pit, RP 231-2F, located to the northwest of F Area (Figure 1-4). These BRPs are permanently inactive RCRA Facility Investigation/Remedial Investigation (RFI/RI) units. The three inactive pits have been backfilled and the top covered with 5 to $8 \mathrm{~cm}$ ( 2 to $3 \mathrm{in}$ ) of clay. A complete description of the surface and subsurface features of this area can be found in the RFI/RI (WSRC, 1996a). 
Figure 1-1 Location of the Savannah River Site in Relation to Georgia and South Carolina

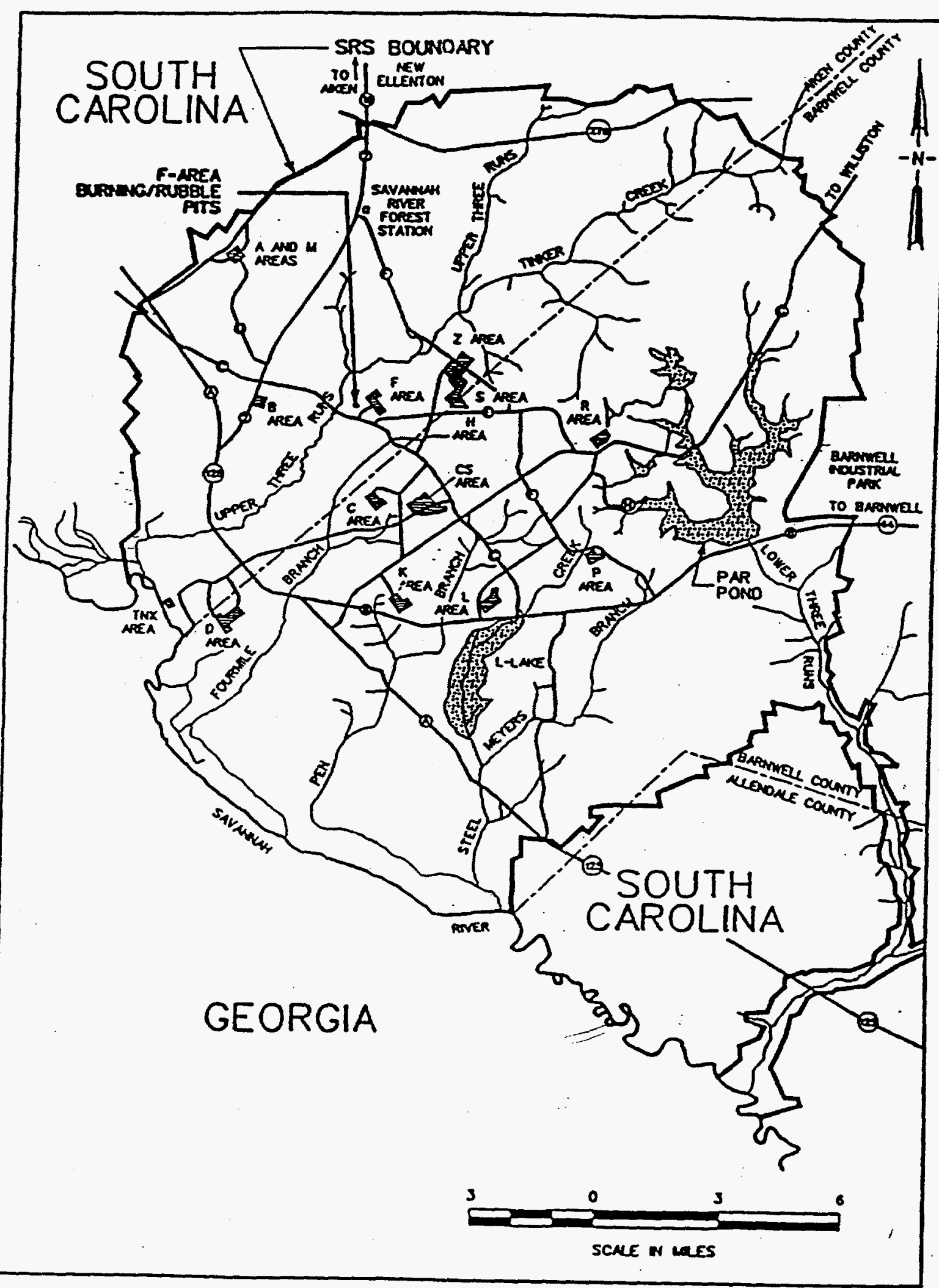


Figure 1-2 Location of the Savannah River Site in Relation to the Nearby Area

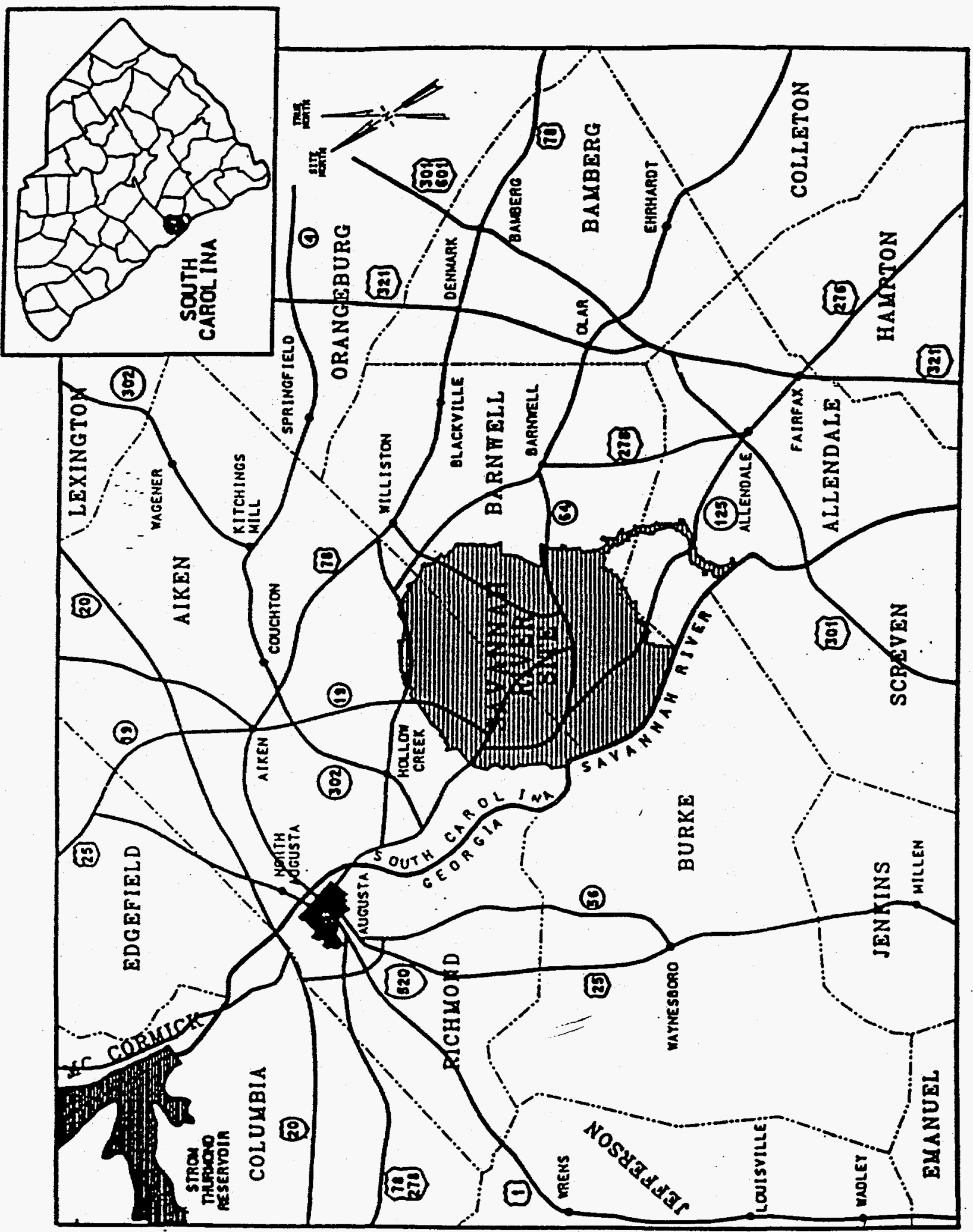


Figure 1-3 F-Area Burning/Rubble Pits (FBRP) in Relation to the F-Area

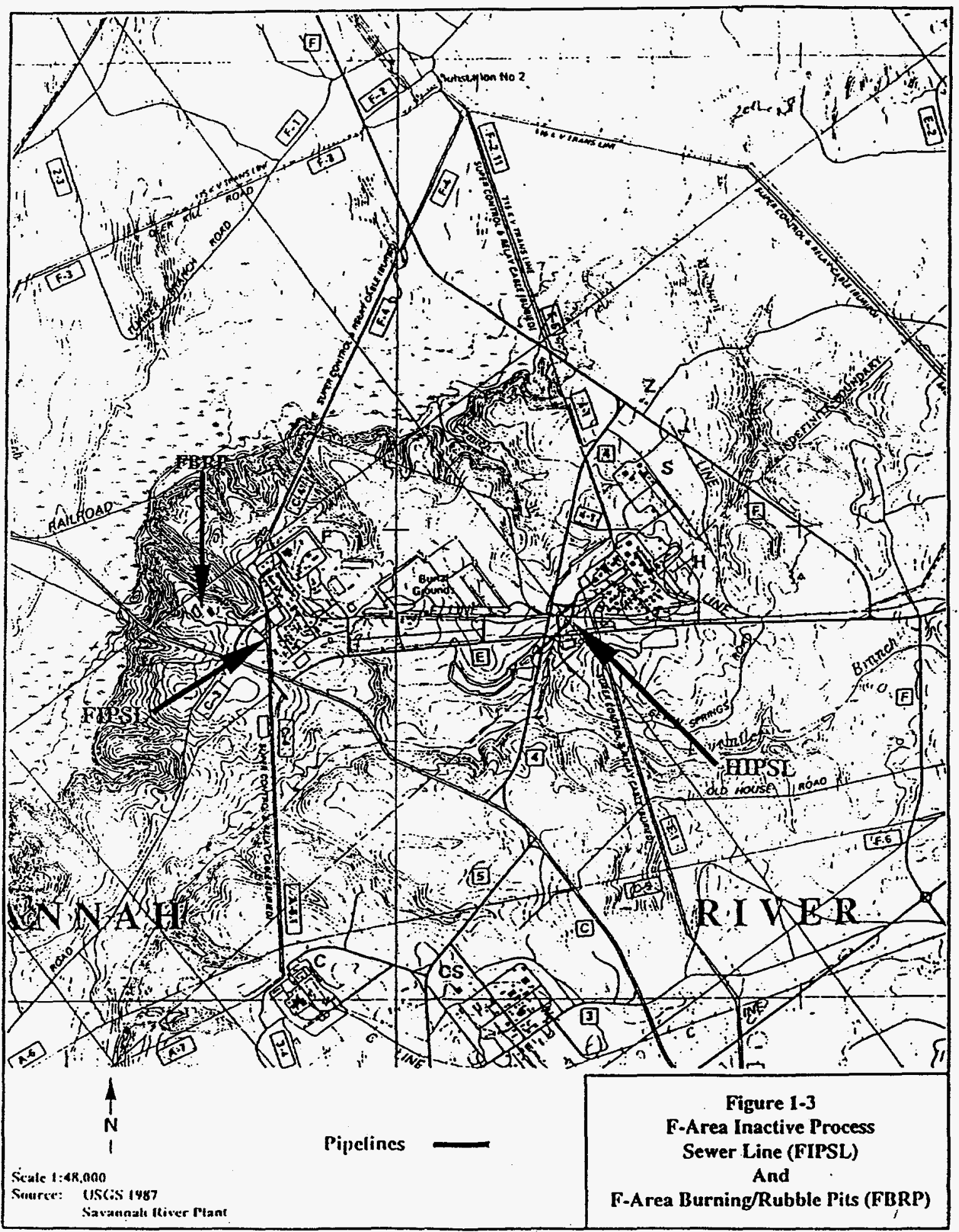




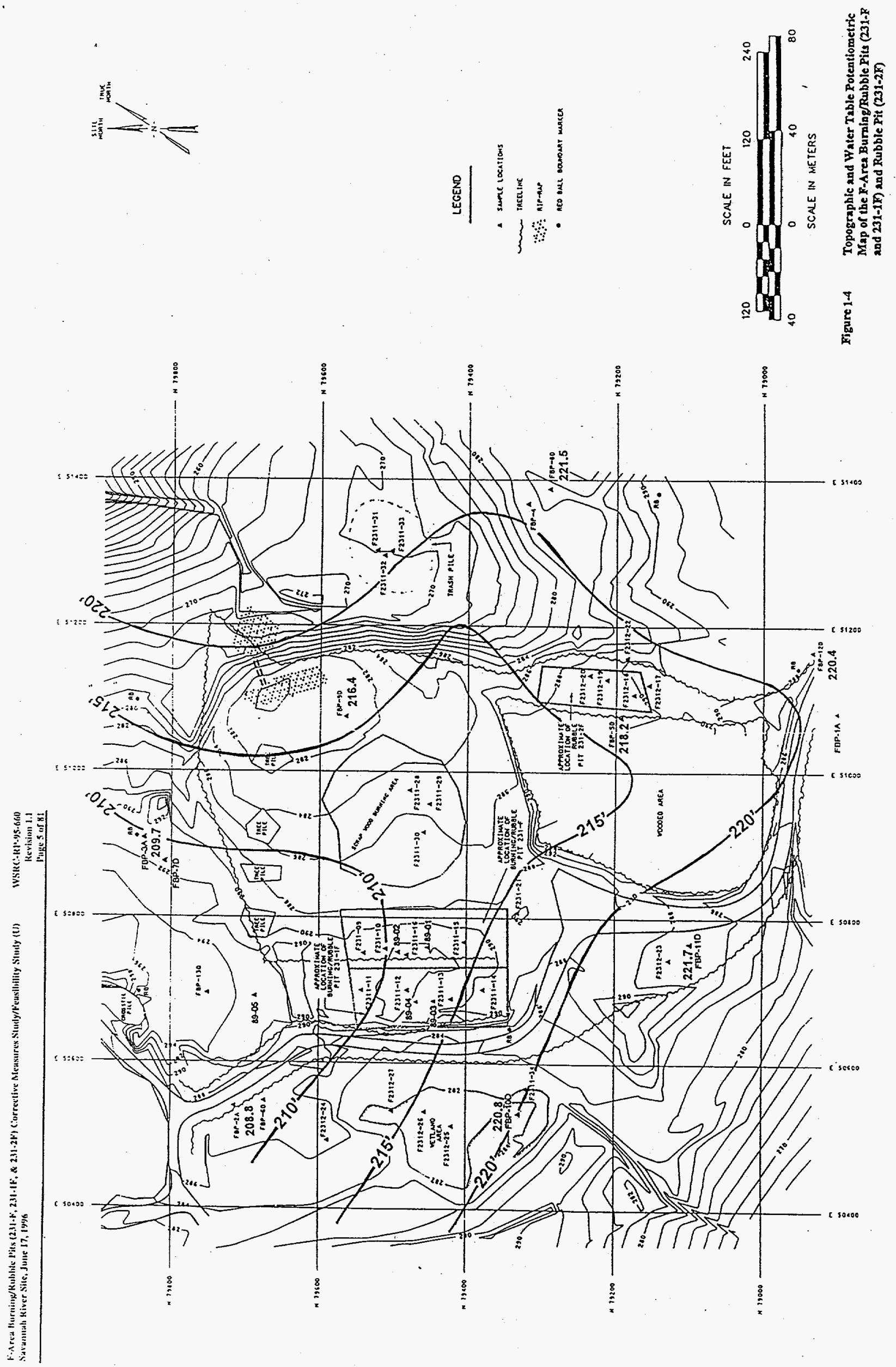


This page intentionally left blank. 


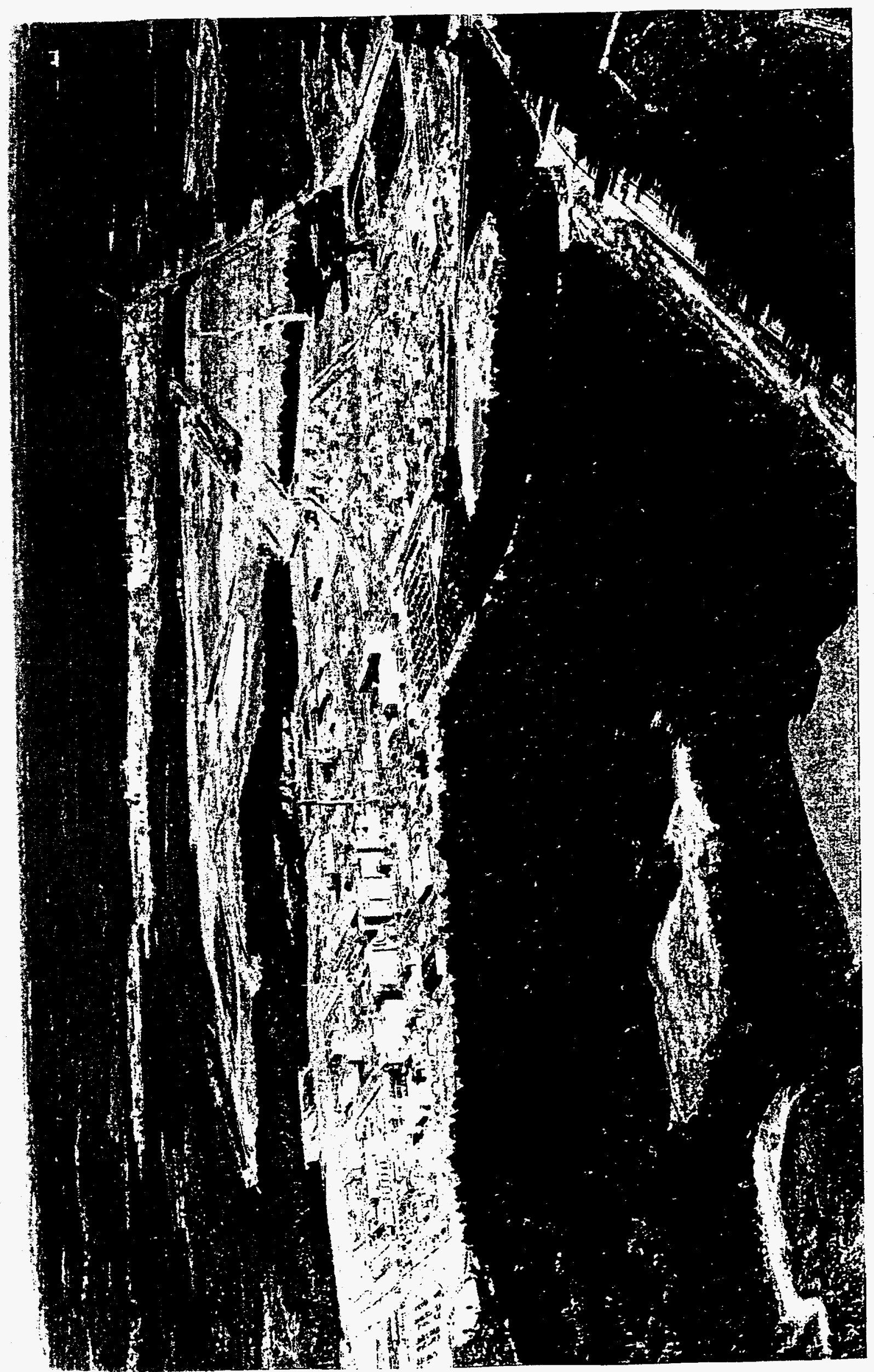


Plate 1-1 Location of F-Area BRP/RP with respect to F Area. Oblique aerial photograph looking east, the F-Area BRP/RP is the non forested area in the left foreground, the railroad tie pile is in the extreme left foreground, F Area is across the center of the photograph, the Burial Ground Complex and $H$ Area are in the background. $C$ Road crosses the lower right corner of the photograph and $E$ Road parallels the right margin of the photograph. 
Plate 1-2

Pits 231-F and 231-1F, while active, circa September 1973. Most of the waste consists of wooden pallets and cardboard boxes. 


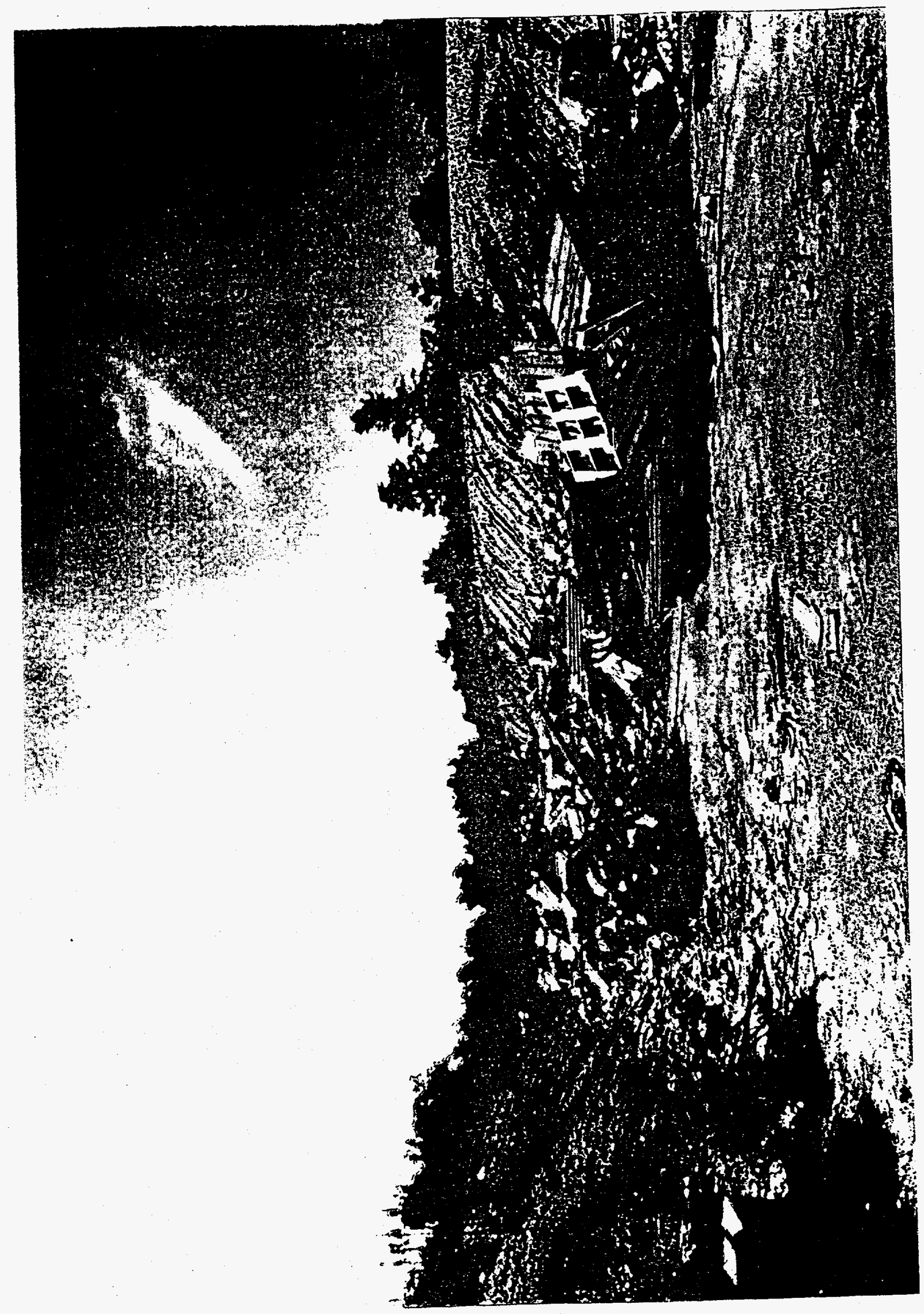




\subsubsection{Unit Description}

The FBRP unit consists of two burning/rubble pits and one rubble pit (Figure 1-4). The two burning/rubble pits, 231-F and 231-1F, are contiguous units. An undisturbed clay berm, approximately $6.1 \mathrm{~m}(20 \mathrm{ft})$ wide, separates the two pits. Facility records indicate that the dimensions of BRP 231-F are $83.8 \mathrm{~m}(275 \mathrm{ft})$ long by $18.9 \mathrm{~m}(62$ $\mathrm{ft})$ wide by $3.1 \mathrm{~m}(10 \mathrm{ft})$ deep. The dimensions of BRP $231-1 \mathrm{~F}$ are $99 \mathrm{~m}(325 \mathrm{ft})$ long by $27.1 \mathrm{~m}(89 \mathrm{ft})$ wide by $3.1 \mathrm{~m}$ (10 ft) deep. The unit screening conducted in 1989 (WSRC-RP-89-994) indicated that the waste disposal unit widths of each pit ranged from 12.2 to $15.2 \mathrm{~m}$ (40 to $50 \mathrm{ft}$ ) with waste depth ranges from 0.6 to $2.4 \mathrm{~m}$ ( 2 to $8 \mathrm{ft}$ ). The unit reconnaissance conducted in January 1989 indicated that RP $231-2 \mathrm{~F}$ is approximately $50 \mathrm{~m}$ (164 $\mathrm{ft}$ ) long and $10.1 \mathrm{~m}(33 \mathrm{ft})$ wide. The depth indicated from this unit reconnaissance is approximately 5 feet.

\subsubsection{Unit History}

The F-Area Burning/Rubble Pits Operable Unit is comprised of two burning/rubble pits, BRPs 231-F/1F, and one rubble pit, RP 231-2F, located to the west of the F-Area industrial complex. The BRPs were constructed in 1951 for burning of construction debris. During the operating period from 1951 to 1973, waste was typically burned on a monthly basis. Waste materials burned included paper, plastics, wood, rubber, rags, cardboard, oil degreasers, and drummed solvents. Waste burning in BRPs 231-F/1F was discontinued by October 1973 and these pits were backfilled and used as rubble pits until 1978. Waste materials placed as rubble included concrete, bricks, tile, asphalt, plastic, metal, empty drums, wood products, and rubber. The pits reached capacity in 1978 and were taken out of service. The three pits were filled to capacity, backfilled with a layer of soil, graded, compacted, mounded, and covered with 5 to $8 \mathrm{~cm}$ ( 2 to 3 in) of clay.

SRS records indicate that concrete, lumber, cement, fence and telephone poles, rip rap, brick, tile, wallboard, paneling, metal scrap and shavings, drums, electrical conduit, furniture, and firehose may have been disposed in RP 231-2F. There are no known records at SRS that indicate that any radionuclides or hazardous chemicals were disposed in this pit, but the possibility of such disposal in this pit cannot be eliminated. Management philosophy was not to dispose of anything suspected to be radioactive in the BRPs/RPs. Rather, any materials suspected to contain radioactive contamination were sent to the SRS Radioactive Waste Burial Ground (643-G, now 643-E). As discussed in the Executive Summary and Sections 1.2.2.2, 1.2.3.3, and Table 1.3 of the RFI/RI report, very little waste material was encountered, during the characterization, in the $231-2 \mathrm{~F}$ pit. After the last use of RP $231-2 F$ in 1981, the unit was backfilled and the land surface seeded. Additional history for the burning/rubble pits can be found in the RFI/RI report (WSRC, 1996a).

\subsubsection{Nature and Extent of the Contamination}

Unit screening for BRPs 231-F/1F and RP 231-2F. was completed in November 1989. Screening for BRPs 231 F/IF indicated the presence of metals which occur naturally in SRS soils (arsenic, cadmium, chromium, lead, mercury, nickel), semivolatile organic contaminants (components of waste oils or waste insecticides and phthalate ester plasticizers), and trace levels of indicators of radionuclides that occur naturally in SRS soils (gross alpha, nonvolatile beta, total radium), tritium, and one polychlorinated biphenyl (PCB) species. Data from the SRS Groundwater Monitoring Program from 3Q84 through 2Q92 indicated exceedances of MCLs for carbon tetrachloride, iron, lead, manganese, nitrate, radium, and trichloroethylene. There was no evidence that hazardous substances were contained in RP 231-2F. However, sidegradient groundwater data indicated that manganese, nitrate, radium, and trichloroethylene exceeded MCLs. Therefore, additional soil and groundwater sampling was conducted as part of the F-Area BRPs RFI/RI Unit Assessment completed in 1993. Additional groundwater characterization has been proposed in the RFI/RI Plan, Revision 2.1. This characterization will determine the source of the groundwater contamination and allow the groundwater to be evaluated in the appropriate operable unit. Remedies discussed within this CMS/FS are for the source control operable unit only.

A radiological survey was conducted on July 1,2,and 3, 199 I by SRS Health Protection personnel. Background readings were taken from between 100 and 150 yards from the three pits. No radiological readings above 
background levels were detected in any of the pits using a handheld portable unit. All soil samples collected and analyzed in the laboratory gave radioactive counts less than the clean area release limits of less than $10 \mathrm{dpm}$ alpha and less than $80 \mathrm{cpm}$ beta and gamma.

The four areas of suspected contamination at the BRP area included: soils at the BRP 231-F/1F area, soils at the RP 231-2F area, surface water and sediment in the ephemeral wetland area, and general area groundwater. Data were collected from these four areas. Data used for the BRA were collected during the period May 4, 1993, through December 1, 1993, as part of the F-Area BRP RFI/RI Unit Assessment. Additional data used were collected as part of the ongoing groundwater monitoring program at SRS during the period March 1993 through May 1993.

Groundwater contamination by tritium, trichloroethylene (TCE), and tetrachloroethylene (PCE) has been observed at the F-Area BRP in both up- and down-gradient wells (See WSRC, 1996a, RFI/RI, Table 1.7). The Baseline Risk Assessment for the F-Area Burning/Rubble Pits indicates that groundwater does not currently pose a significant risk to onsite workers or visitors. This finding is corroborated by a review of groundwater monitoring data in the vicinity of the F-Area Burning/Rubble Pits. For the future on-unit worker the risk from ingestion of groundwater due to nonradioactive contaminants is $2 \times 10^{-5}$ from arsenic and carbon tetrachloride and, from radioactive contaminants, the risk is $2 \times 10^{-5}$ from I-129 and Sr-90. For the future on-unit resident the nonradioactive risk was calculated to be $5 \times 10^{-5}$ for ingestion of groundwater from arsenic and carbon tetrachloride and, for radioactive contaminants, the risk was $6 \times 10^{-5}$ from I-129 and Sr-90. Summaries of the risk assessment and the groundwater monitoring data are included in RFI/RI Report for F -Area Burning/Rubble Pits (231-F, 231-1F and 231-2F), WSRC-RP-94-938, Rev 1.1.

\subsubsection{Contaminant Fate and Transport}

This section is taken from the BRA and addresses the environmental fate and transport of the chemicals of potential concern (COPCs) and the potential pathways by which human populations (e.g., workers, visitors, and residents) could be exposed to radionuclides and non-radioactive analytes at or originating from the F-Area BRPs. In identifying primary pathways of exposure, current and plausible future land uses of the unit and surrounding area are considered. This section describes exposure scenarios, develops information on exposure pathways, estimates the concentration of the radioactive and non-radioactive COPCs at points of human exposure, and determines receptor intakes (doses). Reasonable Maximum Exposure (RME) estimates are presented for radiation dose and chemical intakes within each scenario.

\subsubsection{Data Collection and Evaluation}

Data used for the BRA were collected during the period May 4, 1993, through December 1, 1993, as part of the F-Area BRP RFI/RI Unit Assessment. Additional data were collected as part of the ongoing groundwater monitoring program at SRS during the period March 1993 through May 1993. Unit-specific background data, collected as part of the RFI/RI Unit Assessment, were used to screen Chemicals Present in Unit Samples (CPUSs). Unit screening data and data obtained from the SRS Groundwater Monitoring Program from 3Q84 through $2 \mathrm{Q} 92$ did not meet data quality objectives and, therefore, were not used in the BRA.

Soil sampling involved continuous sampling (i.e., no interval between samples) at 11 locations within the pit confines and through the bottom of the pit boundary. Two additional soil sample locations were selected adjacent to pit confines, including one background location. Soil sampling locations were chosen to adequately characterize and define the lateral and vertical extent of contaminant impact on soils from the F-Area BRPs. Soil analytes included Target Compound List/Target Analyte List constituents (TCL/TAL), radionuclides and dioxins/furans.

Soil data were aggregated into three groups: inside the two contiguous pits $231-F / 1 F$, inside pit $231-2 F$, and background. This grouping of data was performed to provide relatively homogencous areas of potential contaminant impact. 
Groundwater data were taken from two sources, the ongoing quarterly monitoring program and the unit assessment sampling effort. Analytes for groundwater samples included TCLTAL constituents, radionuclides and dioxins/furans.

Surface water sampling was conducted to confirm the presence or absence of contaminants in the surface water near the pits: specifically, the wetland area to the west of the BRPs 231-F/1F. Analytes for surface water included SVOCs (including PAHs), VOCs, total metals, radionuclide indicators, pesticides/PCBs, and polychlorinated di-benzo dioxins and furans.

Sediment sampling was conducted to confirm the presence or absence of unit-related contaminants in the sediment of any surface water body near the pits: specifically, the wetland area to the west of the burning/rubble pits. Sediment sample analytes were the same as those for surface water with the addition of individual radionuclides.

Both radionuclides and nonradioactive analytes were evaluated as COPCs. After combining analytical data and eliminating those analytes that were not detected in any samples in a given medium, the analytical data were evaluated on the basis of quality with respect to sample quantitation limits, laboratory qualifiers and codes, and blanks. Only naturally occurring radionuclides and nonradioactive inorganic analytes were compared to unitspecific background data by medium.

Following the elimination of unreliable data, analyte concentrations were compared to appropriate background levels. Nonradioactive inorganic analytes and naturally occurring radionuclides in soil, groundwater, and sediment were eliminated as COPCs if the maximum detected concentration was less than twice the mean background concentration.

\subsubsection{Baseline Risk Assessment}

Four areas (soils at the BRP 231-F/1F area, soils at the RP 231-2F, media in the ephemeral wetland area and general area groundwater) were evaluated in the BRA under current and future land use scenarios. These land use scenarios are discussed in the following paragraphs.

The soil leachability to groundwater modeling conducted in Appendix B of the BRA indicated that iodine-129, technetium-99, and cadmium contributed to the future risks in the groundwater. The assumptions made in the modeling were conservative and likely overestimate the future concentrations in groundwater. The iodine-129 source term concentration is based on 2 detects out of 13 samples, which were $J$ qualified (estimated below the practical quantification limit) and are, therefore, highly uncertain. Iodine-129 was not detected in groundwater samples. Technetium-99 is extremely mobile. The estimated transport time to the water table is about 18 years. The pits were in use from 1951 to 1973 , which is longer than 18 years from the present. Technetium-99 is currently not detected in groundwater samples. Cadmium source concentrations were influenced by a single soil sample at $22 \mathrm{mg} / \mathrm{kg}$ at a depth of 6 to $8 \mathrm{ft}$. However, cadmium was not detected in 5 consecutive samples below this sample which indicates that the cadmium is not migrating. Therefore, iodine-129, technitium-99, and cadmium are not considered to be soil chemicals of concern for future leachability to groundwater.

For current land use (a current on-unit visitor), risks and HIs were calculated for exposure to soil, air, surface water and sediment. The total risks and hazard index (HI) values from all media did not exceed the EPA targets for cancer risk of $1 \times 10^{-6}$ or an $\mathrm{HI}$ of 1.0 , indicating that negligible adverse health effects are expected for the current on-unit visitor.

Future hypothetical on-unit residents were assumed to be exposed to soil, air, groundwater, homegrown produce, and surface water and sediment in the ephemeral wetland area. For future residents at the BRP 23I-F/1F area, a total risk of $2 \times 10^{-4}$ and an $\mathrm{HI}$ of 3.0 were calculated. These HIs and risks result primarily from exposure to groundwater. The chemicals and radionuclides resulting in the increased groundwater risks $\left(>1 \times 10^{-6}\right)$ include carbon tetrachloride, dichloromethanc, tetrachlorocthylene, arsenic, iodine-129, radium-226, radium-228, strontium-90, technctium-99 and tritium. Iodine-129 and technctium-99 were not detected in groundwater, and 
were included through modeling of future soil leachability to groundwater. The highest concentration of dichloromethane was detected in an upgradient well. The chemicals resulting in an HI greater than 1.0 include carbon tetrachloride, arsenic, cadmium and manganese. Potential exposure to soils in the BRP 231-F/1F area, media in the ephemeral wetland area and homegrown produce did not result in risks in excess of $1 \times 10^{-4}$ or $\mathrm{HI}$ values in excess of 1.0 for hypothetical future residents.

For hypothetical workers exposed to soil, air, and groundwater at both the BRP 231-F/1F and RP $231-2 \mathrm{~F}$ units, neither the cancer risk nor the HI exceeded the EPA targets of $1 \times 10^{-4}$ or 1:0, respectively, for any media. Consequently, negligible carcinogenic risks and noncancer HIs are likely to be associated with workers exposed to media at these units. The risk from ingestion of groundwater is $2 \times 10^{-5}$. The risks from ingestion of soil at BRPs $231-\mathrm{F}$ and $-1 \mathrm{~F}$ is $5 \times 10^{-6}$ for both the $0-2 \mathrm{ft}$ and $0-4 \mathrm{ft}$ soil. The risk from dermal contact is $1 \times 10^{-6}$ over the same soil layers. The risk from direct radiation is $3 \times 10^{-6}$. For RP $231-2 \mathrm{~F}$ the risk from ingestion of soil in the $0-2 \mathrm{ft}$ and $0-4 \mathrm{ft}$ layer is $4 \times 10^{-6}$. The risk from direct radiation from the soil is $2 \times 10^{-6}$.

For future residents at the RP 231-2F, a total risk of $2 \times 10^{-4}$ and a HI of 5.0 were calculated. These HIs and risks result from exposure to groundwater and soil. The increased risks from groundwater are the same as for BRPs 231-F/1F because the groundwater contamination is an area-wide phenomenon. The increased $\mathrm{HI}$ from soil was associated with exposure to PCB-1254. The risk from ingestion of groundwater is $5 \times 10^{-5}$ for nonradioactive contaminants and $6 \times 10^{-5}$ for radioactive contaminants. The risk in BRPs $231-\mathrm{F}$ and $-1 \mathrm{~F}$ for ingestion of the soil is $2 \times 10^{-5}$ for both the $0-2 \mathrm{ft}$ and $0-4 \mathrm{ft}$ layers. The risk from dermal contact with the soil for both layers is $3 \times 10^{-6}$. The risk for RP $231-2 \mathrm{~F}$ is $2 \times 10^{-5}$ for ingestion of the soil in the $0-2 \mathrm{ft}$ layer. The risk from dermal contact with the soil is $2 \times 10^{-6}$.

The radioactive risks for BRPs $231-\mathrm{F}$ and $-1 \mathrm{~F}$ are $1 \times 10^{-5}$ for direct radiation from the soil, $3 \times 10^{-6}$ for ingestion of fruit, $6 \times 10^{-6}$ for ingestion of leafy vegetables, and $4 \times 10^{-6}$ for ingestion of tuberous vegetables. The radioactive risks for RP $231-2 \mathrm{~F}$ are $8 \times 10^{-6}$ from direct exposure to the soil, $2 \times 10^{-6}$ for ingestion of fruit, $5 \times$ $10^{-6}$ for ingestion of leafy vegetables, and $3 \times 10^{-6}$ for ingestion of tuberous vegetables.

The only increased cancer risks and HIs in excess of $1 \times 10^{-4}$ and 1.0, respectively, were associated with hypothetical future on-unit residents. The risks and HIs derived for current on-unit visitors did not exceed $1 \mathrm{x}$ $10^{-6}$.

Of the four areas of concern associated with the FBRP (soils at BRP 231-F/1F, soils at RP 231-2F, groundwater, and surface water and sediment in the ephemeral wetland area), only two were associated with cancer risks in excess of $1 \times 10^{-4}$ or $\mathrm{HI}$ values exceeding 1.0; soils at RP $231-2 \mathrm{~F}$ and general area groundwater. As discussed above, the increased risks and HIs were only associated with future residents, which are unlikely to be present at SRS, given the future land use plans for SRS. The current visitor and future worker, should not be adversely effected by exposure to media at the unit.

Table 1-1 is a summary of the carcinogenic risks and noncarcinogenic HI values for soil for current visitors, hypothetical future residents, and workers for burning rubble pits 231-F and 231-1F. This table shows that the risk from the top two feet of soil to a current visitor is $4 \times 10^{-7}$ while the $\mathrm{HI}$ is 0.02 . This risk is below the lower end of the EPA's target risk range of $1 \times 10^{-6}$. The HI is below 1.0 which indicates that adverse effects resulting from exposure to the top two feet of soil at the rubble pits are not expected. The risk to hypothetical future residents is $4 \times 10^{-5}$ for the $0-2 \mathrm{ft}$ layer of soil and $7 \times 10^{-5}$ for the 0-4 $\mathrm{ft}$ layer. Both of these values are within the EPA's target risk range. The HI values are 0.6 for both of these soil layers. The risks for a hypothetical future worker are $9 \times 10^{-6}$ for both soil layers. The $\mathrm{HI}$ values are 0.03 for both soil layers.

Table 1-2 is a summary of the carcinogenic risks and noncarcinogenic HI values for soil for current visitors, hypothetical future residents, and workers for rubble pit $231-2 \mathrm{~F}$. This table shows that the risk from the $0-2 \mathrm{ft}$ layer of soil to a current visitor is $5 \times 10^{-7}$ while the $\mathrm{HI}$ is 0.003 . The risk to hypothetical future residents is $3 \mathrm{x}$ $10^{-5}$ for the $0-2 \mathrm{ft}$ layer of soil and $4 \times 10^{-5}$ for the $0-4 \mathrm{ft}$ layer. Both of these values are within the EPA's target risk range. The $\mathrm{HI}$ values are 2.0 for both of these soil layers. The risks for a hypothetical future worker are $7 \mathrm{x}$ $10^{-6}$ for both soil layers. The $\mathrm{HI}$ values are 0.1 for the $0-2 \mathrm{ft}$ soil layer and 0.09 for the $0-4 \mathrm{ft}$ layer. 
Figure 1-5 is a conceptual site risk model for the FBRP which summarizes all of the risks greater than $1 \times 10^{-6}$ and chemical HI values greater than 1.0. This figure gives a brief overview of the risks present for each of the exposure pathways identified.

The BRA has indicated that the wetland identified in the RFI/RI is insignificant. The size of the wetland is estimated to be only 0.2 acres. While the area does contain some residual vegetation typical of a wetland (dead cat-tails, etc.), the area only holds water due to runoff from the pits and the surrounding area. The wetland was recently visited two days after a fairly heavy rain. It was observed that puddles were standing in the roadway, but the wetland was dry.

\subsubsection{Human Health Risk}

Potential human exposure routes were identified for each medium based on a specific receptor and anticipated activity at an exposure point. Exposures to radionuclides and non-radioactive contaminants present in air (dust and vapor), soil, homegrown produce, surface water, sediments, and groundwater were evaluated. Radiological exposures also were evaluated for direct radiation.

Exposure point concentrations were calculated, or modeled for future migration to groundwater, and used to estimate potential risks. Carcinogenic risks and noncarcinogenic HIs for the exposure scenarios and receptors described above were then calculated and compared to EPA risk guidelines. To interpret the risk characterization results, a risk of less than one excess cancer in one million people $\left(1 \times 10^{-6}\right)$ is not considered significant by EPA. Additional cases of cancer resulting from risk less than $1 \times 10^{-6}$ cannot be distinguished in an exposed population. The EPA target risk range is from one in ten thousand $\left(1 \times 10^{-4}\right)$ to one in one million (1 $\left.\times 10^{-6}\right)$. Risks falling within this range require an evaluation of remedial action alternatives to determine if risks can be reduced below the one excess cancer in one million people $\left(1 \times 10^{-6}\right)$ level. Risks greater than one excess cancer in ten thousand people $\left(1 \times 10^{-4}\right)$ represent risks where remedial action is generally warranted (EPA $1991 \mathrm{a}, \mathrm{b})$.

Noncarcinogenic effects were evaluated by comparing an estimated exposure level (dose) over a specified time period (e.g., lifetime) with a reference dose (RfD) derived for a similar exposure period. To evaluate the noncarcinogenic effects of exposure to contaminants, the hazard quotient (HQ) is calculated. The HQ is the ratio of the estimated dose to the RfD. An HQ was calculated for each contaminant. There is a level of exposure (i.e., the Reference Dose) below which it is unlikely for even sensitive populations to experience adverse health effects. If the estimated dose exceeds the RfD (i.e., if the HQ exceeds one), there may be concern for potential noncarcinogenic adverse health effects. The HQs for individual chemicals are summed for each exposure pathway to create a pathway-specific HI for each exposure scenario. Generally, the more the HI exceeds one, the greater the concern for potential adverse health effects.

For the human health evaluation, chemicals present in unit samples (CPUSs) in groundwater and soils were screened against background concentrations, risk-based concentrations, nutrient essentiality, and frequency of detection. Given that background concentrations and human health risk-based concentrations were not available for sediment and surface water, a screening was not performed for these media. All contaminants detected in surface water and sediment were quantitatively evaluated in the human health risk assessment.

The risks and $\mathrm{HI}$ values determined in the BRA for human health for all paths are summarized in Table 1-3 through 1-8. Table 1-3 indicates that the summary of carcinogenic risk for on-unit visitors to BRPs $231-\mathrm{F} / \mathrm{F}$ is $6 \times 10^{-7}$ and the $\mathrm{HI}$ is 0.02 . Table $1-4$ shows that the summary risk from RP $231-2 \mathrm{~F}$ to an on-unit visitor is $8 \mathrm{x}$ $10^{-7}$ and the HI is 0.004 . Thus there are no risks greater than $1 \times 10^{-6}$ or HIs greater than 1.0 for visitors to the FBRP. 
Table 1-1 Summary of Carcinogenic Risk and Noncarcinogenic HI Values for Soil, Current Visitors; Hypothetical Future Residents and Workers, Burning Rubble Pits 231-F and 231-1F

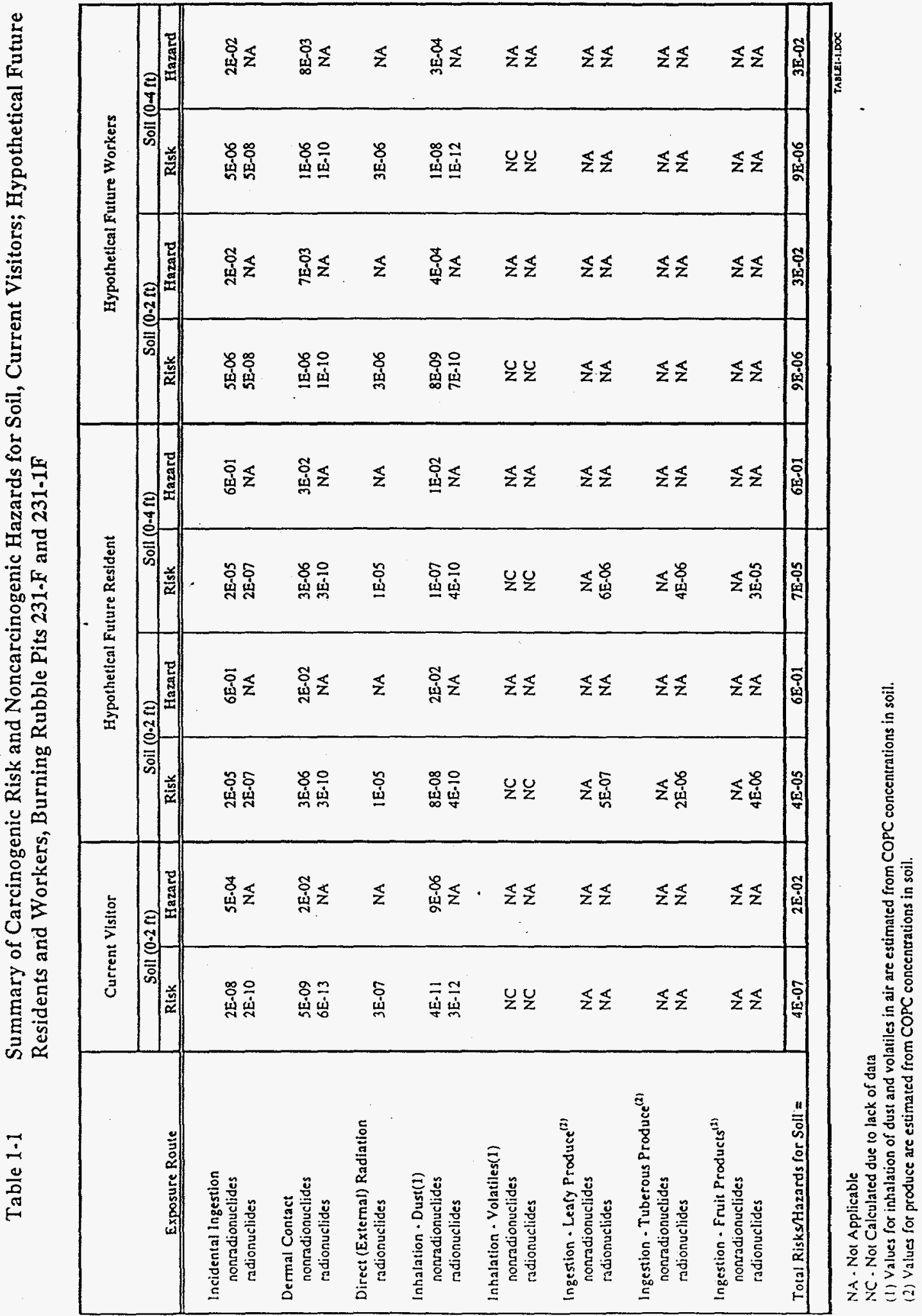


Table 1-2

Summary of Carcinogenic Risk and Noncarcinogenic HI Values for Soil, Current Visitors; Hypothetical Future Residents and Workers, Rubble Pit 2312F

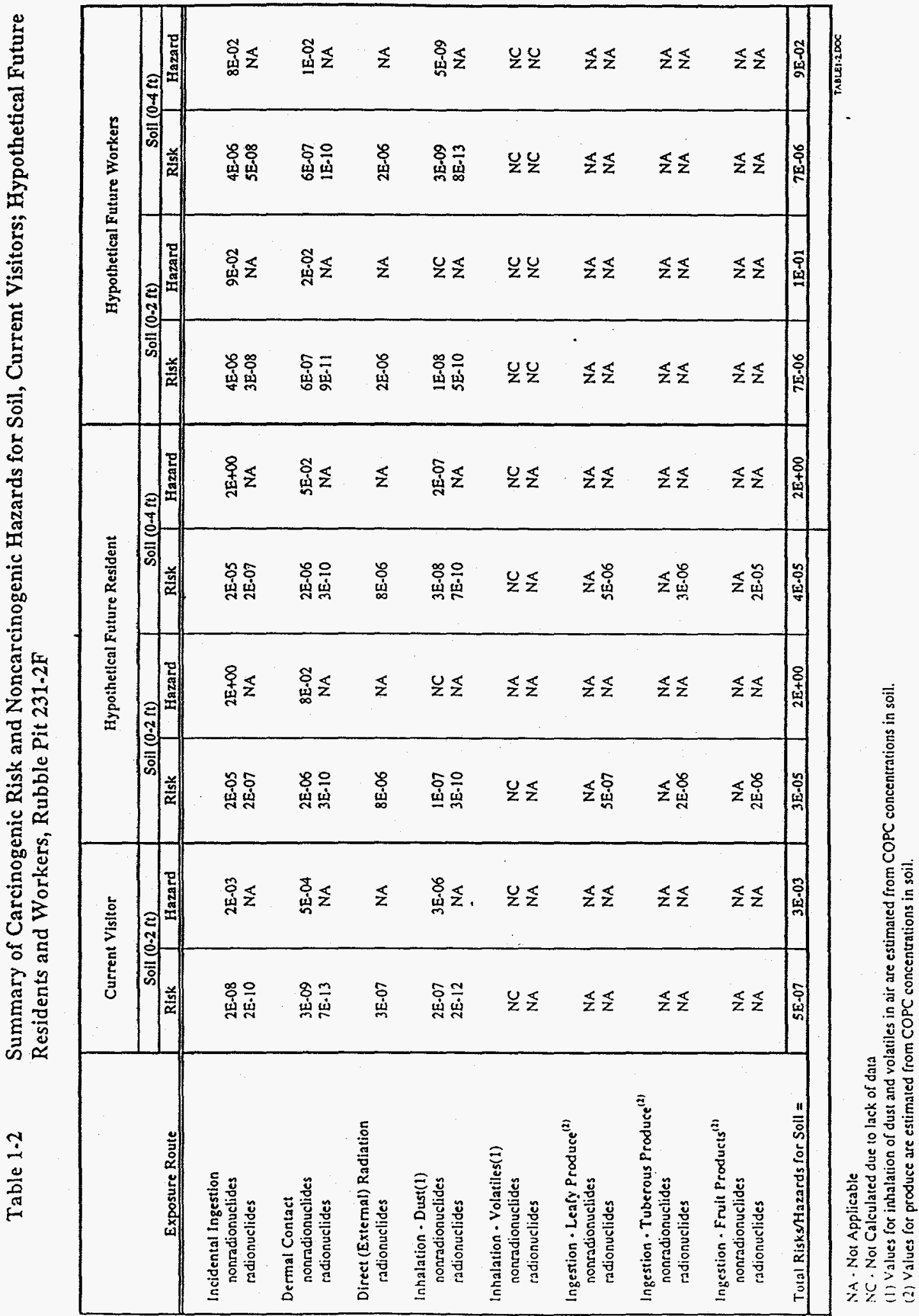


NONRADTOACTIVE

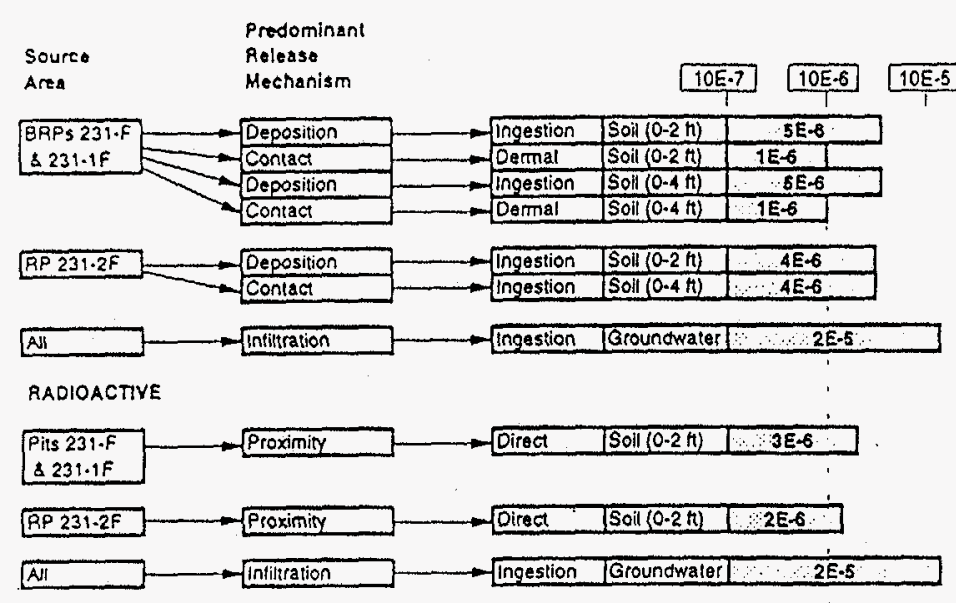

Riskrotivers

10E-4 10E.3 10E.2 10E.1 10E-0

As $28 \%$, HPCDO $24 \%$, Biajp $18 \%$

Alalp 55\%

B(a)P $55 \%$

PCB-1254 93\%

Arsenic $73 \%$, Carbon tetractionde 14

Cs. $13760 \%, K \cdot 4039 \%$

Cs. $13761 \%, K \cdot 4038 \%$

1. $12947 \%$, S -90 17\%

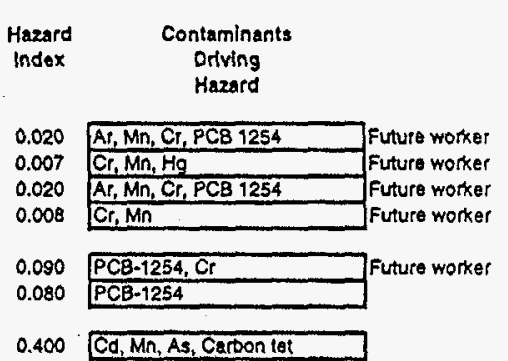

0.400 Ca, Mn, As, Carbon tet
NONAADIOACTIVE

F-AREA BRP FUTURE ON-UNIT RESIDENT (RME)

$10 E-7$ 10E-6 10E-5 10E-4 10E-3 10E-2 10E-1 10E-0

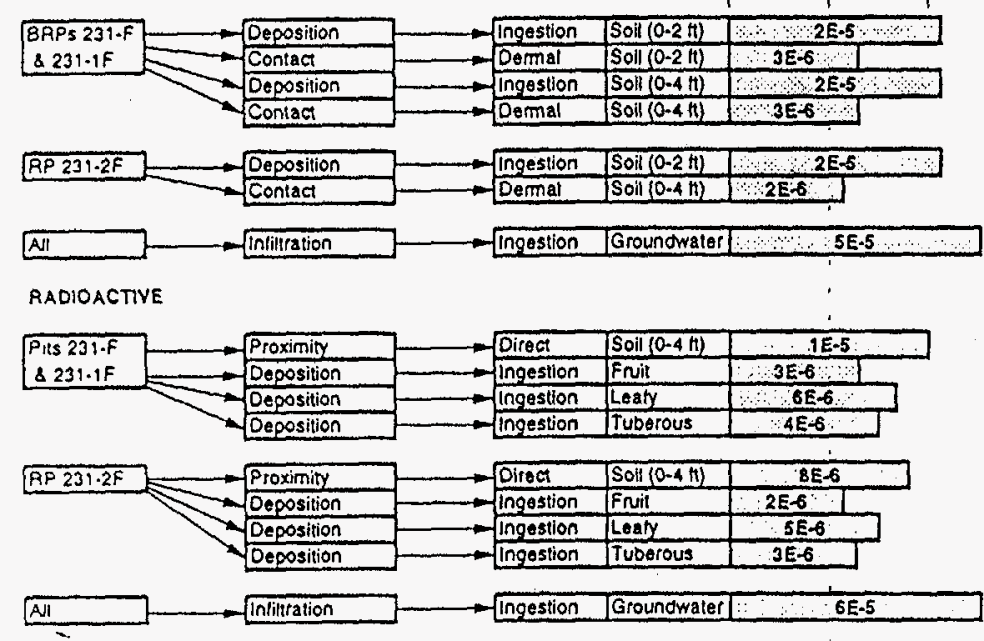

As $28 \%, \mathrm{MPCDO} 24 \%, \mathrm{~B}(\mathrm{a}) \mathrm{P}, 18 \%$ B[a]P 55\%, HPCDD 16\% As $30 \%, \mathrm{HPCDD} 23 \%$, B[a]P $18 \%$

PCB. $125493 \%$
PCB-1254 93\%

Arsenic $73 \%$, Carbon tetrachloride $14 \%$

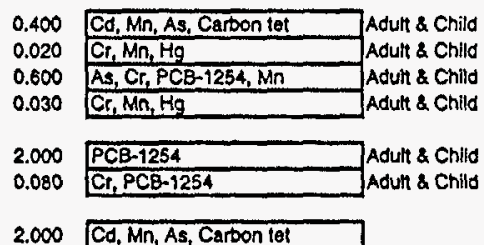

Cs-13760\%, K-40 39\%

$k-4089 \%$

$K=4089 \%$

Cs. $13762 \%, K-4037 \%$

K. $4088 \%$

$K-4088 \%$

K.4088\%

$1.12943 \%, 5 r-9016 \%$ 
Table 1-5 is a summary of risks and HIs for all paths for future on-unit residents at BRPs $231-\mathrm{F} / 1 \mathrm{~F}$. The total risk is $2 \times 10^{-4}$ while the total $\mathrm{HI}$ is 3.0. Table 1-6 shows the summary of risks for RP $231-2 \mathrm{~F}$ for future on-unit residents is $2 \times 10^{-4}$ while the total HI is 5.0. The risks for future residents exceed the upper limit of the EPA's target risk range of $1 \times 10^{-4}$ and the $\mathrm{HI}$ exceed 1.0.

Table 1-7 is a summary of risks and HIs for all paths for future on-unit workers at BRPs 231-F/1F. The total risk is $4 \times 10^{-5}$ while the $\mathrm{HI}$ is 0.4 . Table 1-8 is a summary of risks and HIs for all paths for future workers at RP 231-2F. The total risk is $4 \times 10^{-5}$ while the $\mathrm{HI}$ is 0.5 . None of these risks exceed $1 \times 10^{-4}$ or HIs exceed 1.0.

\subsubsection{Ecological Risk}

The purpose of the ecological risk assessment component of the BRA was to evaluate the likelihood that adverse ecological effects are occurring or may occur as a result of exposure of ecological components to unit-related chemicals. The methodology used in this assessment was based on and complies with the intent of the Draft Ecological Risk Assessors' Guide for Evaluation of Waste Units on the Savannah River Site (WSRC, 1993), the Framework for Ecological Risk Assessment (EPA, 1992), and the Risk Assessment Guidance for Superfund, Volume II, Environmental Evaluation Manual (EPA, 1989a).

Only mercury in soil at BRPs $231-\mathrm{F} / 1 \mathrm{~F}$ and in the wetland sediment was identified in the risk estimation step of the risk characterization as having the potential to pose risk to assessment endpoints for the F-Area BRP waste unit. Actual community-level ecological effects are highly unlikely given the small area of the unit, its limited biological productivity and diversity, and its minimal utilization as a food source for predators. As a result, the likelihood of unit-related chemicals causing an ecologically significant decline in populations of native mice at the unit was estimated to be low; the likelihood of ecologically significant effects on amphibian populations due to surface water contaminants at the ephemeral wetland was estimated to be negligible; and there was concluded to be essentially no likelihood that ecologically significant impacts to the community of species in the vicinity of the unit will occur. 
Summary of Carcinogenic Risk and Noncarcinogenic HI Values for Potential On-Unit /Visitor Exposure Pathways for Burning Rubble Pits 231-F and 231-1F

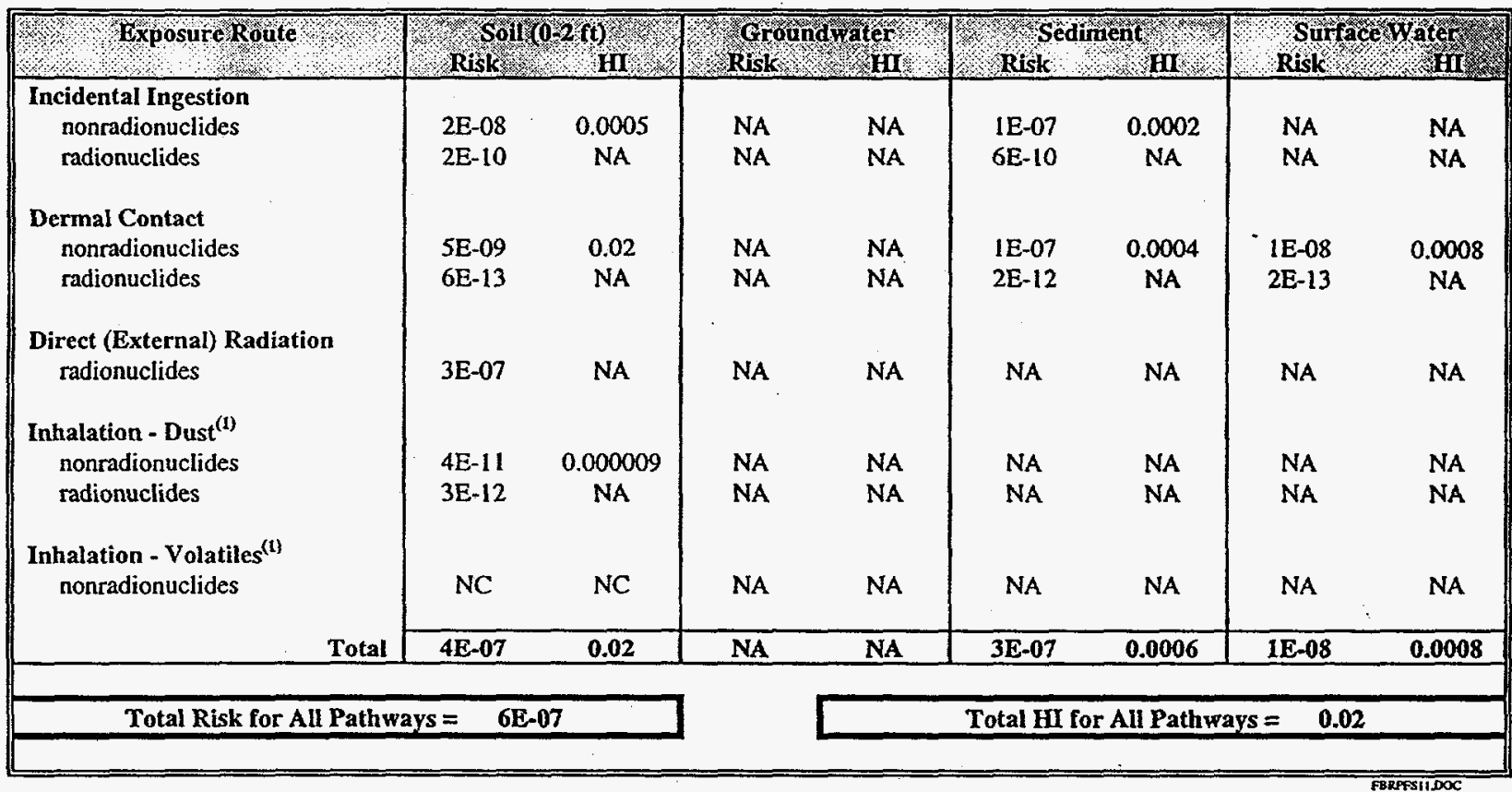

NA - Not Applicable

NC - Not Calculated due to a lack of data

(1) Values for inhalation of dirt and volatiles in air are estimated from COPC concentrations in soil.

Table 1:4

Summary of Carcinogenic Risk and Noncarcinogenic HIs for Potential On-Unit /Visitor Exposure Pathways for Rubble Pit 231-2F

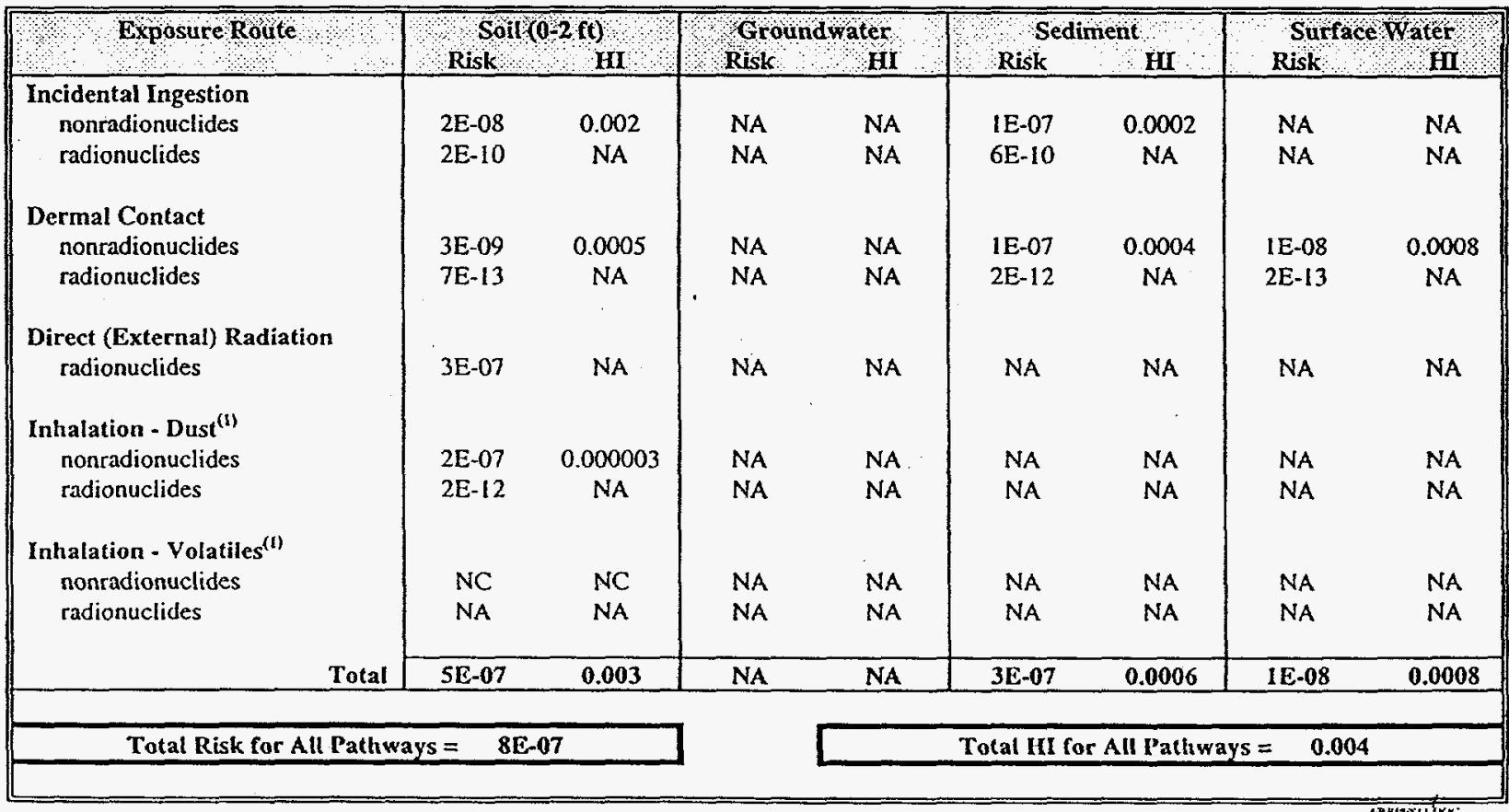

NA - Not Appilicable

NC - Not Culculated duc to a lack of data

(1) Values for inhalation of dirt and volatiles in air are estimated from COPC concentrations in soil 
Table 1-5 Summary of Carcinogenic Risk and Noncarcinogenic HIs for Potential Future On-Unit Resident Exposure Pathways for Burning Rubble Pits 231-F and 231-1F

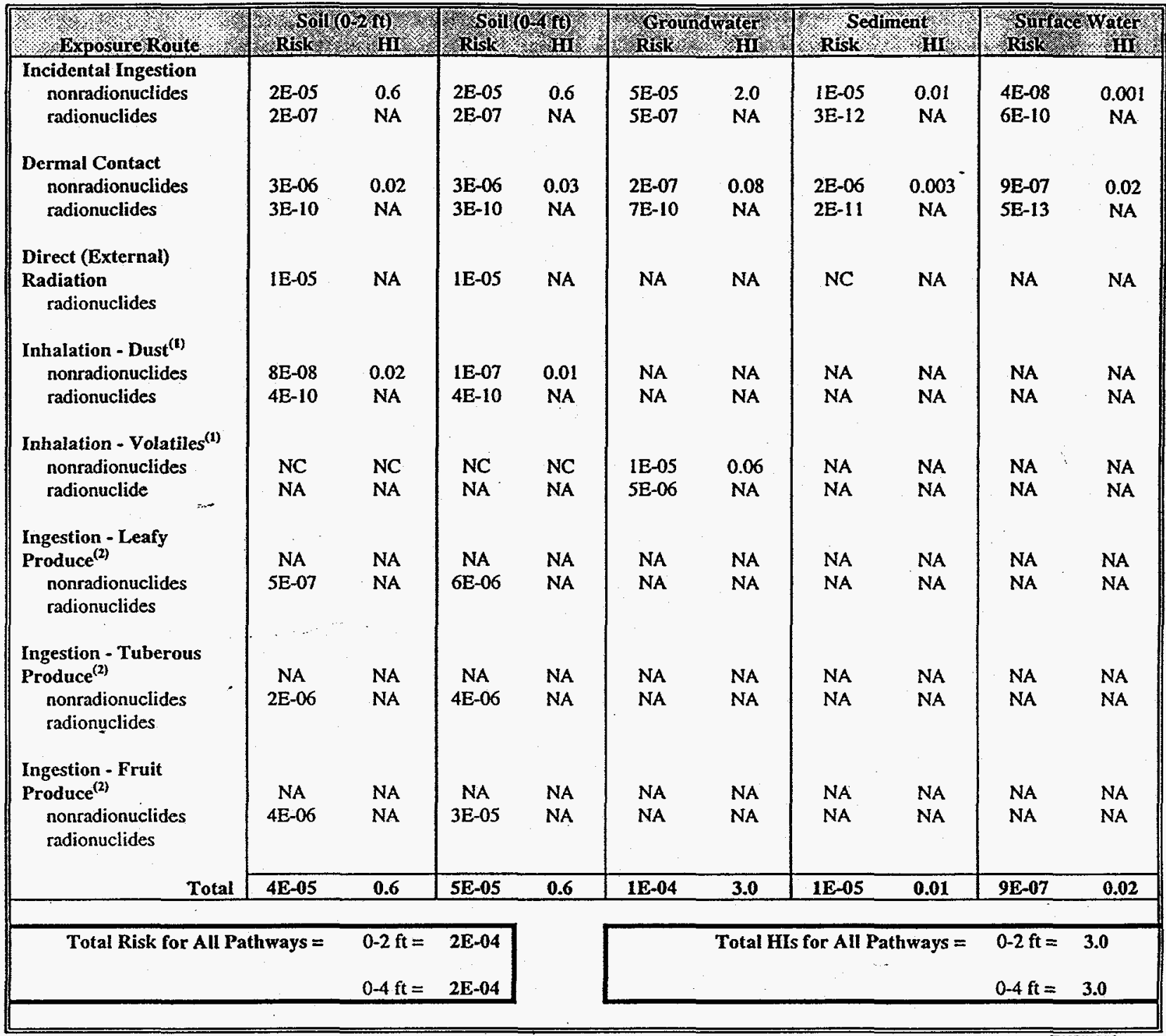

NA - Not Applicable

NC - Not Calculated due to a lack of data

(1) Values for inhalation of dirt and volatiles in air are estimated from COPC concentrations in soil.

(2) Values for produce are estimated from COPC concentrations in soil. 
Table 1-6

Summary of Carcinogenic Risk and Noncarcinogenic HIs for Potential Future On-Unit Resident Exposure Pathways for Rubble Pit 231-2F

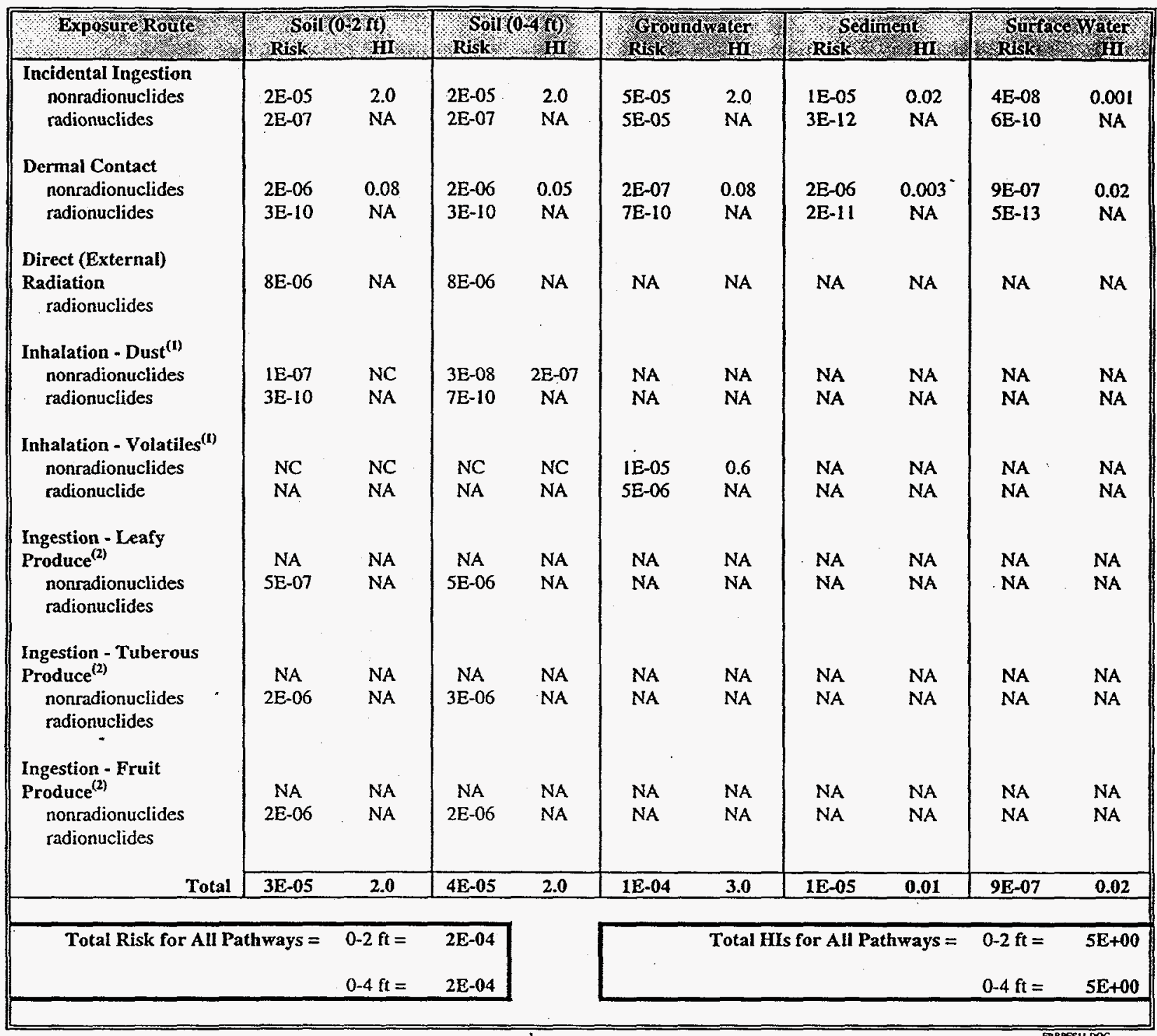

NA - Not Applicable

NC - Not Calculated due to a lack of data

(I) Values for inhalation of dirt and volatiles in air are estimated from COPC concentrations in soil.

(2) Values for produce are estimated from COPC concentrations in soil. 
Table 1-7

Summary of Carcinogenic Risk and Noncarcinogenic HIs for Potential On-Unit Commercial/Industrial Worker Exposure Pathways for Burning Rubble Pits 231-F and 231-1F

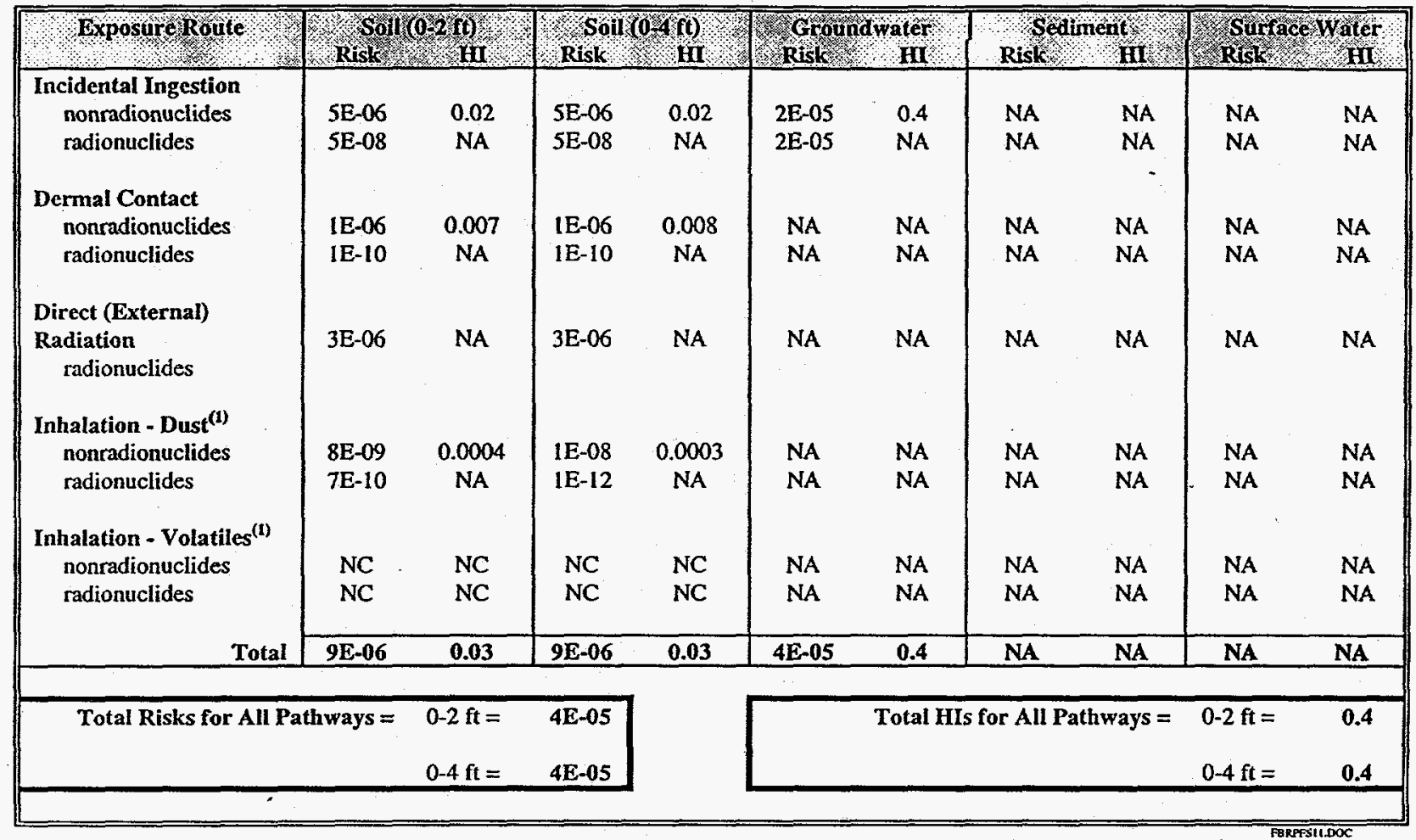

NA - Not Applicable

NC - Not Calculated due to a lack of data

(1) Values for inhalation of dirt and volatiles in air are estimated from COPC concentrations in soil. 
Table 1-8 Summary of Carcinogenic Risk and Noncarcinogenic HIs for Potential Future On-Unit Commercial/Industrial Worker Exposure Pathways for Rubble Pit 231-2F

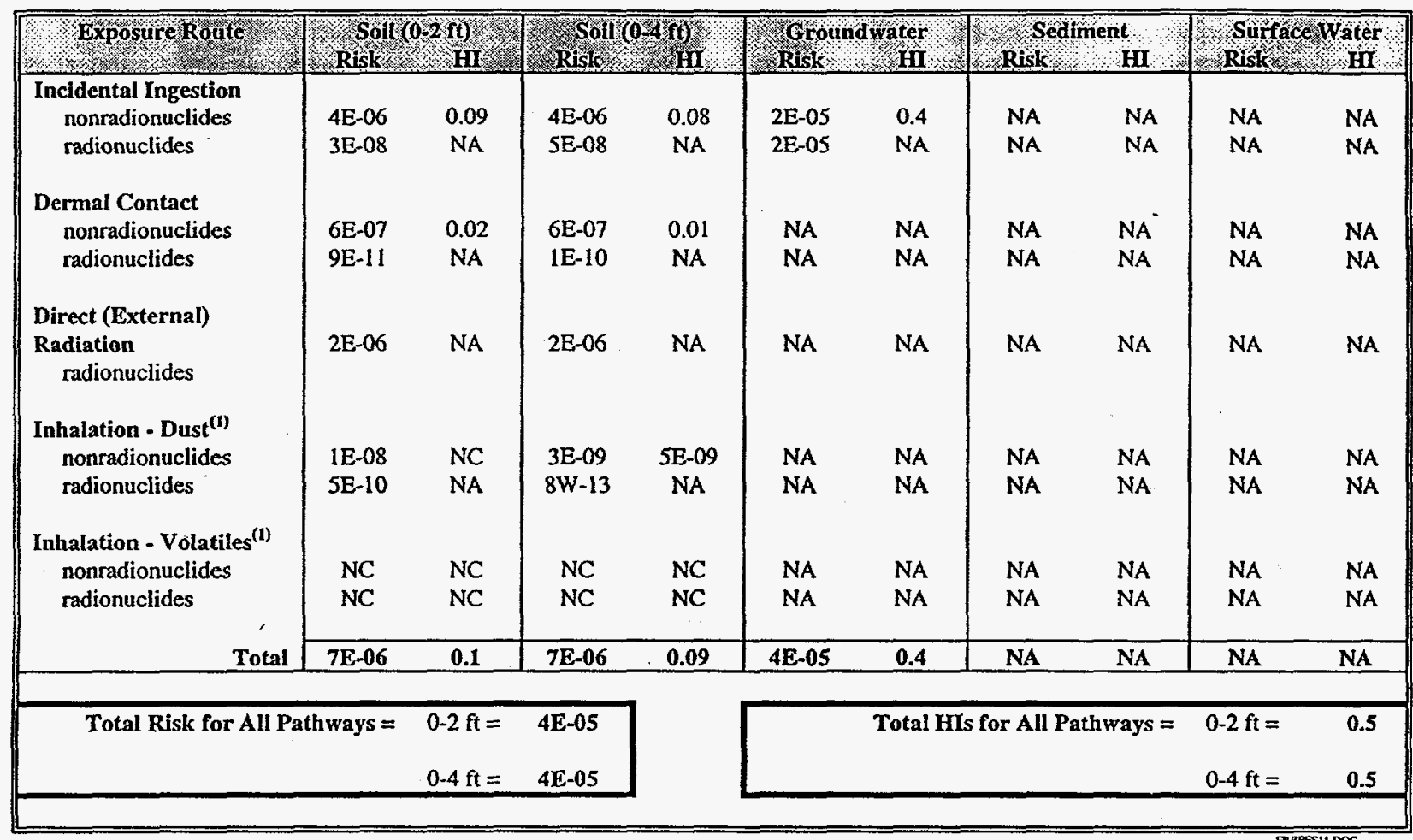

NA - Not Applicable

NC - Not Calculated due to a lack of data

(1) Values for inhalation of dirt and volatiles in air are estimated from COPC concentrations in soil. 


\subsubsection{Uncertainties from the Baseline Risk Assessment}

The evaluation of chemical and radiological risks to human health and ecological receptors presented in this baseline risk assessment was, by necessity, based on a number of assumptions. In addition, many uncertainties are inherent in the risk assessment process. This section briefly discusses the uncertainties associated with the BRA and their potential impact on the results reported.

\section{Uncertainties Leading to Potential Over-Estimation of Risk}

The source for the groundwater contamination has not been determined. Additional characterization will be conducted to determine the source and to delineate the downgradient extent of contamination. This will allow a better estimation of risk attributable to the FBRP.

Radiological uncertainties are tentative due to conservative modeling assumptions concerning leaching of iodine-129 and technetium-99 from deep soils to groundwater. Iodine-129 and technetium-99 are not currently detected, nor have they been historically detected, in the groundwater at the unit and it is unlikely that they will reach detectable levels from leaching in the future.

The summing of risk across pathways is inherently uncertain because:

a. Summing the risk across pathways combines risks as if they were additive.

b. Summing risk assumes that all concentrations of COPCs will be at their reasonable maximum concentrations for all pathways for all times ( i.e., there is no depletion of sources of contamination). Present day concentrations used in the BRA are not reduced to account for degradation, dilution, or dispersion on any media evaluated. However, the leaching to groundwater from deep soils did consider chemical and radioactive degradation mechanisms and dilution in the aquifer.

c. Scenario specific assumptions concerning exposure pathways, duration of exposure, and COPCs contribute to a conservative estimation of risk.

\section{Uncertainties Leading to Potential Under-Estimation of Risk}

It should be noted, that for any subsurface characterization, short of complete excavation, there will always remain some level of uncertainty as to the completeness of the characterization. The sampling strategy at the FBRP was developed utilizing professional judgment upon thorough review of process history and historical data, in conjunction with financial, logistic, administrative, regulatory, and schedule limitations.

In the COPC screening process used in this BRA, chemicals were eliminated following screening against background, risk-based concentrations, essential human nutrients and frequency of detection. Limited background data in soil and groundwater, and the lack of background data for surface water and sediment, resulted in a uncertainty in the background screening portion of the COPC process. Very few chemicals in soil and groundwater, however, were eliminated using the background screening process. The majority of the chemicals were eliminated following the screening against risk-based concentrations. Risk-based concentrations are dynamic and, therefore, uncertainty in these values cannot be eliminated. Eliminating contaminants in the COPC screening process can lead to lower estimates of potential health effects than inclusion of all analytes. 


\subsection{IDENTIFICATION AND SCREENING OF TECHNOLOGIES}

The primary objective of this section of the Corrective Measures Study/Feasibility Study (CMS/FS) is to evaluate the universe of possible treatment options, screen these options to eliminate those that cannot be implemented technically for this specific application or are ineffective for the specific contaminants, and determine representative technologies for each technology type which can be used when creating the alternatives.

\subsection{Introduction}

The following sections of the CMS/FS will develop the remedial action objectives (RAO) for each media of interest, describe the general response actions for each medium of interest, identify various technology types which may be used in this remedial action, and screen the technologies according to their implementability, cost, and effectiveness. A discussion of the technologies and reasons for eliminating or retaining them is included. The goal of the remedy selection process established by the EPA is to select corrective measures/remedial actions that protect human health and the environment, that maintain that protection over time, and that minimize untreated waste [CERCLA 300.430 (a)(1)(i)]. The CMS/FS process ensures that the appropriate corrective measures/remedial options are developed and evaluated and that the pertinent information required to select a recommended approach is presented.

The National Oil and Hazardous Substances Pollution Contingency Plan (NCP) specifies six expectations for developing remedial alternatives [CERCLA 300.430 (a)(1)(iii)]. These include:

- using treatment, whenever practicable, to address principal threats posed by the unit,

- using engineering controls for waste that poses a relatively low, long-term risk or when treatment is impractical,

- combining methods, such as treatment with engineering controls, to protect human health and the "environment,

- supplementing engineering controls with institutional controls, as is appropriate, for short- and longterm management to prevent or limit exposure

- using innovative technology when practicable, and

- returning useable groundwaters to their beneficial uses or preventing further degradation.

Selecting a response action proceeds in a series of steps designed to reduce the universe of potential alternatives from which a final remedy may be selected. The response action selection process as defined in the NCP is outlined in Figure 2-1. 
Figure 2-1 Response Action Selection Process

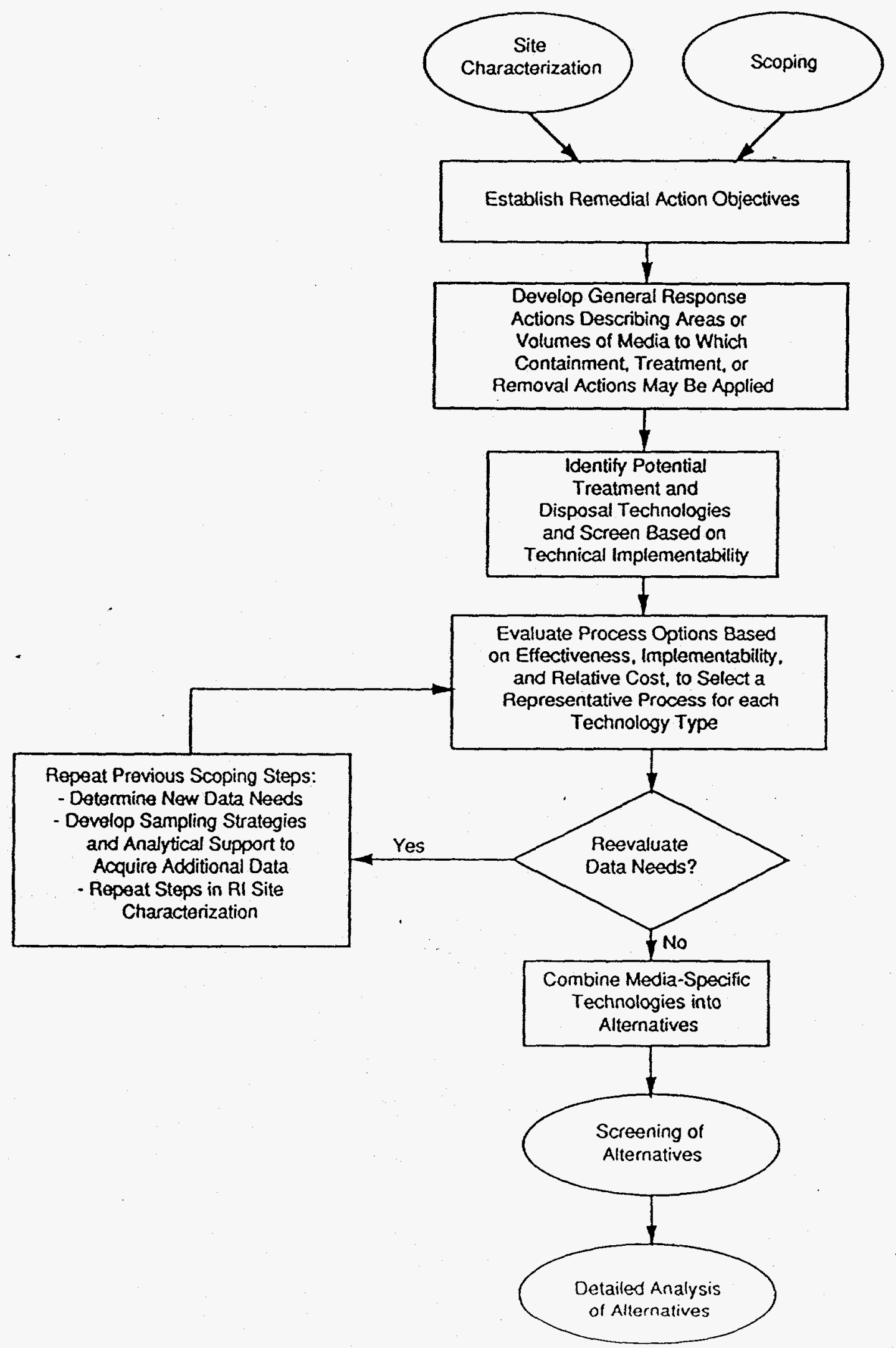




\section{$2.2 \quad$ Remedial Action Objectives}

Remedial action objectives specify unit-specific contaminants, media of concern, potential exposure pathways, and remediation goals. The remedial action objectives are based on the nature and extent of contamination, threatened resources, and the potential for human and environmental exposure. Initially, preliminary remediation goals are developed based upon ARARs, or other information from the RFI/RI and BRA. These goals should be modified, as necessary, as more information concerning the unit and potential remedial technologies becomes available. Final remediation goals will be determined when the remedy is selected and shall establish acceptable exposure levels that are protective of human health and the environment [CERCLA $300.430(\mathrm{e})(2)(\mathrm{i})]$.

The list of chemicals of concern (COCs) for the FBRP is shown in Table 2-1. COCs are defined as chemicals of potential concern that significantly contribute to a pathway in a use scenario for a receptor that either (a) exceeds a $1 \times 10^{-4}$ cumulative site cancer risk; or (b) exceeds a non-carcinogenic hazard index of 1 . (Supplemental Guidance to RAGS: Region 4 Bulletins, Bulletin No. 5, November, 1995) Chemicals which exceed an ARAR, but do not exceed the $1 \times 10^{-4}$ risk level or the HI level of 1 are also included as COCs. The media in which the COCs are found are also indicated in this table.

Table 2-1 List of FBRP Risk-Based Chemicals of Concern and the Media in Which They Exist

\begin{tabular}{|l|c|c|}
\hline Chemical of Concern & Soil & Groundwater \\
\hline \hline Carbon tetrachloride & & $\mathrm{X}$ \\
\hline Dichloromethane & & $\mathrm{X}$ \\
\hline Tetrachloroethylene & & $\mathrm{X}$ \\
\hline PCB-1254 & $\mathrm{X}$ & \\
\hline
\end{tabular}

This report deals only with soil remediation, therefore, the only COC that will be considered is PCB-1254.

While chemicals that do not significantly contribute to a pathway in a use scenario for a receptor that has a risk value between $1 \times 10^{-6}$ and $1 \times 10^{-4}$ are not considered to be COCs, Table 2-2 has been provided to indicate chemicals that meet this intermediate risk range criteria.

Table 2-2 FBRP Intermediate Risk Range Chemicals of Concern and the Media in Which They Exist

\begin{tabular}{|l|c|c|}
\hline Intermediate Risk Range Chemical of Concern & Soil & Groundwater \\
\hline \hline Arsenic & $\mathbf{X}$ & $\mathbf{X}$ \\
\hline B[a]P & $\mathbf{X}$ & \\
\hline Cs-137 & $\mathbf{X}$ & \\
\hline HpCDD & $\mathbf{X}$ & \\
\hline K-40 & $\mathbf{X}$ & \\
\hline I-129 & & $\mathbf{X}$ \\
\hline Sr-90 & $\mathbf{X}$ & $\mathbf{X}$ \\
\hline Tritium & & $\mathbf{X}$ \\
\hline
\end{tabular}




\subsection{Remedial Goal Options From the BRA}

Chemical-specific remedial goal options (RGOs) are concentration goals for individual chemicals for specific media and land-use scenarios at CERCLA sites. General sources of chemical-specific RGOs include: (1) concentrations based on ARARs, and (2) concentrations based on risk values produced from the risk assessment.

\section{Human Health RGOs}

The COCs identified from the human health portion of the baseline risk assessment showed only PCB-1254 in soil at RP 231-2F. This chemical was evaluated to determine whether RGOs were appropriate. A comparison to ARARs was completed to establish whether the risk drivers were present in concentrations that exceeded regulatory levels. Although a chemical or radionuclide may result in a calculated risk or HI in the risk assessment, a comparison to ARARs is necessary to establish whether the concentrations exceed regulatory standards. Regulatory standards may be higher than risk-based standards because regulatory standards take into account the feasibility of achieving a risk-based goal. If a risk-based goal is unachievable, an achievable value is designated as the regulatory standard. RGOs were derived for PCB-1254 which exceeded a to-be-considered guidance value. No ARARs were exceeded in any of the pits.

Soil

PCB-1254 was detected in only 1 of 8 samples in the 0 to $0.6 \mathrm{~m}(0$ to $2 \mathrm{ft}$ ) soil interval at RP 231-2F. The maximum detected value of PCB-1254 $(2.87 \mathrm{mg} / \mathrm{kg})$ was quantitatively evaluated for human health risk over the entire pit area, which likely overestimates the risk from PCBs at RP 231-2F. While an increased HI was calculated for the hypothetical future on-unit residents, given the low frequency of detection and the low level of the maximum detected concentration, it is unlikely that PCBs are a unit-wide contaminant at levels that would cause concern for human health protection, but rather represent an isolated area of contamination. Additionally, the PCB levels detected do not pose an unacceptable hazard for future industrial workers.

According to EPA (A Guide on Remedial Actions at Superfund Sites with PCB Contamination, August 1990b), soil action levels for PCBs in soil are $1 \mathrm{mg} / \mathrm{kg}$ for residential land use and $10-25 \mathrm{mg} / \mathrm{kg}$ for industrial land use. The $1 \mathrm{mg} / \mathrm{kg}$ action level for residential exposure was exceeded in this to-be-considered guidance and, therefore, an RGO was derived for PCB-1254. The maximum detected concentration of PCB-1254 does not exceed the 10 $\mathrm{mg} / \mathrm{kg}$ level for the TSCA ARAR.

The RGOs, as determined in the BRA, are shown in Table 2-2. RGOs are calculated for COCs which are primary contributors of potential risk and/or adverse effects for the current and future use scenarios using standard EPA default equations. Risk-based RGOs are estimated only for pathways exceeding a potential carcinogenic risk of $1 \times 10^{-4}$ and HIs exceeding unity and if the COCs exceed regulatory limits for ARARs (i.e., MCLs). RGOs are not required remediation goals or standards, but are developed as part of the BRA to provide a range of risk-based cleanup goals for consideration in the CMS/FS process. These RGOs are listed in Table 23.

A set of RGOs was also developed for chemicals which contributed significantly to calculated risk values in between $1 \times 10^{-6}$ and $1 \times 10^{-4}$. These RGOs are labeled as intermediate risk RGOs and are shown in Table 2-4.

\subsubsection{Applicable or Relevant and Appropriate Requirements (ARARs)}

Section 121(d) of the CERCLA of 1980, as amended by the SARA of 1986, requires that remedial actions comply with requirements or standards set forth under Federal and State environmental laws. Types of ARARs include action-specific, location-specific, and chemical-specific.

As mandated by CERCLA $121(\mathrm{~d})(2)(\mathrm{A})$, remedies must consider "any promulgated standard, requirements, criteria, or limitation under a State environmental or facility siting law that is more stringent than any Federal standard, requirement, criteria, or limitation" if the former is applicable or relevant and appropriate to the site 
Table 2-3 Remedial Goal Options for Contaminants of Concern for Soil by Receptor for the F-Area Burning Rubble Pits (231-F/1F) and Rubble Pit (231-2F)

\begin{tabular}{|c|c|c|c|c|c|c|c|c|}
\hline \multirow[b]{2}{*}{ Medium } & \multirow[b]{2}{*}{ Receptor } & \multirow[b]{2}{*}{ Chemical } & \multicolumn{3}{|c|}{ Target Cancer Risk } & \multicolumn{3}{|c|}{ Target Hazard Quotient } \\
\hline & & & $1 \times 10^{-4}$ & $1 \times 10^{-5}$ & $1 \times 10^{-6}$ & 3. & 1 & 0.1 \\
\hline \multirow[t]{2}{*}{ Soil (mg/kg) } & Future Resident & PCB-1254 (231-2F only) & $1.44 \mathrm{E}+01$ & $1.44 \mathrm{E}+00$ & $1.44 \mathrm{E}-01$ & 4.72 & 1.57 & 0.157 \\
\hline & Future Worker & PCB-1254 (23! -2F only) & $6.51 \mathrm{E}+01$ & $6.51 E+00$ & $6.51 \mathrm{E}-01$ & 123 & 40.9 & 4.09 \\
\hline
\end{tabular}

Note:

PCB- 1254 is a contaminant of concem for $231 \cdot 2 \mathrm{~F}$ soil only.

Potential future residenuworker exposure to soil contaminants includes ingestion, dermal contact, and inhalation of particulates.

Table 2.4 Remedial Goal Options for Intermediate Risk Chemicals of Concern for Soil by Receptor for the F-Area Burning/Rubble Pits (231-F/1F) and Rubble Pit (231-2F)

\begin{tabular}{|c|c|c|c|c|c|c|c|c|}
\hline \multirow[b]{2}{*}{ Medium } & \multirow[b]{2}{*}{ Receptor } & \multirow[b]{2}{*}{ Chemical } & \multicolumn{3}{|c|}{ Target Cancer Risk } & \multicolumn{3}{|c|}{ Target Hazard Quotient } \\
\hline & & & $1 \times 10^{-4}$ & $1 \times 10^{-5}$ & $1 \times 10^{-6}$ & 3 & 1 & 0.1 \\
\hline BRPs 231-F \& -1F & & Hor on & 3in- & y.r. & $20-2$ & 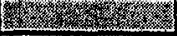 & 25is & $(128-12$ \\
\hline Soil (mg/kg) & Future Resident & $\begin{array}{l}\text { Arsenic } \\
\text { HpCDD } \\
\text { B }[\text { a]P }\end{array}$ & $\begin{array}{c}80.152 \\
0.079 \\
16.225 \\
\end{array}$ & $\begin{array}{c}8.015 \\
0.0079 \\
1.623 \\
\end{array}$ & $\begin{array}{c}0.8015 \\
0.00079 \\
0.0162 \\
\end{array}$ & $\ldots$ & $\cdots$ & $\cdots$ \\
\hline Soil (pCi/g) & & $\begin{array}{l}\mathrm{Cs} \cdot 137 \\
\mathrm{~K}-40 \\
\end{array}$ & $\begin{array}{c}27.918 \\
103.390 \\
\end{array}$ & $\begin{array}{c}2.792 \\
10.339 \\
\end{array}$ & $\begin{array}{l}0.279 \\
1.034 \\
\end{array}$ & $\ldots$ & $\ldots$ & $\ldots$ \\
\hline Soil (mg/kg) & Future Worker & $\begin{array}{l}\text { Arsenic } \\
\text { HpCDD }\end{array}$ & $\begin{array}{c}370.769 \\
0.374 \\
\end{array}$ & $\begin{array}{l}37.077 \\
0.0374 \\
\end{array}$ & $\begin{array}{c}3.708 \\
0.00374 \\
\end{array}$ & $\ldots$ & $\ldots$ & $\ldots$ \\
\hline Soil $(p \mathrm{pi} / \mathrm{g})$ & & $\begin{array}{l}\text { Cs-137 } \\
\mathrm{K}-40 \\
\end{array}$ & $\begin{array}{r}104.118 \\
384.685 \\
\end{array}$ & $\begin{array}{l}10.412 \\
35.469 \\
\end{array}$ & $\begin{array}{l}1.041 \\
3.847 \\
\end{array}$ & $\cdots$ & $\cdots$ & $\cdots$ \\
\hline RP 231.2E & $\therefore \ldots \quad-2 \times$ & 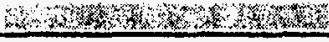 & $36 x+2$ & $\sqrt{15 x+28 x+3 x}$ & 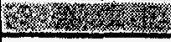 & 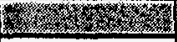 & 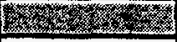 & 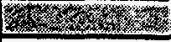 \\
\hline Soil $(p \mathrm{p} i / g)$ & Future Resident & $\begin{array}{l}\text { Cs-137 } \\
\mathrm{K} \cdot 40 \\
\mathrm{Sr}-90 \\
\end{array}$ & $\begin{array}{c}27.898 \\
103.268 \\
51.282 \\
\end{array}$ & $\begin{array}{c}2.790 \\
10.327 \\
5.128 \\
\end{array}$ & $\begin{array}{l}0.279 \\
1.033 \\
0.513 \\
\end{array}$ & $\ldots$ & $\ldots$ & $\ldots$ \\
\hline Soil (pCi/g) & Future Worker & $\begin{array}{l}\mathrm{Cs} \cdot 137 \\
\mathrm{~K} \cdot 40\end{array}$ & $\begin{array}{l}104.118 \\
384.685\end{array}$ & $\begin{array}{l}10.412 \\
38.469\end{array}$ & $\begin{array}{l}1.041 \\
3.847\end{array}$ & $\ldots$ & ... & $\ldots$ \\
\hline
\end{tabular}

Nole: $\quad$ HpCDD is Heptachlorodibenzo-p-dioxin

$B[a] P$ is Benzola]pyrene 
and associated remedial activities. SARA requires that the remedial action for a site meet all ARARs unless a waiver is invoked. Five circumstances under which a waiver may be invoked are:

- the remedial action is an interim measure where the final remedy will attain the ARAR upon completion

- $\quad$ compliance will result in greater risk to human health and the environment than other options

- $\quad$ compliance is technically impracticable

- an alternative remedial action will attain the equivalent of the ARAR

- for State requirements, the State has not consistently applied the requirement in similar circumstances

In addition to ARARs, many Federal and State environmental and public health programs also develop criteria, guidance, and proposed standards that are not legally binding, but that may provide useful information or recommended procedures (EPA, 1988b). These to-be-considered guidance values are not potential ARARs but are reviewed along with ARARs and considered when setting remediation objectives (e.g., cleanup goals).

\subsubsection{Definition of ARARs}

Potential ARARs may be classified as either applicable or relevant and appropriate. Applicable requirements are those cleanup standards, standards of control, and other substantive environmental protection requirements, criteria, or limitations promulgated under Federal or State law that specifically address a hazardous substance, pollutant, contaminant, remedial action, location, or other circumstance at a CERCLA site (EPA, 1988b).

Relevant and appropriate requirements are those cleanup standards, standards of control, and other substantive environmental protection requirements, criteria, or limitations promulgated under Federal or State law that, while not applicable to a hazardous substance, pollutant, contaminant, remedial action, location, or other circumstance at a CERCLA site, address problems or situations sufficiently similar to those encountered at the CERCLA site so that their use is well suited to the particular site (EPA, 1988b).

The determination that a requirement is relevant and appropriate is a two-step process: (1) determination if a requirement is relevant and, if relevant, (2) determination if a requirement is appropriate. In general, this involves a comparison of a number of site-specific factors, including the characteristics of the remedial action, the hazardous substances present at the site, or the physical circumstances of the site, with those addressed in the statutory or regulatory requirement. In some cases, a requirement may be relevant but not appropriate based on site-specific circumstances; such a requirement would not be ARAR for the site. In addition, there is more discretion in the determination of relevant and appropriate; it is possible for only part of a requirement to be considered relevant and appropriate in a given case. When the analysis results in a determination that a requirement is both relevant and appropriate, such a requirement must be complied with to the same degree as if it were applicable.

\subsubsection{To-Be-Considered Information}

To-be-considered requirements are non-promulgated advisories or guidance issued by Federal or State government that are not legally binding and do not have the status of potential ARARs. However, TBCs may be considered along with ARARs in determining the necessary level of cleanup for protection of health or the environment. For example, DOE Orders are not ARARs since they have not been formally promulgated under Federal or State law; however, these Orders should be considered along with ARARs in determining remedial action objectives. DOE Orders are legally binding for DOE and all of its contractors through the Price Anderson Amendments Act of 1988, which is an amendment to the Atomic Energy Act.

\subsubsection{Types of ARARs}

Three types of ARARs were developed to further clarify how to identify and comply with environmental requirements. These types are described in the following sections. 
Action-Specific ARARs

Action-specific requirements set controls or restrictions on the design, performance and other aspects of implementation of specific remedial activities. Examples include RCRA regulations for off-site disposal of hazardous residuals and the Clean Water Act standards for discharge of treated groundwater. Because actionspecific ARARs apply to discrete remedial activities, their evaluation is discussed in Section 4.0 in the detailed analysis performed on each retained alternative. A retained alternative must conform to all ARARs unless one of the five statutory waivers list in Section 2.2.1 is invoked.

SARA Section 121(e) exempts any on-site response action from having to obtain a Federal, State and/or local permit. The on-site actions must, however, still comply with the substantive aspects of these requirements (EPA, 1988b).

\section{Location-Specific ARARs}

Location-specific ARARs must consider Federal, State, and local requirements that reflect the physiographical and environmental characteristics of the unit or the immediate area. Remedial actions may be restricted or precluded depending on the location or characteristics of the unit and the resulting requirements. A list of potential location-specific ARARs evaluated for the FBRP is provided in Table 2-5.

Table 2-5 Potential Location-Specific ARARs for the FBRP

\begin{tabular}{|l|l|l|l|}
\hline \multicolumn{1}{|c|}{ Site Feature/Location } & \multicolumn{1}{|c|}{ Citation } & \multicolumn{1}{c|}{ Requirement/Synopsis } & \multicolumn{1}{c|}{ Consideration for FBRP } \\
\hline $\begin{array}{l}\text { Within area where action may } \\
\text { cause irreparable harm, loss, or } \\
\text { destruction of significant } \\
\text { artifacts }\end{array}$ & $\begin{array}{l}\text { National Historical } \\
\text { Preservation Act (16 USC } \\
\text { Section 469); 36 CFR Part } \\
65\end{array}$ & $\begin{array}{l}\text { Requires the action be taken to } \\
\text { recover and preserve artifacts } \\
\text { when alteration of terrain } \\
\text { threatens significant scientific, } \\
\text { prehistorical, or archaeological } \\
\text { data. }\end{array}$ & $\begin{array}{l}\text { Not an ARAR since FBRP is not } \\
\text { a designated archaeological area. }\end{array}$ \\
\hline Wetlands & $\begin{array}{l}\text { Clean Water Act Section } \\
\text { A04; 40 CFR Part 230.33 } \\
\text { CFR parts 320-330 }\end{array}$ & $\begin{array}{l}\text { Army Corps of Engineers U. S. } \\
\text { regulations, must take action to } \\
\text { prohibit discharge or dredged or } \\
\text { fill material into wetlands without } \\
\text { permit. }\end{array}$ & $\begin{array}{l}\text { Not an ARAR. Wetland } \\
\text { described in the FBRP area is } \\
\text { not a wetland as described by the } \\
\text { U. S. Army Corps of Engineers. }\end{array}$ \\
& &
\end{tabular}

\section{Chemical-Specific ARARs}

Chemical-specific ARARs are media-specific concentration limits promulgated under Federal or State law. The NCP requires the development of health-based site-specific levels for chemicals or media where such limits do not exist and there is a concern with their potential health or environmental impacts, where possible. Potential chemical-specific ARARs are discussed by media in the following sections.

The chemical-specific ARARs for RP 231-2F are shown in Table 2-6. There are no chemical-specific ARARs for BRPs 231-F and 231-1F. 
Table 2-6

Applicable, or Relevant and Appropriate Requirements for Soil at the FBRP

\begin{tabular}{|l|c|c|c|c|l|}
\hline Constituent & Units & $\begin{array}{c}\text { Maximum } \\
\text { Measured } \\
\text { Conc. }\end{array}$ & ARAR & $\begin{array}{c}\text { To-be- } \\
\text { Considered } \\
\text { Values }\end{array}$ & \multicolumn{1}{c|}{ Comments } \\
\hline $\mathrm{PCB}$ & $\mathrm{mg} / \mathrm{kg}$ & 2.87 & 10 & 1 & $\begin{array}{l}\text { Toxic Substances Control Act (TSCA); 40 } \\
\text { CFR Part 461 } \\
\text { Recommended soil action level for } \\
\text { residential areas, to-be-considered guidance, } \\
\text { A Guide on Remedial Actions at Superfund } \\
\text { Sites With PCB Contamination, Directive } \\
\text { 9355.4-01 FS, August 1990. } \\
\text { Recommended soil action level for industrial } \\
\text { areas, to-be-considered guidance, A Guide on } \\
\text { Remedial Actions at Superfund Sites With } \\
\text { PCB Contamination, Directive 9355.4-01 } \\
\text { FS, August 1990. }\end{array}$ \\
\hline
\end{tabular}

\subsubsection{Remedial Action Objectives}

The remedial action objective for soil is to prevent unacceptable risks to human health and the environment. None of the risks associated with the soil in the FBRP have been found to be greater than $1 \times 10^{-4}$. The only HIs that were above 1.0. were for PCB-1254 in RP 231-2F for future residents for both the $0-2 \mathrm{ft}$ and $0-4 \mathrm{ft}$ soil layers. The HI value for both of these scenarios was 2.0. No ARARs for soil concentrations were exceeded. The onty to-be-considered guidance that was exceeded for soil concentrations was for PCB-1254 which had a maximum value of $2.87 \mathrm{mg} / \mathrm{kg}$. The to-be-considered guidance level for PCBs is a recommended soil action level of $1 \mathrm{mg} / \mathrm{kg}$ for residential use and $10 \mathrm{mg} / \mathrm{kg}$ for industrial use.

The ecological setting of the FBRP is not unique, there are no known endangered, threatened, or special concern species in the vicinity. The area of the unit is small and the habitat is relatively low in diversity and productivity. The probability of unit-related chemicals causing an observable decline in the populations of native species was estimated to be very low; it was concluded that there was no likelihood that ecologically significant impacts in the vicinity of the unit would occur (BRA Report WSRC-TR-94-108, Rev 1.2, March 1996b). Therefore, the development of ecological RAOs is not warranted.

\subsection{General Response Actions}

General response actions are those actions that will satisfy the remedial action objectives. These actions are medium-specific and include no action, institutional controls, recovery or removal actions, containment actions, collection/treatment actions, and disposal actions. The specific technology types and process options are listed in section 2.4 .

\subsection{Estimated Volume of Impacted Soil}

The top four-foot layer of soil must be considered for remediation in a residential scenario where the soil has been found to contain contaminants which pose risks to future residents. This allows future residents to perform excavations typically made during the construction of housing foundations where the soil removed may be spread over the surface of the land. 
The BRA determined that the only soil contamination concern was for rubble pit 231-2F due to levels of PCB1254 in excess of the residential to-be-considered guidance level of $1 \mathrm{mg} / \mathrm{kg}(\mathrm{ppm})$ and an $\mathrm{HI}$ greater than 1 . For residential remediation of soil only the first four feet of soil are considered for remediation. BRPs 23l-F and $231-1 \mathrm{~F}$ show risks for soil ingestion and dermal contact which are between $1 \times 10^{-6}$ and $1 \times 10^{-4}$. The volume of contaminated soil, using the unit reconnaissance dimensions for the pits, can be calculated as follows:

\begin{tabular}{|ccccc|}
\hline Pit & $\begin{array}{c}\text { Length } \\
(\mathbf{f t})\end{array}$ & $\begin{array}{c}\text { Width } \\
(\mathbf{f t})\end{array}$ & $\begin{array}{c}\text { Depth } \\
(\mathbf{f t})\end{array}$ & $\begin{array}{c}\text { Volume } \\
\text { (cubic ft) }\end{array}$ \\
\hline $231-\mathrm{F}$ & 275 & 62 & 4 & 68,200 \\
$231-1 \mathrm{~F}$ & 325 & 89 & 4 & 115,700 \\
$231-2 \mathrm{~F}$ & 164 & 33 & 4 & 21,648 \\
\hline
\end{tabular}

\title{
2.4 Identification and Screening of Technology Types and Process Options
}

The purpose of this section is to describe specific technology types, including process options, for the following general responses:

\author{
Soil Remediation \\ No Action \\ Institutional controls \\ Containment \\ Recovery/Removal \\ Ex situ treatment \\ In situ treatment \\ Disposal
}

Identified technologies are screened initially using technical implementability as the basis and then using the criteria of effectiveness, implementability, and cost. Some technologies which pass this screening (i.e., are retained) may apply to only a discrete portion of a medium, but may be used in conjunction with other technologies to form an overall remediation strategy.

\subsubsection{Screening Criteria}

The initial screening is performed by evaluating the options with respect to technical implementability. During this screening step, process options and entire technology types may be eliminated.

The next step in screening alternatives is to select one process to represent each technology type. This is done using the criteria provided in the NCP. The NCP provides three basic criteria for screening of technologies. The criteria are:

$$
\begin{array}{ll}
- & \text { Effectiveness } \\
- & \text { Implementability }
\end{array}
$$

CMS guidance does not specify the three NCP criteria as such; however, guidance does indicate that the screening process should eliminate corrective measures that may prove unfeasible to implement, that rely on technologies unlikely to perform satisfactorily or reliably, or that do not achieve the remedial action objectives within a reasonable time period. These screening requirements are all aspects of the three NCP criteria discussed below. 


\subsubsection{Effectiveness}

For a technology to be effective it must achieve specified objectives, must be compatible with the contaminant characteristics and unit conditions, and must be protective of public health and the environment. To accomplish this, the technology itself must be effective in reducing or eliminating any short-term and long-term risk to human health or the environment directly associated with the waste unit and must not pose adverse impacts on the environment, public health, or public welfare. Technologies for which unit contaminants or conditions clearly limit their effectiveness or which do not provide adequate protection of the environment, public health, and public welfare will be rejected (i.e., not retained) and will not be considered for detailed analysis. Additionally, technologies which have not demonstrated effectiveness at similar units will be eliminated from further consideration.

\subsubsection{Implementability}

Implementability addresses both the technical and institutional feasibility of applying a technology. Under this criterion technologies are evaluated based on the technical feasibility, availability of resources and equipment, and the administrative feasibility of implementing them. The nature of the technology should be such that it can be implemented in a cost effective and timely manner in the physical setting associated with the FBRP. In addition, the implementation of the technology should not elicit substantial public concerns in the community. Site accessibility, available area, and potential future use of the property may also affect the implementation of certain technologies. Mobilization and permitting requirements, where applicable, must be workable and previously demonstrated at equivalent projects. Preliminary consideration is also given to regulatory constraints such as handling, disposal, and treatment requirements that would affect the implementation of certain remedial technologies. These considerations will be evaluated further during detailed analysis (Section 4.0) for retained technologies when action-specific ARARs are developed. Technologies that are not technically or administratively feasible will be removed from further consideration.

\subsubsection{Cost}

A qualitative cost evaluation is provided so that cost comparisons can be made among technologies. Technology costs are described as being high, medium, or low, relative to technologies of similar type (e.g., containment technologies). Qualitative evaluations take into consideration capital costs and operation and maintenance costs, and are based upon prior estimates, previous experience, and engineering judgment. Those technologies that demonstrate comparable levels of applicability, effectiveness and implementability as other technologies but at significantly greater cost will be eliminated. Similarly, technologies that are equivalent in cost but are clearly less effective than other retained technologies will also be rejected. Otherwise, cost will not be used as a criterion to screen technologies at this point in the CMS/FS process.

\subsubsection{General Response Actions}

General Response actions are medium-specific actions which will lead to the accomplishment of remedial action objectives. The following sections discuss the general response actions for soil remediation. These sections also include an evaluation of the individual general response actions based on the three screening criteria discussed above.

\subsubsection{No Action}

No action is not a technology, but is a general response action that relies on natural attenuation mechanistís to reduce contaminant concentration levels to below proposed concentration-based remediation goals. Under this general response, no efforts would be taken to monitor, remove, treat, or otherwise mitigate the potential spread 
of FBRP contamination. In addition, no actions would be taken to further minimize the potential for human exposure to FBRP contaminants.

No action will not meet the effectiveness criteria for the FBRP as there are risks to hypothetical future residents that exceed $1 \times 10^{-4}$. The total risk for future residents at BRPs $231-\mathrm{F} / 1 \mathrm{~F}$ and RP $231-2 \mathrm{~F}$ has been calculated to be $2 \times 10^{-4}$. HIs also exceed 1.0 for all of these pits (5.0 for $231-2 \mathrm{~F}$, and 3.0 for $231-\mathrm{F} / 1 \mathrm{~F}$ ).

The no action response would be readily implemented and represents the least expensive (baseline) alternative possible. There are no costs associated with the no action alternative.

Although the no action alternative would not be effective at the FBRP, the NCP requires that the no action alternative be retained throughout the CMS/FS as a basis for comparison during the detailed analysis of alternatives. Therefore, no action will be retained for further evaluation.

\subsubsection{Institutional Controls}

Institutional controls are administrative measures taken to minimize the potential for human exposure to FBRP contamination. Institutional controls include items such as: fences, warning signs which describe the hazards associated with a waste site, maintenance of an area to control plant growth or limit erosion, security measures to prevent access to an area, and deed restrictions. Deed restrictions would inform hypothetical developers or buyers of previous waste disposal activities at the unit, and would limit the types of future activities that could be conducted on the property (e.g., restrictions on excavating and groundwater use). CERCLA 120 (h) requires that DOE create a deed when the land is to be transferred to non-federal ownership. This deed must include a notification of former waste management and disposal activities on the property as well as any continuing groundwater monitoring commitments or use restrictions.

Institutional controls would be potentially effective in further minimizing the potential for human exposure to FBRP contaminants and would be relatively easy to implement. None of the risks for current visitors or hypothetical future workers exceeded $1 \times 10^{-4}$. The institutional controls that would be used at the FBRP would be to make a survey plat of the FBRP and place deed restrictions in the Aiken County Records to limit future land use for industrial purposes only. If a soil cover was added and the land was made available for residential use, a notification would be placed with the Aiken County Records stating that this area was used to manage hazardous material. These controls would effectively reduce the risk from the FBRP for human receptors.

Institutional controls are readily implementable. Deed restrictions can easily be placed on this land when it is to be transferred to non-federal ownership. Warning signs are currently in place. Costs associated with institutional controls are considered low relative to other remedial responses. This general response action is retained for use at the FBRP.

Access Controls Controlling site access involves temporary or permanent physical restrictions that prevent or reduce exposure to site contaminants. These controls can be used alone as a risk reduction measure for untreated sites or in combination with other remediation technologies to prevent vandalism of: onsite remedial equipment or disturbance of containment systems.

The advantage of access controls is that they provide some degree of protection of human health, and are relatively simple to implement. Implementation activities do not require handling of the contaminated media so worker and community safety concerns associated with other remedial alternatives which might release contaminants are not an issue.

The disadvantage of access controls is that they do not effectively achieve any of the standard measures of performance such as containment, removal, destruction, or treatment of contaminants. Actions that reduce the mobility, toxicity, or mass of contaminants are preferred. This technology is difficult to implement if 'the contamination has spread to privately owned land or to land that contains public roadways. Also, the on-going administrative costs associated with maintaining the control measures and monitoring the sitc will be open ended. Continual contaminant monitoring is required to ensure that the access control measures continue to 
cover the extent of contamination. This technology does not contain contamination and as a result, the effected area may increase over time. If the contaminants do not naturally disperse, degrade or decay, costs for treatment of the contaminated site may still be required at a later date, potentially for a larger volume of contaminated media.

Possible methods of controlling the access to contaminated sites include signs, entry control, artificial or natural barriers, and active surveillance. The measures used depend on the specific site conditions, demography and proximity of the local population, and the degree of hazard associated with the contamination at the site. Implementation and maintenance costs increase as the amount of protection the measure supplies increases.

The lowest measure of protection is supplied by signs. Signs surrounding the facility with the legend "DangerUnauthorized Personnel Keep Out" in English and any other language in use in the area supplies a warning but does not represent a physical barrier. These signs are posted at each entrance to the restricted area and at other appropriate locations in sufficient numbers to be seen from any approach.

The next level of protection is controlling entrances to the restricted portion of the contaminated site. For example, all roadways to a contaminated site may be blocked to control access. These measures make it more difficult for individuals to inadvertently be exposed to site contaminants, but are easily defeated if individuals desire access.

The next level of protection involves artificial or natural barriers. These barriers include fences or fences combined with natural barriers such as a cliff, waterway, or bluff that completely surround the restricted portion of the facility.

The greatest level of protection is supplied by active surveillance. This surveillance can include television monitoring and/or surveillance by guards or facility personnel.

Access.controls are effective in limiting risk when used as part of an institutional controls general response action which limits the area for future industrial use only. Access controls such as warning signs are readily implementable at the FBRP and are currently in place. The cost of access controls is low. This general response action is retained for further evaluation at the FBRP.

Land Use Restrictions Land use restrictions prevent or reduce future human exposure to contaminants remaining on-site. This general response action involves administrative actions that control the types of activities allowed at the site. For example, the land may be designated for recreational uses, which would prevent potential spread of contamination through construction and agricultural activities. Other common EPA future land use indices that restrict different activities include residential, industrial, and agricultural designations. Deed restrictions may also be designed to permanently prohibit specific activities such as excavation or subsurface construction on any part of the site that contains hazardous materials after remedial work is completed.

Land use restrictions, such as deed restrictions, are effective in limiting risk for future residents by restricting the land to industrial use only. This action is readily implementable at the FBRP when the land is transferred to non-federal ownership and would simply require creating a deed and filing deed restrictions with the local authorities. CERCLA 120 (h) requires that a deed be created when the land is transferred to non-federal ownership. This deed must include a notification of former waste management and disposal activities on the property and any land use or continuing groundwater monitoring commitments or use restrictions. The cost for land-use restrictions is low. This general response action is retained for further evaluation at the FBRP.

\subsubsection{Containment}

Containment technologies involve the construction of an engineered barrier to isolate wastes. When properly constructed and maintained, containment technologies can provide a reliable and effective method for controlling direct exposure to waste and limiting the spread of contaminated soil through airborne dust. 
Soil covers consist of a layer of soil placed over the contaminated area. They are not actually caps in that they do not effectively limit infiltration of water, however they do provide some of the same benefits as caps at a substantially lower cost. The soil used in the cover is typically clean, native soil selected from a nearby area. The purpose of the cover is to provide an additional barrier between potential receptors and the contaminants. A four-foot cover is typically considered as this would allow residential use of the land provided excavation beyond four feet was prevented through institutional controls. Soil covers effectively keep both adults and children away from hazards associated with the top four feet of soil in a waste area. Ingestion of contaminated soil is eliminated as a pathway for these receptors. Homegrown produce is also much less likely to exhibit any risks above $1 \times 10^{-4}$. This soil layer is also useful in providing shielding from direct radiation risks posed by low-level radioactive contaminants in the soil. This general response action does not remediate any contamination, but does provide an effective barrier. In order to keep this barrier in intact, additional controls are needed. Institutional controls limiting excavation and the installation of shallow wells should be included along with provisions for erosion control. Typically, the soil cover is feathered into the surrounding area to help minimize the chance that erosion will compromise the soil cover.

Soil covers will be retained for further evaluation at the FBRP. Soil covers are effective in providing a barrier between the contaminated soil and potential receptors and will prevent contaminated dust from becoming airborne. They are readily implementable at the FBRP. The cost of a soil cover is relatively low.

Erosion Control Erosion control is a set of proven containment technologies designed to prevent the movement or transportation of surface soils by overland runoff of rain and melting snow. These technologies primarily involve the stabilization of surface soils but can also work to control the volume of runoff water.

Containment technologies as a group are applicable to a wide range of contaminants and reduce worker and short term public risk because the contaminated materials are not handled. However, containment alone does not treat the contaminants and if containment measures fail, contaminants will begin to migrate from the site and result in potential public health concerns. As a result, containment technologies are generally used when treatment is impractical, as a temporary measure while determining the best treatment strategy, or in conjunction with treatment technologies to improve overall performance.

The two main factors that determine the amount of soil and associated contamination that is transported off the site as a result of overland runoff are the quantity of water that leaves the site as overland runoff and the susceptibility of the surface soil to erosion. A water balance at the surface of the site shows that precipitation leaves the surface either by infiltrating through the soil and reaching the groundwater; returning back to the atmosphere through evapotranspiration mechanisms, or flowing overland to a surface water body. The overland flow causes erosion and, if infiltration or evapotranspiration are increased, the amount of overland runoff is reduced. However, increasing infiltration is often not desirable because this water release mechanism can spread contamination to deeper soil layers and eventually contaminate the ground water aquifer. The other erosion control approach deals with modifying the nature of the surface soils so they are less susceptible to erosion or covering the soil to prevent soil/water interactions.

Common erosion control technologies include grading, revegetation, soil stabilization, surface covers, and diversion/collection systems. The selection of specific controls must consider topography, soil type, drainage area, compatibility with soil contaminants, and local climatic conditions. Different types of erosion control are discussed below.

Grading uses standard earthwork construction equipment and methods to shape and slope the site surface to help manage surface water infiltration and runoff. Grading may be conducted to minimize the concentration of flowing water and promote uniform runoff that is less likely to cause erosion. Slope angle, length, and direction are also adjusted to achieve the desired balance between infiltration and runoff. Steep slopes may be reduced to lessen runoff/erosion or flat areas susceptible to ponding may be graded at an increased slope to increase runoff and reduce infiltration. Grading is often done in conjunction with surface covers or revegetation as part of an integrated stabilization/erosion/infiltration control system. 
Revegetation can both reduce the volume of runoff and help stabilize the surface soils. Planting and cultivating a vegetative cover with substantial root growth can help stabilize soils and reduce erosion. A vegetative cover can also increase the water holding capacity of the top soil and reduce the volume of runoff generated. These covers increase evapotranspiration but vegetative layers also generally increase infiltration rates because roots make the surface layer more permeable. A vegetation stabilization design includes selection of a suitable plant species, seed bed preparation, seeding/planting and fertilization/watering/maintenance. Revegetation is often used in combination with other technologies.

Soil stabilization methods can be used as to help establish a vegetative cover or can be used independently if site conditions such as phytotoxic soil contaminants or low precipitation rates make vegetative covers impractical. Loose straw and hay mulches are the most common and cost-effective, temporary soil stabilization materials available. These stabilizers reduce soil water loss and enhance plant growth by temporarily stabilizing seeded soils against wind and water erosion. Chemical stabilizers are binders and tacks that are sprayed on bare soils or mulches to coat, penetrate, and temporarily bind soil particles together. Chemical stabilizers include latex emulsions, plastic films, oil-in-water emulsions, and resin-in-water emulsions. Cementious, pozzolanic, and clay additives are often used to bind soil particles together if a more permanent method is required.

Surface covers place a barrier between the soil and the overland runoff water. Temporary surface covers include various types of synthetic membranes. Synthetic membranes are available in a wide variety of materials and can be reinforced with fabric or scrim. Selection of the membrane is based on compatibility with contaminants, site climate, and required design life. Semi-permanent surface covers include layers of gravel/riprap, asphalt pavement, or asphaltic emulsions. Portland cement, concrete, or mortar can also be applied as a permanent pad over the contaminated surface. Erosion control is also a side benefit of capping technologies.

Surface water diversion and collection systems include dikes and berms; channels and waterways; terraces and benches; chutes and downpipes; and levees and flood walls. These structures are constructed upslope to channel overland runoff around critical areas or downslope to control erosive transport of contaminated sediments. These structures are often used as part of an overall erosion control strategy.

Erosion controls are effective in preventing the integrity of caps and soil covers from being undermined. These controls also can help reduce water infiltration into the contaminated soil and may be used to divert runoff from potential wetland areas. Erosion controls are readily implementable at FBRP and would be needed with most of the remediation alternatives selected for this site. The cost of erosion controls is low.

This technology is retained for further consideration at the FBRP.

\subsubsection{Recovery/Removal}

Excavation Excavation is a method of removing contaminated surface and subsurface soils from hazardous waste sites by scraping, cutting, digging, scooping, or vacuuming. Dry to moist earth, gravel, or other non-rock materials above the water table and within 20 meters of the surface are usually easy to excavate and remove from the site. Deeper soils can be excavated with appropriate equipment or terraced excavations. Groundwater aquifer soils can also be excavated but dewatering of the aquifer is usually required before digging starts. Areas containing drums, buried tanks, or similar obstructions may require significant amounts of hand and smallmachine excavating, surveying, sampling, and rehandling.

The main advantage of excavation of solids is that the corrective action is very effective because contaminated materials are physically removed from the site. The technology is not selective and any contaminant can be removed if enough soil is excavated. Excavation is a standard construction practice and methods are available to handle most construction-related problems expected to occur in excavating and handling contaminated materials. Requirements for safety, monitoring, and sampling are generally understood.

The disadvantages of excavation are that the removal of contaminated materials can be extremely hazardous since it requires handling, transporting, and treating or disposing of cxcavated matcrials. This is cspecially true 
at formerly uncontrolled sites where little is known about the interred waste products. Control of fugitive dust and vapor transport may be of particular concern at some sites. Extensive safety procedures and monitoring plans may be required to ensure the protection of the workers, the public, and the environment. Safety and environmental concerns must be balanced against the benefits of removal.

Excavation involves standard construction equipment and/or special equipment that is adapted to minimize disturbance of the deposit or secondary migration. Equipment is manufactured in various types and sizes. The equipment and sequence of operations depend on physical characteristics of the excavated materials, dimensions of the excavation, size of a project, desired rate of excavation, degree of excavation accuracy-required, available work space, and haul distances. Typical types of excavation equipment include: backhoes, front-end loaders, scrapers, bulldozers, clamshells, draglines, and vacuum trucks.

Backhoes are used primarily when excavation is below grade and performed from a stable working surface such as a road or gravel pad. Various rubber-tired and tracked models exist with a range of reach and bucket capacity. Backhoes allow good control of excavation dimensions and supply a more powerful digging action that works better in hard and compacted soils.

Dragline diggers are used for excavations that are large in area and may be on slope, in submerged area), or on soils that will not support conventional equipment. Placement of the dragline bucket is less precise than a backhoe and digging in hard soil is difficult.

Clamshell diggers are used for deep excavations that can be submerged. Typical excavations are narrow or small in plan area.

Front-end loaders are used to excavate materials at grade from a stable working surface. Various models exist with a range of bucket capacities.

Scrapers are used to excavate, haul, dump and spread large amounts of soil over short distances. Typically used for site grading and balancing cut and fills.

Bulldozers are used in combination with other equipment to excavate, spread, and move materials.

Vacuum trucks are used for small surface cleanups of materials that can be extracted by suction.

Excavation is very effective in removing contaminated soil from the pits. It is readily implementable with numerous local contractors available for this operation. The cost of this operation should be considered low to medium, however when excavation is used, it is part of a high cost operation.

This technology is retained for further consideration at the FBRP. Excavation must be used as part of remediation processes such as soil washing or thermal desorption/incineration.

Drum and Debris Removal Drum and debris removal is a specialized form of excavation that targets the removal of buried drums and waste debris. Drums can contain both solid and/or liquid wastes while waste debris varies widely and can consist of plastics, wood or cardboard boxes, paper, machinery, clothing, and other contaminated items. These buried materials can interfere with other in situ treatment technologies and sometimes are removed to make the remaining portions of the contaminated media amenable to other treatments. The buried drum and debris can also be the source of contamination at a site and removal can significantly reduce the inventory of contamination available for future transport.

The possibility of concentrated contamination in buried drums requires additional precautions. Personnel protective equipment requirements and general operational procedures for dealing with drummed material of unknown composition are set forth in CFR 1910.120, "Hazardous Waste Operations and Emergency Resporlse." Portions of these procedures are also applicable to debris of unknown composition. 
After the overburden is removed with conventional excavation methods, the drum and debris can be removed with several different types of equipment. The choice of equipment represents a compromise between worker safety, production rates and additional release of contamination. Removing containers/debris that may be contaminated with shock-sensitive, explosive or highly toxic waste requires special measures to ensure worker safety. In these cases, drum grappling equipment and other conventional excavation equipment modified to enhance worker safety are used for the removal operations. This equipment maximizes worker safety but increases the risk of rupturing sealed containers and releasing additional contamination. Additional modifications to conventional excavation equipment may be made to help minimize these problems. For example, backhoes can be equipped with bars to cover the teeth of buckets that help to reduce the number of drums ruptured during excavation. The shovels and buckets of digging equipment can be composed of or sheathed with nonsparking metals, such as beryllium, for potentially explosive debris. Smaller sites often use hand and small-machine excavating to carefully expose and remove drums and debris. These less efficient operations may save money in the long run by preventing additional release of contamination into the surrounding soils.

After removal, the heterogeneous nature of drum and debris requires additional staging, sampling/analysis, and consolidation steps. Materials are staged in different areas according to the characteristics of the waste. Leaking drums or drums that lack integrity are usually overpacked or emptied into new containers in the field before staging. Drums and debris that emit ionizing radiation are often segregated and moved to a staging area away from the work area to reduce worker exposure. Drums with bulging tops and bottoms are assumed to be pressurized and moved to an area prepared for relieving the pressure. Staging areas for pressurized drums and gas cylinders are usually cool, shaded areas to prevent further pressurization. Depending on the nature of the waste and the potential hazards, pressure is relieved by manual or remote methods. Debris that is not contaminated may sometimes be sold, recycled, or used for fill. Temporary dikes and berms are often used in staging areas to contain spills of liquid waste that might occur during drum venting and sampling operations.

After staging, the contents of the drums and other containers in the debris are opened and sampled. Precautions during opening operations depend on the nature of the waste. Any opening operation needs to guard against splashing of liquids and massive releases of vapor. Explosive or shock-sensitive drums should be opened remotely in a controlled area.

Once the containers are safely open, simple techniques are often employed in the field to analyze drum head spaces for preliminary screening. Instruments used include organic vapor analyzers, Dreager tubes, oxygen meters and explosimeters. These techniques determine how the containers should be segregated and identify drums requiring further testing. Liquid-filled waste drums may contain more than one liquid phase and are usually sampled with glass thieves to obtain discreet sample layers. Drums are always sampled and analyzed individually to avoid concerns within compatible chemicals. Debris waste may also be roughly characterized (e.g. combustible, metallic, inorganic, radioactive, etc.) and segregated for different treatment/disposal options.

Following sampling and analysis, wastes may be further segregated and disposed individually by repackaging and shipping to an appropriate facility, or by consolidating compatible wastes for subsequent treatments. Liquid waste are usually combined in a mix tank while solids are loaded into containers such as Baker tanks, box trailers, or rolloff dumpsters.

This technology is very effective in removing drums and other potential source materials which may further contaminate the soils. The technology is readily implementable at the FBRP, however there has not been an indication that drums are buried in this waste unit. Cost of this operation is higher than simple excavation and should be considered to be medium to high.

This technology is removed from further evaluation at the FBRP as there is no need for it. No buried drums have been indicated in this waste unit. 


\subsubsection{Ex situ Soil Treatment}

Ex situ treatment involves the excavation and subsequent treatment of soils. The treated soils are either returned to the unit or taken off-unit for final disposal. Relative to comparable in situ treatment technologies, ex situ remedial technologies have the advantages of being able to verify the effectiveness of the treatment, verify that all contaminated media has been treated, and, in the case of off-unit disposal after treatment (e.g., incineration), remove all soil borne contamination from the unit. Ex situ treatment technologies being considered for FBRP soils are vitrification, incineration, stabilization/ solidification, chemical extraction, and physical separation.

Ex situ Vitrification. Vitrification technology is explained in detail in Section 2.4.2.6 under in situ vitrification. An evaluation of ex situ vitrification technology as it would apply at the FBRP follows.

Three types of joule heating melters that can be used for ex situ vitrification of waste are the liquid-fed ceramic melter, stir-melter, and the Terra-Vit melter. The liquid-fed ceramic melter and the stir-melter are typically used to vitrify high-level radioactive waste and are therefore relatively large and stationary, whereas the Terra-Vit melter is mobile and designed for temporary, on-unit applications such as the FBRP. Consequently, the application of ex situ vitrification technology will focus on the Terra-Vit design.

The Terra-Vit melter is a low-cost vitrification design consisting of an earthen pit covered by a roof of hightemperature refractory materials. The roof provides access ports for the deployment of electrodes. The electrodes are positioned more than six feet inside the pit periphery and terminate well above the bottom of the pit. The pit geometry is designed to intentionally provide a low thermal convection velocity and a relatively low glass temperature at the glass/earthen pit interface. Alternatively, the melter's operational lifetime can be increased by lining the pit with low-cost refractory materials (e.g., clays, boulders, manufactured refractory materials) or a water-cooled jacket that can be designed to surround the pit. Finally, if placement of the melter in the earth is unacceptable, the Terra-Vit can be constructed inside a metal wall and placed on top of the ground (Chapman and Robinson, 1993).

Once constructed, the electrodes are lowered into the pit and joule heating is commenced to establish a molten floor. Wastes are then gravity fed through an influent port located between the electrodes onto the already molten material. As the waste is heated, it too becomes molten after which it is discharged from the pit periphery and is poured into waste containers for final disposal.

A. 22.7 metric tons/day ( 25 ton/day) unit was reportedly constructed at the Hanford Site to treat contaminated soil. Unit construction took less than four weeks and the total project, including design, safety approvals, and procurement lasted eight weeks. Total construction costs were less than $\$ 500,000$. The project was sponsored by DOE's Environmental Restoration program (Chapman and Robinson, 1993).

Ex situ vitrification is a demonstrated technology for treating high-level radioactive waste and is potentially effective for remediating FBRP soil. Vitrification is the BDAT for treating high level radioactive wastes and should therefore demonstrate comparable effectiveness on low-level radioactive waste streams, as is the case with FBRP soils. Because the process is ex situ, soils can be amended with additives to overcome deficiencies of alkali elements in SRS soil. Treatability testing would be warranted to determine the optimum blend of amendments. Implementability of the Terra-Vit design is a concern since it would be necessary to design and construct a Terra-Vit melter for application at the FBRP. It is projected that design and construction of a TerraVit melter can be accomplished within one year (Tixier, 1995).

Ex situ vitrification is very effective in encasing many contaminants. While this technology is implementable at FBRP, it is usually not considered for low risk applications that exist at the FBRP. Typically, this technology is reserved for highly contaminated areas that would present extreme risks to workers or future residents. Costs associated with the ex situ vitrification treatment technology are relatively high compared to other ex situ treatment technologics. This assessment is based upon capital costs to treat the waste and does not take into consideration costs associated with waste excavation or final disposal. Ex situ vitrification costs would increase significantly should the Terra-Vit melter design be unavailable. Ex situ vitrification is not retained for further consideration due to the fact that this technology is not well suited to the waste found at the FBRP. 
Thermal Desorption Thermal desorption is a relatively low temperature, 150 to $425^{\circ} \mathrm{C}$, thermal separation process for soils, sludges, and other solid media contaminated with organics. Thermal desorption is similar to incineration but is directed towards the removal of organics, where as incineration is directed towards destruction of organics.

The system typically consists of a thermal dryer to indirectly heat contaminated materials and vaporize water and organic contaminants; a high-energy scrubber to remove particulates and water-soluble gases; heat exchangers to condense the organic and aqueous phases; and a vapor phase carbon treatment system or fume incinerator to remove or incinerate residual organics from the vapor phase, respectively. The degree of contaminant removal is controlled by adjusting the feed rate, the dryer temperature, or the residence time of materials in the dryer. The treated solids may be backfilled or disposed of by other means, depending on the final contaminant concentrations in the end product.

There are several types of indirectly heated dryers. Some are jacketed; others have jackets and hollow screws and/or flights. The heat transfer medium, typically hot gases from a propane or oil fired burner, can be passed through the jackets or hollow screws to transfer heat to the solids to be processed. To reduce the risk of explosion, an inert gas such as nitrogen, instead of air, may be provided to transport the contaminants that volatilize, or desorb, from the soil matrix. If contaminant concentrations are low enough to preclude the possibility of explosions, preheated air or combustion gases can be contacted directly with the contaminated soils.

The flow diagram for this module shows a typical thermal desorption process where contaminated material is fed into one end of the dryer. Internal flights or screws in the dryers slowly convey the solids in the axial direction. The dryer residence times are adjusted so that the soil exits the dryer as a powdered or dry granular solid. Organic contaminants and water vapors driven from the soil are transported out of the dryer by an inert gas carrier, to provide an oxygen-free environment, to reduce the risk of explosion. The carrier gas flows through a duct to the gas treatment system, where organic vapors, water vapors, and dust particles are removed and recovered from the gas. The organic vapor, dust, and particulate removal systems can vary, depending on the concentration and composition of the gases exiting the dryer. Inert carrier gases are generally recovered and recycled.

Thermal desorption has been demonstrated successfully on pilot-scale levels, but full-scale soil remediation is yet to be demonstrated. Hence case-by-case pilot testing is essential before considering this technology for fullscale remediation.

Thermal desorption is effective in separating most organic materials from a soil matrix, however it will not remediate most metals or radionuclides.. The vapor stream created from this operation must usually be treated before release to the atmosphere. For this application, incineration is proposed as the next process step. This technology is implementable at FBRP. There are a somewhat limited number of contractors with portable equipment for this process, however scheduling the remedial action within a reasonable time should not be a problem. The cost of this processing is high. This technology, followed by incineration, is retained for further evaluation at the FBRP.

Incineration (gas) Incineration is a thermal destruction process that destroys organic materials in the presence of adequate oxygen for combustion. The basic process chemistry of incineration consists of oxidation of the organic constituents of the waste material to form carbon dioxide, water vapor, sulfur oxides, phosphorus oxides, and hydrogen halides. Toxic organic contaminants are permanently destroyed by high-temperature oxidation, but a residual ash may be created that contains heavy metals and toxic products of incomplete combustion. The waste material to be incinerated may be supplemented with natural gas or fuel oil to provide supplemental heating. Flame safety systems are provided to ensure controlled ignition of the waste material and the supplementary fuels. Incineration systems consist of a feed system, combustion chamber, and an ash removal system. Air pollution control systems must frequently be incorporated into incinerator design to capture particulates, aerosols, hydrogen chloride, sulfur oxides, and other emissions. Typical air pollution control devices include quench chambers, baghouse fitters, gas absorbers, and mist eliminators. 
Incineration of gaseous media differs only slightly from catalytic oxidation of gaseous media and is discussed in two different modules. The primary difference in the two processes is in the use of a catalyst in catalytic oxidation.

Many different types of incinerators are used for waste treatment. All are combustion devices designed for various feed types. Two representative incinerator types for gaseous media are described below:

Afterburners are typically gaseous incinerators located downstream of a primary combustion device. The primary combustion device is often a rotary kiln or similar incinerator. Afterburners are enclosed combustion devices useful for destroying unburned or partially burned carbon compounds in the offgas from the primary combustion device. Supplemental fuel may be injected into the afterburner and burned to maintain the combustion chamber at the desired operating temperature for complete destruction of organic contaminants. In addition to gaseous wastes, liquid wastes that can be pumped and atomized may also be treated in an afterburner by injection into the hot exhaust gases from the primary combustion device. Both gaseous and liquid wastes may serve as supplemental fuel to the afterburner if their heating values are large enough. The organic compounds in these wastes will be oxidized completely at the high temperatures reached in the afterburner. Air pollution control systems are frequently incorporated with afterburners to capture particulates, aerosols, hydrogen chloride, sulfur oxides, and other emissions.

Flares are unenclosed combustion devices that utilize an open flame to combust waste gases. They are widely used for landfill gas and refinery applications. The use of flares is limited to gaseous waste streams. Offgas treatment systems to capture particulates, aerosols, hydrogen chloride, sulfur oxides, and other emissions are not associated with flares as with other incineration designs.

Performance of incineration processes can be measured in a number of ways. Two commonly used method are listed below:

Organics Destruction - Destruction of volatile organic waste constituents has been measured from 90 percent in some flares to greater than 99.99999 percent in hazardous waste incinerators. Destruction of semivolatile and nonvolatile organic constituents has also been measured for hazardous waste incinerators and typically exceeds 99.99 percent.

DRE -- Destruction and Removal Efficiencies in excess of 99.9999 percent for organic contaminants are typical in many hazardous waste incinerators.

Incineration is effective in degrading organic vapors. This technology is implementable, however, air permits must be obtained. The cost of this technology is high. Incineration is retained as part of a desorption/Incineration process for further consideration at FBRP.

Stabilization/Solidification. Stabilization/solidification technology is explained in detail in Section 2.4.2.6 under in situ stabilization/solidification. Following is an evaluation of ex situ S/S technology as it would apply at the FBRP.

Ex situ S/S involves the controlled mixing of waste materials with S/S reagents outside of the waste source area. The treated waste may undergo further treatment, returned to the (former) source area, or transported to an offunit location for final disposal. Equipment typically used for ex situ S/S applications includes reagent storage tanks, feed pumps, metering device, mixing equipment, and waste handling equipment.

Ex situ S/S operations may include pretreatment to neutralize or dewater the waste material, treat the waste to remove contaminants that are not amenable to $S / S$ treatment (e.g., porous materials), chemically treat the waste (i.e., oxidation/reduction) to convert a particular contaminant to a less soluble form (e.g., $\mathrm{Cr}^{+6}$ to $\mathrm{Cr}^{+3}$ ), or for particle size reduction. Of these pretreatment options, pretreatment for particle size reduction may be warranted for FBRP soils. Particle size reduction is conducted to optimize the S/S process, either by eliminating significantly larger components of the soil matrix (e.g., rocks, plant roots, debris) to prevent damage of S/S equipment and/or inadequate mixing of the S/S agent. In addition, contaminants often adsorb preferentially with 
the finer soil particles. If a large gradient of soil particles exist in a soil matrix, particle size reduction may be conducted to segregate the soil fines from coarser particles, thereby minimizing the volume of soil to be treated. See physical separation technologies in this section for a more detailed discussion of particle size reduction.

Because the S/S treatment process is conducted ex situ, a broader selection of $S / S$ reagents is available to treat the waste. S/S reagents that have been successfully used or are potentially effective for the treatment of low level radioactive or mixed wastes include (Portland) cement-based systems, pozzolanic systems, organic polymer thermoplastic systems, sulfate polymer thermoplastic systems, and innovative $S / S$ reagents.

Cement-based S/S systems have the advantage of low cost reagents that are safe, easily stored, and handling is relatively simple requiring conventional equipment for processing. In addition, Portland cement-based S/S systems are well suited for wet wastes and are available in a variety of formulations. Examples of additives that may be used in Portland cement-based S/S systems include sodium silicate pentahydrate (a curing accelerator), citric acid or sodium citrate (curing retarders; Burbank and Weingardt, 1993). Disadvantages of Portland cement-based S/S systems are that there is an increase in waste volume and/or mass after treatment, and Portland cements are not always compatible with organic solvents, oils, soluble salts, nitrates sulfates, or halides (Gering, 1993)(EPA, 1986).

Pozzolanic grouts are porous with walls of calcium hydrosilica gel. Pozzolanic grouts are typically combined with fly ash of slag as a source of active silica. In the presence of excess unreacted silica, the internal ion exchange capacity of pozzolanic materials increases, thereby reducing the mobility of contaminants. In addition, pozzolanic grouts resist weathering, are geochemically stable for millennia and have relatively low permeabilities ranging from $10^{-6}$ to $10^{-8} \mathrm{~cm} / \mathrm{sec}$ (Dole, 1993). Materials that may interfere with pozzolanicbased S/S systems include organic solvents, oils, or halides (EPA, 1986).

Organic thermoplastic polymer $S / S$ systems use asphalt, paraffin, polyethylene, and other polymers as reagents (England et al., 1991). Wastes treated using this technology have the advantage of having a relatively low permeability and relatively small volume increase. These systems are quick setting and are generally well suited for waste containing organic solvents, or oils; however, they are potentially subject to biodegradation and attack by ultraviolet light. S/S reagent handling is complicated since some reagents may be hazardous, and processing would require specialized equipment. Organic polymer thermoplastic S/S systems require a heating unit and are not well suited wastes containing water. Costs associated with organic polymer thermoplastic S/S systems are relatively high compared to Portland cement-based S/S systems (Gering, 1993).

Wastes treated using inorganic thermoplastic polymer $\mathrm{S} / \mathrm{S}$ systems such as sulfate polymer thermoplastic $\mathrm{S} / \mathrm{S}$ systems have the advantage of having high strength, a relatively low permeability and relatively small volume increase. Sulfate polymer thermoplastic S/S systems are quick setting and are generally well suited for salt containing wastes, especially oxidizers. S/S reagent handling is complicated and processing would require specialized equipment. Costs associated with polymerization S/S systems are relatively high compared to Portland cement-based S/S systems (Gering, 1993).

Innovative S/S reagents such as ferrous sulfate hydrate are currently being developed that use synthetic analogues of naturally occurring cements. These S/S reagents have demonstrated great promise in laboratoryscale tests and are potentially effective for FBRP soils; however, these reagents have not been demonstrated in a full-scale application in the field. A detailed discussion of these reagents is provided in Section 2.4.2.6.

Macroencapsulation systems generally involve the use of drums, jackets, containers, or vaults to physically contain waste materials. The containers may be constructed of steel (i.e., drums), concrete (i.e., vaults), or other material depending upon waste characteristics and method of disposal. Macroencapsulation can effectively eliminate leaching of the waste material as long as the integrity of the encapsulating material is maintained. Encapsulating materials must be selected that will be compatible with the waste. With good packing and process controls, increases in encapsulated waste volumes can be relatively low.

Macroencapsulation is generally a labor intensive operation. Processing machinery including heating and molding equipment, and skilled labor may be required depending upon the encapsulating process. In addition. 
wastes are often pretreated (e.g., dried, stabilized, solidified) prior to placement in the macroencapsulation containers although pretreatment may not be required. Once encapsulated, the wastes may be placed in retrievable storage so that the wastes and encapsulating material can be monitored for breaches in container integrity. Because macroencapsulation is labor intensive, this technology is usually applied to limited volumes of either very toxic or very mobile wastes. Furthermore, waste storage facilities may have limited capacity. Because the volume of FBRP wastes is relative large, and the waste can be effectively treated using more conventional $\mathrm{S} / \mathrm{S}$ technologies, macroencapsulation will not be retained for further consideration.

Ex situ S/S is a potentially cost effective technology for treating contaminated soil at the FBRP. Treated soils may be placed back into the FBRP or disposed at an off-unit disposal facility. If treated soils are returned to the FBRP, the mobility of FBRP contaminants should be significantly reduced over current conditions. Similarly, treated soils that are disposed of at an off-unit facility should exhibit improved handling characteristics (e.g., reduced contaminant mobility, minimal problems associated with airborne particulate emissions). A detailed treatability study is always recommended when considering treatment using $\mathrm{S} / \mathrm{S}$ technology since it is important to identify the optimum $S / S$ reagent recipe under unit-specific conditions. The cured waste form will require testing to verify that it meets EPA and/or SRS disposal standards (England et al., 1991).

Specialized waste and material handling equipment may be required, depending upon the S/S reagent selected to treat FBRP soils; however, required equipment should be available. Otherwise, ex situ S/S technology should be reasonably implementable. Extensive site preparation (e.g., clearing, construction) would likely be required, but efforts to prepare the unit should not interfere with implementation of this technology. Costs associated with ex situ S/S are considered low relative to other ex situ treatment technologies.

Ex situ S/S of hazardous waste soils is a demonstrated technology that would be used before final disposition of wastes generated during remediation. This technology is readily implementable at the FBRP. The costs are medium compared to other remediation methods, however this would be part of a high cost alternative. Ex situ $\mathrm{S} / \mathrm{S}$ will be retained for further consideration as a treatment or pretreatment option for FBRP wastes. Should ex situ S/S technology be used at the FBRP, selection of the type S/S reagent would be based upon treatability study results and $S / S$ treatment objectives. This technology will be retained for further evaluation.

Chemical Extraction. Chemical extraction is a separation technology that uses chemicals to extract contaminants from an environmental media (e.g., soil, sediments). Historically, chemical extraction technology has been used in ore benefication processes; however, the objective for its use was to remove only specific radioactive constituents from uranium mill tailings.

Information needed to apply chemical extraction technologies includes (1) physical, chemical, and mineralogical characteristics of the soil, (2) radionuclide concentration for each particle size fraction, and (3) water analysis for total suspended solids, $\mathrm{pH}$, hardness, and background radiation.

One of the primary objectives of chemical extraction is to concentrate radioactive contaminants contained in unit soils, thereby reducing the final volume of contaminated media to be treated and/or disposed. The applicability of chemical extraction technologies is very unit-specific. Consequently, extensive treatability testing would be needed to determine whether chemical extraction technology would be potentially effective at achieving remediation goals.

There are four general types of chemical extraction technologies currently being developed. These technologies are chemical extraction using water, inorganic salts, mineral acids, and complexing agents. These technologies are discussed below.

Chemical extraction using water involves the mixing of contaminated soil with relatively large volumes of water. After a sufficient mixing period, the water and water soluble radionuclides are separated from the solids using physical separation methods and the extracted radionuclides are extracted from the water by coprecipitation, solvent extraction, or by ion exchange. Chemical extraction using water has focused on the removal of radium salts, uranium salts, and thorium (EPA, 1988c). 
Chemical extraction using inorganic salts involves the mixing of contaminated soil in an inorganic salt solution. After a sufficient mixing period, the slurry is filtered, and the radionuclides are separated from the extractant using coprecipitation, membrane filtration, or ion exchange. Efforts to use inorganic salts for chemical extraction have focused on the removal of radium and thorium. The inorganic salts used include sodium chloride $(\mathrm{NaCl})$, potassium chloride $(\mathrm{KCl})$, and sodium hexametaphosphate $\left(\left[\mathrm{NaPO}_{3}\right]_{6}\right)(\mathrm{EPA}, 1988 \mathrm{c})$.

Chemical extraction using mineral acids involves the grinding of ore (soil) to 28 mesh and mixing the ground product in water to form a slurry. The slurry is pumped into an acid leach circuit and then the solids are separated from the leach liquid using physical methods. The radionuclides are separated from the leach solution using precipitation, solvent extraction, or ion exchange. Efforts to use mineral acids for chemical extraction have focused on the removal of radium, thorium, and uranium. The mineral acids used include sulfuric acid $\left(\mathrm{H}_{2} \mathrm{SO}_{4}\right)$, hydrochloric acid $(\mathrm{HCl})$, and nitric acid $\left(\mathrm{HNO}_{3}\right)(\mathrm{EPA}, 1988 \mathrm{c})$.

Chemical extraction using complexing agents involves a process very similar to that described for chemical extraction using mineral acids, except that complexing agents are used instead of acids. Efforts to use complexing agents for chemical extraction have focused on the removal of radium. The complexing agents used include ethylenediaminetetraacetic acid (EDTA), citrate, and nitrilotriacetic acid (EPA, 1988c).

Of these chemical extraction processes, chemical extraction using mineral acids appears to show the most promise based upon the number of radionuclides for which it is effective, and reported removal efficiencies. Reported chemical extraction rates vary significantly for different soils. In one particular study, removal efficiencies for radium, thorium and uranium were reportedly as high as 97,99 , and 99 , respectively; however, the treated soil must be treated a second time to remove undesirable anions $\left(\mathrm{NO}_{3}{ }^{\circ}, \mathrm{Cl}\right)$ after chemical extraction using mineral acids (EPA, 1988c). Also, FBRP soils contain radionuclides other than those that are amenable to chemical extraction. Extensive treatability testing would be warranted to determine which, if any, of these chemical extraction technologies could effectively treat all contaminants in FBRP soils.

In addition to the process limitations mentioned above, there is limited benefit associated with technologies that reduce the concentration of radioactive contaminants in low-level radioactive waste media since the NRC has instituted a moratorium on "below regulatory concern" (BRC) policy implementation. BRC is a waste classification that was proposed by the NRC in accordance with the Low-Level Radioactive Waste Policy Act that would allow for a greater number of disposal options for waste having "insignificant" levels of radioactivity. It has since been determined that authority to promulgate a BRC regulation or standard lies with "other Federal agencies". Consequently, DOE is not authorized to promulgate either a BRC regulation or a BRC standard, and will continue to manage low-level radioactive wastes that might meet future BRC standards and regulations until appropriate regulations are implemented (DOE, 1994).

Soil washing using chemical extraction is not suited to removing PCBs. This process will not be retained for further evaluation at the FBRP

Physical Separation. Many contaminants in soil, including radioactive contaminants, may be associated with the smallest fraction of soil particles or fines. By segregating contaminated soils based upon the physical characteristic of size, the soil contaminants may be concentrated in the fines, thus reducing the volume of soil requiring subsequent treatment or disposal. Soils may also be segregated on the basis of size as a pretreatment step to remove oversized materials (e.g., rocks, roots, debris) that may interfere with subsequent treatment processes or damage process equipment. Physical separation processes are also used in conjunction with chemical extraction processes to concentrate contaminated media and minimize the volume of media to be treated. Physical separation processes are being evaluated for treatment or pretreatment of FBRP soils.

Screening is a mechanical process used to separate particles on the basis of size. Screening utilizes a surface perforated with openings of uniform size upon which soil and/or other media is placed. Particles larger than the screen openings are retained whereas the particles smaller than the screen openings are allowed to pass through. Screen agitation (dynamic screens) may be used to encourage the separation of loosely held soil particles and increase process effectiveness; however, some undersized particles almost always are retained with the oversized fraction of soil that is retained by the screen. Soils may be reprocessed using progressively smaller 
screen sizes to achieve discrete ranges of soil size. Screen size is typically limited to materials larger than 250 microns. Screens called "grizzly screens" are generally used to separate relatively large particles or materials (e.g., rocks, roots, debris) from soils. Grizzly screens generally are used to segregate materials ranging from 20 millimeters (mm) to $300 \mathrm{~mm}(0.79-11.8 \mathrm{in}$.) in size (EPA, 1988c).

Screening effectiveness may be affected by the amount of moisture in the feed material. To be effective, the feed material can be either dry or wet, but should not be damp or sticky. Damp or sticky feeds tend to agglomerate and plug screen openings. Screening efficiency is generally increased when using wet feed since the smaller fines may be washed from the larger particles by the passing feed.

A disadvantage of screening dry soils is the potential for airborne particulate emissions (dust); however, airborne emissions can be minimized by completely enclosing the screen and using a dust extraction/treatment system (EPA, 1988c). A disadvantage of screening wet soils is the production of a secondary (liquid) waste stream which would also require subsequent treatment.

Density is another physical characteristics of soils that may be exploited when segregating soils. Technologies that rely on differences in particle density are influenced by particle size, shape and weight. Following are descriptions of two physical separation technologies (classification and gravity separation) that segregate particles based upon differences in particle densities.

Classification is the separation of particles according to their settling rate in a fluid, usually water. Classifiers typically produce two streams, one containing the less dense, slower settling particles (overflow or slimes) and the other stream that contains the more dense or faster settling particles (underflow or oversize). Hydraulic classifiers use a stream of water or air introduced so that it is flowing in the direction opposite of the settling particles. The more dense particles are capable of settling through the fluid, whereas the less dense particles are entrained in the fluid flow and unable to settle. Mechanical classifiers rely on fluid overflow to entrain slowsettling particles while particles with a higher settling velocity are deposited on the bottom of the equipment and dragged upwards against the flow of liquid by some mechanical means. Examples of mechanical classifiers include rake classifiers, spiral classifiers, and drag classifiers. Nonmechanical classifiers rely on gravitational or centrifugal force to separate coarse particles. Examples of nonmechanical classifiers include the hydrocyclone and settling cone.

Classification technologies have been demonstrated effective and reliable for many years in the uranium mining industry; however, clays and sandy soil with humic materials may be very difficult to process using this technology. In addition, classification processes that use liquid overflows generate an additional (liquid) waste stream that would require subsequent treatment.

Gravity separation devices initiate and maintain particle separation so that the particles are able to move relative to each other within a fluid and thus separate into layers of dense and light materials. Gravity separation devices include jigs, shaking tables, sluices. An innovative gravity separation technology is the heavy media separation process. Heavy media separation process uses heavy liquids (specific gravity $>1$ ) for segregating light and heavy (dense) particles.

Gravity separation processes generally work well with most soil types; however, gravity processes generally use liquid overflows resulting in an additional (liquid) waste stream that would require subsequent treatment.

Although these physical separation technologies have been field demonstrated for extraction of radioactive material from ores, pilot testing would be needed to determine their effectiveness for concentrating contaminated media at radiologically contaminated sites. The effectiveness of these technologies for segregating contaminated and uncontaminated soils is questionable since the distribution of radioactive contamination on FBRP soils is not known. Consequently, it is not known whether FBRP soil characteristics can be exploited to concentrate radioactive contamination. However, physical separation processes have been demonstrated effective at numerous contaminated sites as a pretreatment method for segregating oversized materials (e.g., rocks, roots, debris) that may interfere with subsequent treatment processes. 
Physical separation is not ideally suited to treatment of PCBs in soil. It will not be retained for further evaluation at the FBRP.

Soil Washing (physical separation) Soil washing using physical separation is an ex situ toxicity reduction technology that removes contaminants from soils by concentrating them into a smaller volume of soil through simple particle size separation techniques known as wet classification (see physical separation in this section). Soil washing is often a combination of physical and chemical separation techniques (see soil washing (chemical separation ] in this section).

The concept of the physical separation process option of soil washing is based on the theory that most organic and inorganic contaminants tend to bind, either chemically or physically, to the fine (i.e., clay and silt) fraction of a soil. The clay and silt soil particles are, in turn, physically bound to the coarser sand and gravel particles by compaction and adhesion. Thus, separating the fine clay and silt particles from the coarser sand and gravel soil particles would effectively concentrate the contaminants into a smaller volume of soil that could then be further treated or disposed. However, the assumption that more contamination is associated with the fine soil particles is not always correct. The distribution of contaminants throughout the soil matrix must be determined in order to assess the applicability of soil washing and to choose the appropriate physical separation technique.

Various wet classification techniques are available to separate the different types of particles that may be present in a soil matrix. The choice depends on the physicochemical nature of the soil and the desired separation and throughput. A few of the more common techniques; screens, liquid cyclones, jigs, tabling, and spiral concentration are described below. For all of these techniques, water is the most common washing solution, although there are other options.

The simplest wet classification technique uses screens to separate soil particles based on size. Screening machines may be divided into five main classes: grizzlies, revolving screens, shaking screens, vibrating screens, and oscillating screens. Grizzlies are used primarily for separating particles that are $0.05 \mathrm{~m}$ and coarser, while revolving screens and shaking screens are generally used for the separation of particles above $0.013 \mathrm{~m}$. Vibrating screens cover a wide range of particle separations, from coarse down into the fine meshes. Oscillating screens are limited in general to the finer meshes below 4 mesh $(0.0048 \mathrm{~m})$.

A second common wet classification technique uses a liquid cyclone to separate the soil particles. In simplest terms the unit has a top cylindrical section and a lower conical section terminating in an adjustable apex opening. The soil and wash solution enter the separator together in the top cylindrical section. Separation occurs in the cone-shaped part of the cyclone by the action of centrifugal and centripetal forces. The heavier portion of the feed leaves the cyclone at the apex opening and the lighter portion leaves at the overflow top orifice.

A jig is a mechanical device used for separating soil particles of different specific gravities by the pulsation of a stream of liquid flowing through a bed of materials. The wash solution pulsates, or "jig" up and down, causing the heavy soil particles to work down to the bottom of the bed and the lighter ones to rise to the top. Each product is then drawn off separately.

Tabling is a concentration process whereby a separation between two or more soil particles is effected by flowing a pulp across a riffled plane surface inclined slightly from the horizontal, differentially shaken in the direction of the long axis, and washed with an even flow of wash solution at right angles to the direction of motion. Separation depends mainly on the difference in specific gravity between the soil particles and to a lesser degree on the shape and size of the particles.

Spiral concentration is also based primarily on the specific gravity differentials of the materials to be separated. A typical spiral concentrator consists of a spirally shaped channel or launder with a modified semicircular cross section. The standard spiral consists of five complete turns, however, less turns are used when an unusually rapid and clean separation takes place. As the feed slurry flows down the spiral channel, the soil particles with the highest specific gravity sink to the bottom and move inward toward the inside of the channel. The lighter weight particles move to the outside and are carried away by the faster more dilute pulp strearn. Wash water is 
available along the entire inside edge of the spiral, thus providing repeated wash stages as the pulp flows down the channel. Although the spiral concentrator is mechanically a very simple piece of equipment, the separating action taking place is complex. It involves centrifugal force, friction against the spiral surface, gravity, and the drag of the water.

Each of the above physical separation techniques can be enhanced by using attrition scrubbing to attain a higher particle separation effectiveness. Attrition scrubbing helps remove and separate fine particles that otherwise would stick to the large particles and remain in the coarse fraction. Attrition scrubbing can also remove the outer surface of larger particles where contaminants can concentrate in small cracks at the surface resulting in a better separation of contaminants into the fine fraction.

This technology is not well suited for treatment of soils contaminated with PCBs. It will not be considered for additional evaluation at the FBRP.

Soil Washing (chemical separation) Soil washing using chemical separation is an ex situ toxicity reduction technology that removes contaminants from soils by dissolving and/or desorbing them into a wash solution (see chemical extraction in this section). Soil washing is often a combination of physical and chemical separation techniques (see soil washing (physical separation \} in this section).

A wide variety of chemical contaminants can be removed from soils through soil washing applications. Removal efficiencies depend on the type of contaminant, washing solution, and soil. The amount of each contaminant that will dissolve or desorb is a function of the partitioning effect of the wash solution and the volume of the washing solution that is contacted with the contaminated soil. Water is the most common washing solution, however, additives are often required to improve the contaminant removal efficiency. These additives may not only help the dissolution/desorption process, but may also modify the interfacial tension between soil particles or provide an electrolyte that improves particle dissociation.

Volatile organic contaminants are usually easily removed from soil by washing with water; experience shows that volatiles can be removed with 90 to 99 percent efficiency or more. Semivolatile organics can be removed to a lessor extent (40 to 90 percent) with the addition of a proper surfactant to the wash water. Metals and pesticides, which are more insoluble in water, often require the addition of acids or chelating agents for successful soil washing. Organic solvents can also be added to the wash solution to improve contaminant removal efficiencies, however, these solvents must be recovered completely from the treated soil.

Complex mixtures of contaminants in the soil (such as a mixture of metals, nonvolatile organics, and semivolatile organics) and heterogeneous contaminant compositions throughout the soil matrix make it difficult to formulate a single suitable washing solution that will consistently and reliably remove all of the different types of contaminants. For these cases, sequential washing steps, using different wash formulations and/or different soil to wash fluid ratios, may be required.'

While washwater additives such as surfactants and chelants may enhance some contaminant removal efficiencies, they also tend to interfere with the downstream wastewater treatment segments of the process. The presence of these additives in the washed soil and in the wastewater treatment sludge may cause some difficulty in their disposal. Costs associated with handling the additives and managing them as part of the residuals/wastewater streams must be carefully weighed against the incremental improvements in soil washing performance that they may provide.

This technology will be not retained for further evaluation at the FBRP because it is not ideally suited to PCB removal from soil.

\subsubsection{In situ Soil Treatment}

In situ soil treatment technologies treat soils in place. For soil containing radioactive and nonradioactive inorganic constituents, in situ treatment technologies generally involve a chemical and/or physical treatment process that immobilizes the contaminants. One exception is electrokinetic processing technology which 
reduces contaminant concentrations in soil. Relative to comparable ex situ treatment technologies, in situ remedial technologies have the advantages of minimal handling of contaminated media, lower capital costs, and minimizing exposure to remedial workers. In situ treatment technologies being considered for FBRP soils are stabilization/solidification, vitrification, and electrokinetic soil processing.

In situ Stabilization/Solidification. The terms "stabilization" and "solidification" have often been used interchangeably, and with other terms such as "chemical fixation" and "immobilization". Stabilization refers to those technologies that reduce the hazard potential of a waste by converting the contaminants into their least soluble, mobile, or toxic waste form without regard to the physical nature or handling characteristics, whereas, solidification refers to technologies that encapsulate the waste in a monolithic solid of high structural integrity. Solidification does not necessarily involve a chemical interaction between the wastes and the solidifying reagents, but may mechanically bind the waste into the monolith. When solidified, contaminant migration is restricted by reducing the surface area exposed to leaching, and/or by isolating the waste within an impervious capsule. Encapsulation may be one of fine waste particles (microencapsulation) or of a large body or container of waste (macroencapsulation)(Conner, 1994).

Most S/S technologies are relatively simple to implement, involving standard stabilizing or solidifying agents and mechanical equipment. Stabilizing or solidifying agents may include lime/fly ash pozzolans, portland cement, thermoplastics, or derivatives of these and/or other reagents. Listed below are brief descriptions of specific S/S technologies based upon reagent type.

Cement-based S/S technology involves the use of portland cement as the primary S/S reagent. Waste material is incorporated in a cement/water mixture which may be augmented with fly ash, sodium silicate, bentonite, or proprietary additives to enhance physical-chemical processes that serve to reduce waste mobility and/or strengthen cement bonding. Typically, ionic metal species are converted to less soluble metal hydroxides when treated using cement-based S/S technologies. The final product may vary from a granular, soil-like material to a cohesive solid. Cement-based S/S technology is applied primarily to metal bearing waste (EPA, 1989b).

Pozzolanic-based S/S technology involves the use of siliceous and aluminosilicate materials (i.e., fly ash, pumice, lime kiln dusts) combined with lime or cement and water. The primary containment mechanism is the physical entrapment of the contaminant in the pozzolan matrix. Pozzolanic reactions are generally much slower than cement reactions. The final product may vary from a soft fine-grained material to a hard cohesive solid. Pozzolanic-based S/S technology can be applied to wastes containing metals and certain organics (EPA, 1989b).

Thermoplastic/polymer S/S technology is a microencapsulation process in which the waste materials do not react chemically with the encapsulating material, but are physically contained in the encapsulating thermoplastic. Examples of organic thermoplastic/polymer materials include asphalt (bitumen) or polyethylene. Sulfate polymer thermoplastics are an example of inorganic thermoplastic materials. Thermoplastic/polymer S/S technology may be applied to a variety of wastes containing metals and certain organics (EPA, 1989b).

Ferrous sulfate hydrates combined with calcium hydroxide are innovative $S / S$ reagents that are currently under development. The concept is based upon the principal that the product of these synthetic analogues of naturally occurring cements. If equilibrium between the encapsulating materials and their natural environment is achieved, then such materials will remain intact as long as the natural environment is not significantly altered.

Macroencapsulation is a process in which the waste materials usually undergo S/S processing followed by placement in an overpack drum or other container (EPA, 1989b). Macroencapsulation generally involves ex situ handling of waste materials and will therefore be presented in Section 2.4.2.5.

Although certain S/S agent recipes or proprietary processes many have demonstrated success for a particular type of contaminant(s) or waste, S/S processes are often modified to accommodate unit-specific conditions. Consequently, treatability studies are recommended whenever S/S technologies are being considered to optimize treatment effectiveness. Some factors that are important in determining the optimum S/S reagent for a particular waste might include: 


$\begin{array}{lll}\text { - } & \text { allowable cure time } & \text { volatilization or evolution of gases } \\ \text { - maximum volume increase } & \text { - } & \text { necessary contact time in the mixer } \\ \text { - } & \text { reagent cost } & \text { restrictions due to rapid gel reactions } \\ \text { heat of reaction } & \text { - } & \text { leachability }\end{array}$

Basic equipment requirements for most $S / S$ operations include chemical storage tanks to store $S / S$ agents, chemical feed devices, pumps; conveyors, mixers; and ancillary equipment. Most S/S equipment is conventional and can be readily obtained from numerous vendors. Specialty equipment, however, may be required for certain applications and will be identified accordingly. Interactions between contaminants, debris, and soil media may influence the effectiveness of a particular S/S technology. Natural soils may contain clay, silt, sand, rock, and naturally occurring organic substances. The interaction of radioactive and metal non-radioactive contaminants with soils is very complex, involving adsorption and ion exchange, typically with clay minerals, and complexation with humic substances in the organic fraction of the soil. Complexation may lead to either increased or decreased solubilization, depending upon the ligands present.

Most S/S pretreatment operations involve either chemical treatment and/or particle size reduction. Both of these processes must be performed separately from S/S operations to allow for proper treatment. Chemical treatments include chromium reduction, cyanide destruction, and oxidation of certain organics and metal complexes. Chemical pretreatment of soils is not anticipated for FBRP soil and will not be discussed hereafter.

Debris encountered with the waste soil (e.g., scrap metal, concrete, cans, bottles) may interfere with the S/S process (e.g., incomplete mixing, equipment damage) and are usually screened from the soil matrix prior to treatment and handled separately; however, small pieces (i.e., less than two inches in diameter) can usually be treated along with the soil itself if the debris is nonporous or will not cause a leaching problem in the long term. Contamination adsorbed onto small nonporous materials will usually be contacted by the S/S agent and thus treated; however, in the case of porous materials (e.g., wood, paper, cloth) soluble contaminants may be absorbed within the porous matter from that which leaching could occur. This may not pose a problem if excess $S / S$ reagent is available to react with the contaminant as it diffuses out; however, some contaminant species may not be immobilized if the S/S agent is no longer active in the treated soil. Therefore, porous debris must be separated from the soil and then ground to fine particle size to allow proper treatment, or handled by some other means (Conner, 1994).

S/S technologies may be applied in situ or ex situ. In situ S/S technologies are conducted leaving the waste inplace without the benefit of excavation from, or treatment outside of, the unit. Reasons for stabilizing or solidifying a waste in situ may include:

- to minimize waste handling

- $\quad$ to minimize exposure to remedial workers during treatment

- to eliminate the need for off-unit tranisport and/or disposal of the waste

- to improve waste handling characteristics should the waste be transported off-unit for further treatment and/or disposal

- $\quad$ to minimize the potential for contaminant leaching should the waste be left in place

- to reduce total remediation costs

A description of ex situ S/S technology and its potential for application at the FBRP is presented in Section 2.4.2.5.

In situ $S / S$ is accomplished by mixing the $S / S$ reagent into the waste by some mechanical means, such as a backhoe, tiller, auger, or injection/jetting technique. The most common device used for mixing S/S reagent into relatively shallow soils is the backhoe because it is widely available and is suitable for many applications; however, intimate mixing is difficult to achieve using conventional backhoes and they are limited by their reach. Tractor mounted rotary tillers can achieve more intimate mixing than can the backhoe, but they are limited to applications at depths of $1.5 \mathrm{~m}(5 \mathrm{ft})$ or less. 
For deep soil grouting, vertical augering and injection/jet grouting can provide intimate mixing or contact with the $S / S$ reagent, respectively, and are less restricted by depth than most in situ $S / S$ reagent delivery techniques. Vertical augering involves drilling augers equipped with cutting and hollow mixing blades. The augers are advanced to the desired maximum depth where they churn and mix the soil in place without removing the soil. The S/S reagent is pumped or injected into the treatment zone during mixing. A variety of mixing technologies are available that can potentially be used to mix stabilizing reagents with contaminated media in situ to depths of $45.7 \mathrm{~m}$ (150 ft). Auger blade diameters may vary, but companion augers can be operated simultaneously to create an effective mixing diameter of $3 \mathrm{~m}(9.8 \mathrm{ft})$ yielding a soil process rate of $3.4 \mathrm{~m}^{3}$ soil/day $\left(120 \mathrm{ft}^{3}\right.$ soil/day). A shroud, maintained under low vacuum, can be placed on the ground surface immediately over the mixing zone to contain and direct volatilized contaminants and airborne particulates to an off-gas treatment system (Siegrist et al., 1995).

In situ grout injection involves the injection of grout into the waste matrix via an injection pipe. The pipe is either drilled or hammered into the waste matrix and the grout is injected under pressure into voids within the waste matrix via the injection pipe. Once all of the voids are filled at a particular depth, the pipe is raised and more grout is injected from the bottom of the pipe. The injection process continues until the surface is reached. Grout injection has been conducted at depths of $18.3 \mathrm{~m}$ (60 ft) (EPA, 1993).

In general, jet grouting works under the same principles as grout injection with the most significant difference being that the grout is projected horizontally from a rotating bit instead of vertically from the bottom of the injection pipe. A conceptual track mounted jet-grout drilling system is illustrated on Figure 2-3. Jet grouting has successfully encapsulated waste (e.g., drums, paper, wood) buried in a compacted silty clay soil matrix in a recent pilot-scale study. Based upon findings of this study, advantages of the jet grouting include minimal generation of dust or airborne emissions, essentially no increase in waste volume, and complete encapsulation of the waste material. However, a potential limitation of the jet grouting technology is incomplete or inadequate mixing or contact with the waste matrix. Approximately $10 \%$ (visual determination) of the monolith volume contained irregularly shaped pockets $[10.2 \mathrm{~cm}$ diameter $30.5 \mathrm{~cm}$ length (4 in. diameter $/ 1 \mathrm{ft}$ length)] of moist soil that were not stabilized or solidified (Loomis and Thompson, 1995). Although it was observed that these pockets of soil were completely encapsulated and there were no apparent conduits for water transmission, these pockets of untreated soil could potentially be released should the monolith become fractured. Similarly, loose debris (cloth, paper, wood, and small metal) apparently weakened the monolith as demonstrated by the relative ease in which the portion of the monolith that contained debris could be retrieved. It was also observed that when retrieved, encapsulating grout easily broke off of the loose debris, leaving the debris surface exposed to air (Loomis and Thompson, 1995).

Should in situ stabilization be conducted at the FBRP, the type of S/S reagent delivery system used may depend primarily upon the type of S/S reagent and recipe that is to be used since the reagent must be amenable to the reagent delivery system. An advantage of the auger soil mixing system is that it is capable of utilizing a wider range of $S / S$ reagent recipes than can injection or jet grouting techniques. Other advantages of the auger soil mixing $\mathrm{S} / \mathrm{S}$ systems over injection or jet grouting systems include:

- many auger soil mixing systems generally have a higher processing rate than injection or jet grouting systems

- the auger soil mixing systems allow more positive control of treatment overlap than do injection or jet grouting system

- to make intimate contact with soil contamination, the particle size of S/S reagents used in injection or jet grouting systems must be smaller than the soil pore size (EPA, 1993). S/S reagent particle size is not as critical in auger soil mixing systems since they rely on active soil/reagent mixing to make intimate contact with soil contamination

The primary disadvantage of the auger soil mixing systems over injection or jet grouting systems is that the auger soil mixing systems typically generate more air emissions than do injection or jet grouting systems, or require an off-gas collection and treatment system. Also, there is generally an increase in treated soil volumes 
associated with auger soil mixing systems, whereas injection or jet grouting systems produce little or no volume increase.

Cement-based grouts are typically used with most in situ S/S delivery systems. Cement grouts are readily available, relatively inexpensive, easy to work with, and are a proven material to withstand extreme natural forces. However, cement-based grouts are susceptible to chemical attack or undesirable chemical reactions by certain waste types that can interfere with cement setting (e.g., nitrate or sulfate bearing wastes, halides and some organics) (EPA, 1993)(EPA, 1986). Consequently, S/S reagents must be verified compatible with all components of the waste matrix.

Pozzolanic-based reagents may be used in in situ applications. Naturally occurring pozzolanic materials include volcanic lava masses, or deposits of hydrated silicic acid of mostly organic origin (i.e., diatomaceous earth). Artificial pozzolanic materials include blast-furnace slag, ground brick, and some fly ashes from powdered coal furnaces. Pozzolanic grouts are porous with walls of calcium hydrosilica gel. Pozzolanic grouts are typically combined with fly ash or slag as a source of active silica. In the presence of excess, unreacted silica, the internal ion exchange capacity of pozzolanic materials increases, thereby reducing the mobility of contaminants. In addition, pozzolanic grouts resist weathering, are geochemically stable and have relatively low permeabilities ranging from $10^{-6}$ to $10^{-8} \mathrm{~cm} / \mathrm{sec}$ (Dole, 1993). Materials that may interfere with pozzolanic-based S/S systems include organic solvents, oils, or halides (EPA, 1986).

For most applications, organic polymer thermoplastic and sulfate polymer thermoplastic S/S reagents are not suitable for in situ treatment of soils because they must be heated when used and set very quickly. In addition, organic polymer thermoplastic and sulfate polymer thermoplastic S/S reagents typically require special equipment and handling procedures (Gering, 1993).

Innovative $S / S$ reagents are currently being developed that use synthetic analogues of naturally occurring cements. The coricept is based upon the principle that if equilibrium between the encapsulating materials and their natural environment is achieved, then such materials will remain intact as long as the natural environment is not significantly altered. Similar low-temperature, natural processes, and materials have combined to produce sedimentary rocks which contain natural cements that are dated at $>1.5$ billion years (Weidner and Shaw, 1995).

S/S reagents used in this developing technology are ferrous sulfate hydrate in the form of melanterite $\left(\mathrm{FeSO}_{4} \cdot 7 \mathrm{H}_{2} \mathrm{O}\right.$ ), rozenite $\left(\mathrm{FeSO}_{4} \bullet 4 \mathrm{H}_{2} \mathrm{O}\right.$ ), and lesser amounts of other ferrous sulfate compounds, combined with calcium hydroxide $\left[\mathrm{Ca}(\mathrm{OH})_{2}\right]$. Under oxidizing conditions, the products of the resulting reaction are the minerals hematite $\left(\mathrm{Fe}_{2} \mathrm{O}_{3}\right)$ and gypsum $\left(\mathrm{CaSO}_{4} \cdot 2 \mathrm{H}_{2} \mathrm{O}\right)$. Other similar ferric oxides are formed under anaerobic or reducing conditions. The iron oxide products are chemically very insoluble in water and are known for their ability to adsorb metal ions from solution including uranium from groundwater (Weidner and Shaw, 1995). Consequently, the resulting iron oxide materials have the potential to act as chemical barriers as well as physical barriers even after completion of the initial starting reaction. As a result, this technology may be a potentially effective method for treating soils as well as porous waste materials including FBRP vegetative wastes.

Results of laboratory-scale testing of this developing S/S technology found that the hydraulic conductivity of soils treated with the iron waste encapsulation materials is about $10^{-6} \mathrm{~cm} / \mathrm{sec}$ and that the resulting compressive strength is greater than the Nuclear Regulatory Commission (NRC) 50 psi minimum (Weidner and Shaw, 1995).

Dry reagents (ferrous sulfate hydrate and calcium hydroxide) react upon mixing and set up in a hard state without the addition of water; however, in the presence of excess water detrimental effects were produced (e.g., cracking, reduced compressive strength) in the treated waste. Consequently, it would be desirable to mix the reagents during injection, and to inject the reagents in a dry or nearly dry state (Weidner and Shaw, 1995). Pilotscale testing of ferrous sulfate hydrates and calcium hydroxide reagents has demonstrated great promise for treating inorganic contaminants; however, this technology has not been demonstrated under full-scale applications. Extensive treatability testing and further development would be required should this' S/S technology be selected for application at the FBRP. 
One limitation that is common to most in situ treatment technologies is that there is limited opportunity to verify - treatment effectiveness or monitor process quality control in situ. For example, there exists the potential that the entire soil matrix may not be sufficiently treated at the conclusion of the S/S process. Consequently, in situ S/S technology may be a potentially effective technology for treating FBRP soils as long as it is used in conjunction other remedial technologies (e.g., capping, institutional controls). In situ $S / S$ could also be considered to pretreat contaminated soil and minimize short-term exposure to remedial workers prior to ex situ treatment or off-unit disposal. In situ S/S using Portland cement-based or pozzolanic-based S/S reagents will be retained for further consideration. Should in situ S/S technology be used at the FBRP, selection of the type S/S reagent and $S / S$ reagent delivery system would be based upon treatability study results and $S / S$ treatment objectives.

In situ solidification is primarily used to protect the groundwater from leaching contaminants. The debris present in BRPs 231-F and 231-1F make it very difficult to use this technology without first removing the debris. This technology is eliminated from further consideration at FBRP due to implementability.

In situ Vitrification. Vitrification is a process that is used to convert materials into a glass or glassy substance, typically through a thermal process. Although some vitrification processes do not require heat (e.g., vapor deposition, solution hydrolysis), only thermal vitrification will be considered for application at the FBRP. Thermal vitrification is conducted at temperatures ranging from $1,100^{\circ} \mathrm{C}$ to $2,000^{\circ} \mathrm{C}\left(2,012^{\circ} \mathrm{F}\right.$ to $\left.3,632^{\circ} \mathrm{F}\right)$. At these temperatures, organic constituents that have not volatilized from the source are destroyed via pyrolysis or combustion, whereas inorganic constituents are stabilized within the glass matrix. Stabilization is accomplished by either incorporating nonvolatile inorganics into the glass structure or by encapsulating them in the glass product. In the case of radionuclides, these immobilization processes may also prevent some radioactive decay products from escaping into the environment (EPA, 1992). Volatilized organics and inorganic constituents are captured and processed in an off-gas treatment system.

Vitrification processes can be divided into two major categories: electric process heating and thermal process heating that utilize fossil fuels. Electrical process heating can be further divided into joule heating, plasma heating, microwave heating, induction heating, and electric arc heating. Vitrification using joule heating is considered for application of in situ or ex situ vitrification at the FBRP. Application of ex situ vitrification at the FBRP is presented in Section 2.4.2.5.

The primary advantage of vitrification is that the final waste product is very durable and performs well in leach tests (i.e., TCLP testing). Another advantage of vitrification is that it can incorporate a wide variety of contaminants and accompanying feed materials without a significant decrease in performance of the final product. Vitrification may also reduce the final volume of a waste material. Vitrification, however, is energy intensive and may therefore be more expensive than other remedial technologies. Another limitation of vitrification is that volatile organic and inorganic constituents may be driven from the waste during processing. For in situ vitrification, volatilization and other processes may cause contaminants to migrate from the source into the surrounding soils.

Vitrification is most suited for wastes that are extremely toxic, highly concentrated, or for wastes that contain a complex mix of contaminants (e.g., mixed waste). Although contaminated soils at the FBRP do not constitute a high level waste, vitrification is the best demonstrated available technology (BDAT) for treating high level radioactive wastes (EPA, 1992).

Melt temperature is an important process variable which affects metal retention. Generally, the lower the temperature at which the melt proceeds, the lower the production of volatilized metals, possibly because the metals are incorporated into the molten glass before they are volatilized (EPA, 1992). Melt temperatures can be lowered by adding fluxing agents to the material that is to be vitrified; however, achievement of lower melt temperatures would be accomplished at the expense of product durability and additional time required to complete the melt.

A cold cap is a layer of crust that forms on the liquid surface of the melt. The cold cap is cooler than the melt temperature, but eventually dissolves into the melt. While the cold cap is present, metals that volatile in the melt migrate to the melt surface and contact the cold cap. Because the cold cap crust is cooler than the melt 
temperature, the volatilized metals become trapped in the cold cap and eventually sink back into the melt to possibly be incorporated into the glass.

Cesium-137, which is a semi-volatile metal, is a potential concern of vitrification technology because it must be contained by the off-gas system, which would increase secondary containment requirements and complicate treatment. Cesium volatilized during high level waste vitrification at SRS was scrubbed from the off-gas with a 99.99999+ percent efficiency and recycled to the feed melter (EPA, 1992). Recent attempts to control cesium volatilization have shown promise. Research involving the addition of a $\mathrm{B}_{2} \mathrm{O}_{3}$ flux $(20$ wt\%) to the feed reduced the amount of volatilized cesium by half (EPA, 1992). Cs-137 has not been shown to be a chemical of concern for the FBRP.

In situ vitrification is comprised of five major support systems: (1) electrical power supply, (2) off-gas hood, (3) off-gas treatment, (4) off-gas support, and (5) process control. Of these support systems, all but the off-gas hood are contained in three transport trailers. Although extensive unit preparation would be required, the FBRP unit should be capable of accommodating in situ vitrification process equipment.

Vitrification off-gas systems function to recover heat and cool off-gases, remove particulates, neutralize acid gas, and remove water vapor. Off-gas components may include scrubbers (cool gases and remove particulates), filters (remove particulates), spray chambers (neutralize acid gases), condensers (remove water vapor) and others. The off-gas system is operated at a negative pressure to prevent release of gases to the atmosphere.

In situ vitrification utilizes an electrode feed system which inserts a square array of four graphite electrodes into the contaminated site. The electrodes are allowed to sink deeper into the soil as the melt increases in volume until the desired treatment depth is reached, or until a process limiting depth is reached. The normal processing rate for full-scale operation is three to five tons of soil per hour, and the maximum depth demonstrated has been $5.8 \mathrm{~m}$ (19 ft). The vitrification process at a single location (electrode set) takes about 150 to 200 hours, depending upon the desired melt depth and electrode spacing.

Prior to the initiation of the in situ vitrification process, a conductive mixture of flaked graphite and glass frit is placed between the pairs of electrodes to act as a starter path. An electrical potential is applied to the electrodes and the starter path and surrounding soil is heated to $2000^{\circ} \mathrm{C}\left(3632^{\circ} \mathrm{F}\right)$. The soil melting temperature is $1100^{\circ} \mathrm{C}$ to $1400^{\circ} \mathrm{C}\left(2012^{\circ} \mathrm{F}\right.$ to $\left.2552^{\circ} \mathrm{F}\right)$. The starter path is eventually consumed by oxidation and the current is transferred to the soil, which is electrically conductive when molten. A steel hood placed over the vitrified area directs resulting gases to an off-gas treatment system.

Once initiated, power is maintained to overcome heat losses as the melt progresses downward and outward. The molten zone (melt) is circular and generally flattened. Generally, the melt grows outward from the electrode array a distance approximately half of the electrode spacing. Processing continues until heat loss from the melt approaches energy input, or until power to the electrodes is removed.

Metals retention may be affected by the production and evolution of gases, the presence of a cold cap, the melt temperature, and by the effect certain additives. Gases that evolve from the burning of combustibles can help carry metal particles and vapors to the surface. With increasing gas evolution there is a more rapid movement to the surface, decreased exposure of the metals to the melt, and decreased probability of the metals dissolving into the melt. Consequently, the presence of gas generating combustibles at depth are of potential concern during vitrification. Based upon findings of the FBRP RFI/RI, there is little evidence to suggest that there are sufficient combustible materials (e.g., organics) beneath the FBRP that would interfere with the in situ vitrification process. If contaminated vegetation at the FBRP is ever treated in the basin along with contaminated soils and sediments, the vegetation should be placed on top of the basin melt area so that generated gases $\left(\mathrm{CO}_{2}\right.$ and $\left.\mathrm{H}_{2} \mathrm{O}\right)$ are released directly to the off-gas collection hood and not within the melt.

Waste unit characteristics and treatment objectives play an important role in determining whether in situ vitrification is suitable for a particular application. Moisture content of the process material will affect the efficiency of the vitrification process. Any material with a high moisture content will increase the processing lime and energy demands by first requiring that the water be driven off. Also, it is possible that at greater than 
five percent free water within the matrix, the water may react vigorously with the melt as it vaporizes. The presence of standing water in the FBRP would reduce vitrification efficiency unless the water is first removed prior to processing. This would require that the water be properly characterized, stored and/or treated by other treatment processes.

Soil composition will affect product characteristics such as density and chemical resistance, and will influence processing parameters such as thermal conductivity, fusion temperature, specific heat, electrical conductivity, and melt viscosity. The primary soil characteristics limiting in situ vitrification are high quartz content and low alkali flux content (EPA, 1992). Soils are typically amenable to vitrification since they often contain a sufficient concentration of silica $\left(\mathrm{SiO}_{2}\right)$ and alumina $\left(\mathrm{Al}_{2} \mathrm{O}_{3}\right)$ which provide the which form the skeleton of the amorphous glass product. Higher levels of these compounds tend to increase the chemical durability of the resulting glass but do so at the expense of increased viscosity and decreased electrical conductivity. Fluxes (e.g., $\mathrm{Na}_{2} \mathrm{O}, \mathrm{K}_{2} \mathrm{O}$, and $\mathrm{CaO})$ are also needed to produce glass. Flux agents are all alkali elements $(\mathrm{Na}, \mathrm{K}$, and $\mathrm{Ca})$ that carry the charge that conducts the electric current generating the soil-melting heat. Consequently, soils with low silica, alumina, or alkaline contents may limit the applicability of in situ vitrification. In a recent bench-scale study, samples of SRS soil proved difficult to vitrify because of soil composition. The SRS soil considered for in situ vitrification had an ample amount of silica $(92.5 \mathrm{wt} \%)$ but was deficient in the amount of $\mathrm{CaO}(0.4 \mathrm{wt} \%), \mathrm{Na}_{2} \mathrm{O}$ $(0.2 \mathrm{wt} \%)$, and $\mathrm{K}_{2} \mathrm{O}(0.2 \mathrm{wt} \%)$. A flux of 5 to $10 \mathrm{wt} \%$ sodium carbonate was considered necessary to vitrify soils deficient in alkali elements. Two bench-scale flux enhancement techniques were conducted on the SRS soils. The first test involved the placement of a starter layer (sand) over the SRS soil. This resulted in the melt progressing outward without achieving a significant penetration into the SRS soils. The second test involved pre-mixing of alkali materials into the soil. Although this test was highly successful, the need for pre-mixing of the soils diminished the many advantages of the process of vitrifying the contaminants without pretreatment (EPA, 1992). Unit-specific treatability testing would be conducted should in situ vitrification be considered for treating FBRP soils.

In situ vitrification is effective in immobilizing various types of waste. Its uses, however are generally limited to areas which contain high levels of radioactive materials and heavy metals. In these instances, the risks to remediation workers are usually considered to be too high for excavation processes. This is not the case at the FBRP. The concentrations and associated risks here are relatively low and would therefore, not be suitable for this application. This technology will not be considered for further evaluation for the FBRP.

In situ Electrokinetic Soil Processing. Electrokinetic soil processing decontaminates soil media by influencing the negative charge that is present on almost all soil surfaces. The negatively charged soil surface attracts positively charged cationic species including inorganic contaminants. The degree to which a soil is capable of attracting cationic species is referred to as the soil cation exchange capacity.

In the organic fraction of soils, negatively charged surfaces arise from the $-\mathrm{COOH}$ and $-\mathrm{OH}$ groups. The negatively charged surface on inorganic clay fractions in soil generally arise from two sources; (1) the ionization of hydroxyl groups attached to silicon atoms at the broken edges of the tetrahedral planes, and (2) the isomorphous substitution of an atom of similar geometry but of lower charge (e.g., $\mathrm{Al}^{3+}$ for $\mathrm{Si}^{4+}$ ). The negative charge that develops on organic and mineral colloids may be neutralized by cations attracted to the surface of these colloids. Soil colloids have numerous cations adsorbed to their exchange sites. These cations are held with varying degrees of tenacity, depending upon their charges and their hydrated/unhydrated radii (Dragun, 1988).

Electrokinetic soil processing involves the insertion of anode and cathode electrodes into contaminated soil. Electrode spacing is typically 6 to $10 \mathrm{~m}(20$ to $33 \mathrm{ft})$ apart; however, spacing will vary as a function of soil and contaminant type. A conditioning fluid is circulated at the electrodes and an electric current is applied to produce an electric potential between the anode and cathode. The conditioning fluid serves as a conducting medium and a means to extract and exchange charged species that collect at the electrodes. The application of an electric current produces three effects. First, an acid (proton donor) is produced in the anode compartment. As the hydronium $\left(\mathrm{H}_{3} \mathrm{O}^{+}\right)$or protons $\left(\mathrm{H}^{+}\right)$generated at the anode migrate under an electric field across the soil mass, cationic species (i.c., contaminants) are desorbed from the soil surface. Secondly, the electrical current generates an electric potential that leads to electroosmosis or the mass flux of pore fluid under an electric ficld. 
The conditioning fluid in the anode compartment flows across the soil mass to the cathode compartment under an electric field. The movement of the acid and/or the conditioning fluid across the electrodes assists in desorption of species, as well as dissolution of carbonates and hydroxides. This flow ceases when the counteracting flux under the hydraulic gradient becomes equal to the electroosmotic fluid flux. Finally, the electrical current initiates electromigration of different charged species toward the respective electrodes. This process is called electrophoresis which is the mass flux of charged (ionic) particles under an electric field. Electrophoresis is at least an order of magnitude faster than transport of species by diffusion or electroosmotic advection (EPA, 1993).

During electrokinetic soil processing, some of the contaminant species electrodeposit on the electrodes, whereas others are extracted through the use of chemical processes or ion exchange systems within the process control container. The conditioning fluid is used to control and/or depolarize the cathode reaction so that the base generated does not lead to premature precipitation of the incoming species. Conditioning fluids being investigated include acetic acid and chelating agents. Acetic acid depolarizes the reaction at the cathode and prevents base formation. The acetate anions migrate into the soil and solubilize contaminant species. Chelating agents are used to solubilize specific contaminants (EPA, 1993).

Electrokinetic soil processing can be relatively inexpensive when compared to other in situ treatment technologies for mixed waste. Pilot-scale studies indicate that energy costs associated with electrokinetic soil processing are about $\$ 15 / \mathrm{m}^{3}\left(\$ 0.42 / \mathrm{ft}^{3}\right)$ of soil over a three month period (EPA, 1993). Electrokinetic soil processing costs are therefore considered low.

Electrokinetic soil processing can be used to treat soils for the removal of lead, cadmium, uranium, thorium, radium and polar ionic species (EPA, 1993). Electrokinetic processing may effectively treat soils containing other contaminants (e.g., cesium); however, documentation of this is limited. Application of electrokinetic soil processing has been limited to bench-scale and pilot-scale testing. Although testing results have demonstrated varying degrees of success, this technology has not been demonstrated under full-scale applications. Furthermore, electrokinetics may not effectively treat all FBRP COCs. Consequently, electrokinetic soil processing would have to be conducted in conjunction with other remedial actions to be effective. On the basis of implementability and effectiveness, electrokinetic soil processing will not be retained for further consideration at the FBRP.

In situ Soil Flushing Soil flushing involves the leaching of waste constituents from a contaminated soil for recovery and treatment. A flushing fluid is passed through in-place soil using subsurface injection wells, shallow infiltration galleries, surface flooding, or above-ground sprayers. The flushing fluid filters through the contaminated soil, removing contaminants as it proceeds. Contaminants are removed through solubilization into the flushing fluid, formation of emulsions, or chemical reactions with the flushing fluid. The contaminated flushing fluid mixes with groundwater and is captured and pumped to the surface with standard groundwater extraction wells. Ditches open to the surface and subsurface collection drains may also be used to capture the contaminated flushing fluid and groundwater. The groundwater and flushing fluid are then treated using appropriate wastewater treatment methods. This treated water can be recycled as makeup water for the soil flushing process or discharged. In some cases, soil flushing can reduce contaminant concentrations in the soil to acceptable levels and thus serve as the only soil treatment technology. In other cases, other in situ technologies such as in situ biodegradation or in situ soil heating can be used in conjunction with soil flushing to achieve acceptable contaminant removal efficiencies.

A number of chemical contaminants can potentially be removed from soils using soil flushing. Removal efficiencies depend on the type of contaminant as well as the type of soil. In general, soluble organic contaminants and heavy metal salts are easily removed from soil by flushing with water alone. However, in order to successfully remove other types of contaminants, additives may need to be added to the flushing water. For example, the addition of surfactants may improve the removal of low solubility organic contaminants, while acids, chelating agents, or reducing agents may be added to improve the removal of metals. Treatability studies should be conducted to determine compatibility of the flushing reagents with the contaminants and the site soils. 
Complex mixtures of contaminants in the soil (such as a mixture of metals, nonvolatile organics, and semivolatile organics) make it difficult to formulate a single suitable flushing fluid that will consistently and reliably remove all of the different types of contaminants. In addition, frequent changes in contaminant concentration and composition in the vertical and horizontal soil profiles will complicate the formulation of the flushing fluid. For these cases, sequential steps with frequent changes in the flushing formula, may be required.

While washwater additives such as surfactants and chelants may enhance some contaminant removal efficiencies, they also tend to interfere with the downstream wastewater treatment segments of the process. The presence of these additives in the washed soil and in the wastewater treatment sludge may cause some difficulty in their disposal. Costs associated with handling the additives and managing them as part of the residuals/wastewater streams must be carefully weighed against the incremental improvements in soil washing performance that they may provide.

Soil permeability is a key physical parameter for determining the feasibility of soil flushing. Soil flushing is more likely to be effective in permeable soils because soils with low permeability will limit the ability of flushing fluids to filter through the soil in a reasonable time frame. Soil moisture content is also used to determine the feasibility of soil flushing because it affects the amount of flushing fluids required. Dry soils will require more flushing fluid initially to mobilize contaminants. In addition, high humic content and high cation exchange capacity tend to reduce the removal efficiency of soil flushing. Some organic contaminants may adsorb to humic materials or clays in soils and therefore are difficult to remove during soil flushing. Similarly, the bonding of certain metals with clay due to cationic exchange makes them difficult to remove with soil flushing.

Soil flushing is a new and innovative technology. Few full-scale systems have been operated, and little operating information is available. Typically, laboratory and field treatability studies must be performed under site-specific conditions before soil flushing is selected as the remedy of choice. This technology will not be considered for further evaluation at the FBRP.

Land Treatment Land treatment is a waste treatment and disposal process whereby a waste is mixed with or incorporated into the surface soil and is degraded, transformed, or immobilized through proper management (Freeman, 1989). Synonyms include land cultivation, landfarming, biofarming, land application, and sludge spreading. Unlike landfills, where waste is buried in subsurface cells, and treatment uses the surface soil as a treatment medium and is based primarily on the principle of aerobic decomposition of organic hazardous waste constituents. The most common use of land treatment is for petroleum wastes (over 50\%) with chemical waste a distant second (15\%) (Freeman, 1989).

Typical waste treated in landfills include gasoline, diesel fuel, and jet fuel. Some spent halogenated solvents and pesticides have been successfully treated with this method, however, they require pretreatment to enhance their biodegradability. Essentially, biodegradable, wastes are suitable for land treatment. Radioactive waste; highly volatile, reactive, or flammable liquids; and inorganic wastes such as heavy metals, acids and bases, cyanide, and ammonia are not considered to be candidates for land treatment.

EPA standards require that the treatment zone must be less than $4.5 \mathrm{ft}$ deep and at least $3 \mathrm{ft}$ above a seasonal water table. The site cannot be located in an aquifer recharge area and must have a groundwater monitoring system in place. Land treatment facilities should not be established on deep, sandy soil because of the potential for groundwater contamination.

The actual operation of a land treatment facility may consist of simply spreading the waste over the surface of the soil or may involve plowing the soil to promote mixing and aeration of the soil. Typically, liming is done to bring the $\mathrm{pH}$ close to 7 where microbial activity is enhanced. Applications of nitrogen are also often needed as the microbes quickly use up the available nitrogen when breaking down highly carbonaceous wastes. While most soil contains a wide varicty of microbes, it is sometimes necessary to add laboratory prepared cultures to optimized the microbial activity. 
The main advantage of this process is that it is a relatively inexpensive process which degrades, transforms or immobilizes many organic wastes. Its disadvantages include its suitability to only selected waste, potential air emissions, potential contamination of groundwater, or potential for causing other detrimental environmental impacts.

This technology is not retained for further evaluation at the FBRP. The PCBs associated with RP 231-2F are not ideally suited for this technology as they would resist biological degradation. The metals and radionuclides in the pits would not be affected.

\subsubsection{Off-Unit Disposal}

Remediation of impacted media and residual materials can potentially be managed at an off-unit location. In accordance with the NCP, corrective measures/remedial alternatives involving off-unit disposal must be more cost effective than other remedial actions, and create new waste management capacity, or be necessary to protect public health and welfare or the environment. In addition, the current NCP requires that off-unit disposal methods be considered as potential remedial alternatives.

Off-unit disposal involves removal of the impacted media from the waste unit and properly disposing of the waste at an SRS hazardous waste disposal facility or at permitted disposal facility located outside SRS boundaries. The removal and transportation of impacted media would increase the potential for remedial worker exposure and exposure to the surrounding population, respectively. Consequently, transport of waste materials off-unit would require precautionary measures to protect public health and the environment.

SRS Disposal Soil remediation would generate larger amounts of waste, however proper selection of treatment methods should limit this waste generated to manageable volumes. Further discussion would be needed with the waste management group before the final processing methods are selected.

SRS disposal is not retained for further evaluation at the FBRP. This disposal method is effective in immobilizing hazardous waste. It is not implementable at SRS as there is no facility designed to handle contaminated soil. The cost of disposal onsite is expected to be high if a facility is ever constructed.

Off-Site Disposal Off-Site disposal is an effective method for immobilizing hazardous waste. This disposal method is implementable as licensed waste facilities will take soil contaminated with low levels of PCBs, metals, and radionuclides. The cost is relatively high. This technology is retained for further evaluation at the FBRP.

\subsubsection{Screening for Effectiveness, Implementability, and Cost}

Table 2-7 shows the results of the screening for effectiveness, implementability, and cost for the various technologies. The shaded technologies are those that could not be implemented technically at the site and were screened out. 
Table 2-7

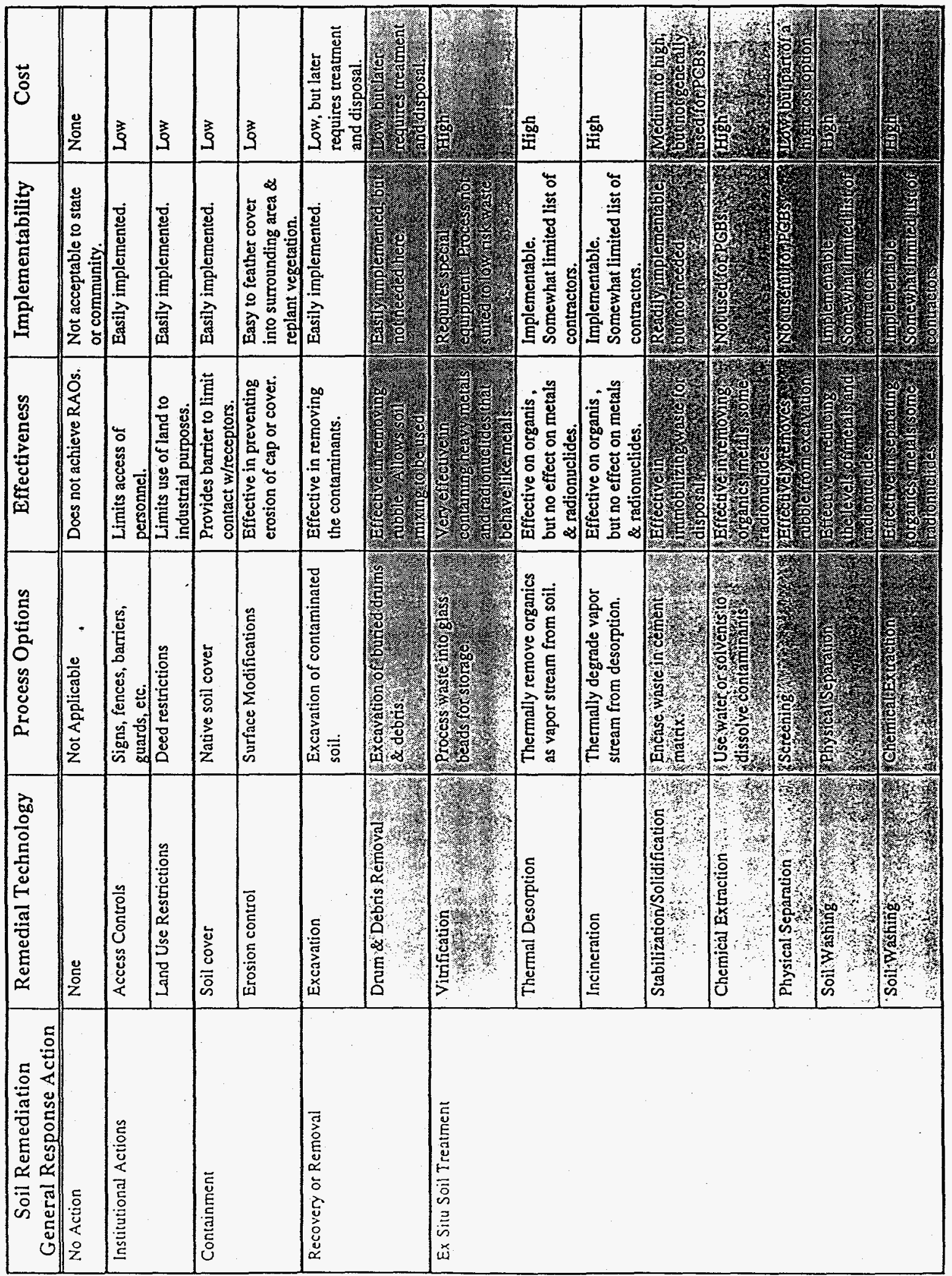


Table 2-7 Screening of Technologies for Effectiveness, Implementability, and Cost (continued)

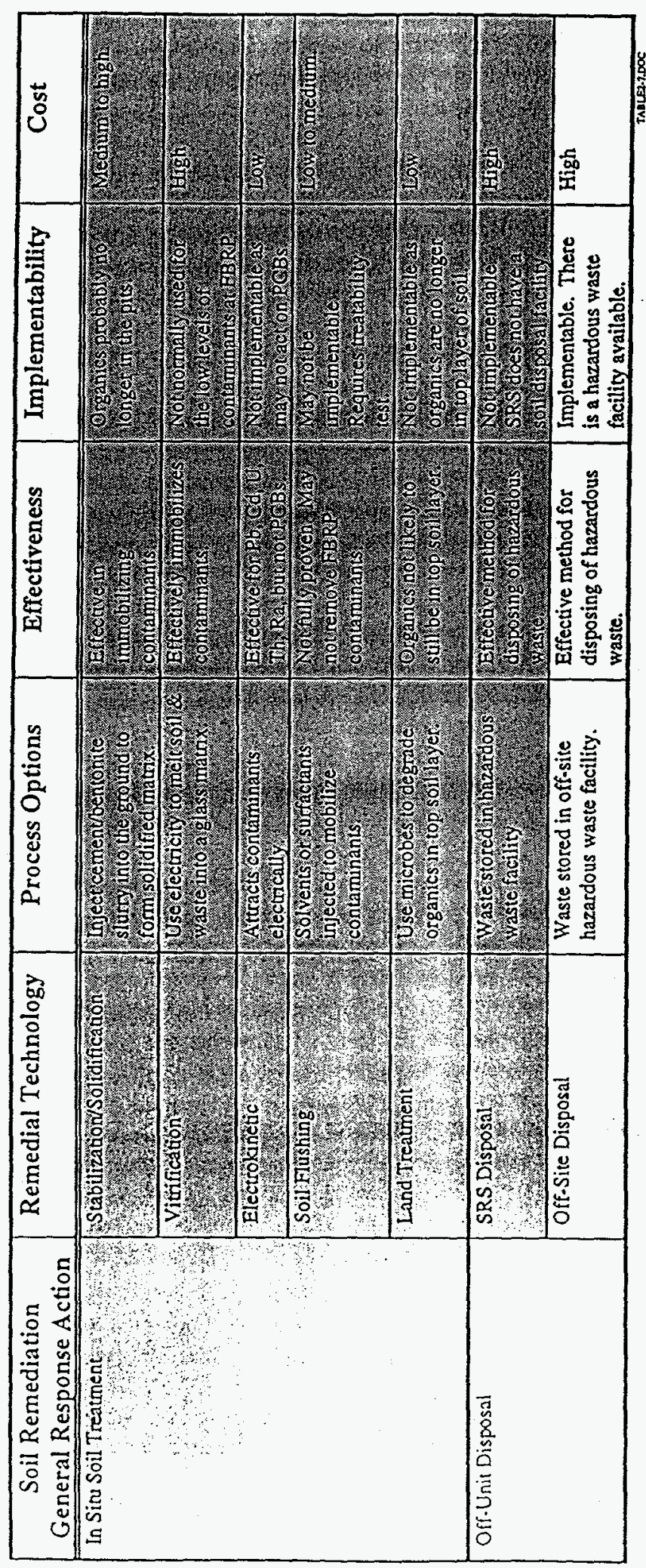




\subsection{DEVELOPMENT AND SCREENING OF ALTERNATIVES}

In Section 2.0, various technologies were screened and evaluated on an individual basis without regard to their part in a comprehensive remedial action. In Section 3.1, the retained technologies will be assembled by media into functional alternatives which address the unit specific factors. These alternatives will then be screened in Section 3.2. The remaining alternatives will then be subjected to detailed analysis in Section 4.0

\subsection{Development of Alternatives}

Potential alternatives have been developed to address the FBRP contaminated soil. At least one of the selected alternatives will remediate the site to unrestricted residential use with final risks not to exceed $1 \times 10^{-6}$ and $\mathrm{HIs}$ not to exceed 1 .

\subsection{Remedial Alternatives for FBRP Soil}

The BRA indicated that the only soil remediation problem (above a to-be-considered guidance level and with an HI greater than 1) exists in RP 231-2F. The risk driver is PCB-1254 which has shown a maximum concentration of $2.87 \mathrm{mg} / \mathrm{kg}$. Levels of Cs-137, K-40, and Sr-90 also generate risks between $1 \times 10^{-6}$ and $1 \times 10^{-}$ ${ }^{4}$ for future residential use at this pit. For a future residential land use scenario, the top four-foot layer of soil would need to be remediated to a level of less than $1 \mathrm{mg} / \mathrm{kg}$. For an industrial land use scenario, the area would not require remediation as the PCB ARAR level is $10 \mathrm{mg} / \mathrm{kg}$.

BRPs 231-F and 231-1F will be considered as one unit due to their close proximity. These pits contain levels of arsenic, HpCDD, B[a]P, Cs-137, and K-40 which produce risks between $1 \times 10^{-6}$ and $1 \times 10^{-4}$ in a future residential scenario. In the industrial land use scenario, only arsenic, $\mathrm{HpCDD}, \mathrm{Cs}-137$, and $\mathrm{K}-40$ produce risks in excess of $1 \times 10^{-6}$ :

A discuission follows for each of the alternatives concerning how well they remediate both BRPs $231-\mathrm{F}$ and $-1 \mathrm{~F}$ and RP 231-2F.

Alternative 1:

Discussion of 1:

Alternative 2:

Discussion of 2:

Alternative 3:

Discussion of 3 :
No Action

The No Action alternative is required by the NCP. All risks remain as stated in the $B R A$ in all of the pits.

Institutional Controls

This alternative would provide deed restrictions which would restrict the future use of this land for industrial purposes only. ROD reviews would be provided every five years to ensure that the deed restrictions were being enforced. The FBRP will meet the to-be-considered guidance if future residents are not allowed to live on this waste site. Risks would still remain within all of the pits between the $1 \times 10^{-6}$ and $1 \times 10^{-4}$ level. The risks would be lowered to the industrial land use scenario levels as residential land use is prohibited.

Native Soil Cover (4').

This alternative would provide a deed notification, upon transfer of the land to nonfederal ownership, to inform future owners of this property that this area was used to manage hazardous material. A soil cover four feet thick would be placed over the waste units and feathered into the surrounding area for erosion prevention. ROD reviews would be provided every five years to ensure that the deed restrictions were being enforced. This alternative would protect future residents from coming in contact with soil which exceeds the $1 \mathrm{mg} / \mathrm{kg}$ to-be-considered guidance for residential use. All of the risks in all of the pits would be reduced to $<1 \times 10^{-6}$. 
Alternative 4:

Discussion of 4 :

Alternative 5:

Discussion of 5:
Thermal Desorption/Incineration.

This alternative would partially remediate the soil to allow restricted future residential land use of this waste site in which excavation beyond four feet is prohibited. The top four-foot layer of soil would be excavated and fed through desorption/incineration equipment. Thermal desorption/incineration would destroy the PCBs and other organic materials thus eliminating any waste stream from this remediation. The soil would be put back in place and revegetated. Levels of metals and radionuclides would not be affected.

Offsite Soil Disposal.

This alternative would completely remediate the top four feet of the pits to allow restricted future residential land use of this waste site in which excavation beyond four feet is prohibited.. The top four-foot layer of soil would be excavated and shipped to a licensed waste facility. Clean soil would be put into the pits and revegetated.

\subsection{Screening of the Alternatives}

In this section, the alternatives will be evaluated against the criteria effectiveness, implementability, and cost. Those alternatives that are not screened out will be analyzed in detail in Section 4.0.

\subsection{Alternative 1 - No Action}

No action is not effective in reducing the risk level from contaminants in the soil. This action is readily implementable as it requires no action. There is no cost for the no action alternative.

\subsubsection{Alternative 2 - Institutional Controls}

This alternative is effective in reducing the risks to the industrial land use scenario values.. The maximum concentration of PCBs measured in the soil was $2.87 \mathrm{mg} / \mathrm{kg}$ which is below the ARAR of $10 \mathrm{mg} / \mathrm{kg}$. This alternative is easily implementable at the FBRP. Deed notifications and restrictions can easily be placed on the land at the time the land is transferred to non-federal ownership. ROD reviews will be provided every five years for 30 years. Signs will be placed at the pits indicating that the land was used to manage hazardous materials. The cost of this alternative is low.

\subsubsection{Alternative 3 - Native Soil Cover (4')}

This alternative is effective in reducing risks from the soil in all of the pits to $1 \times 10^{-6}$ or less.. The additional four-foot soil cover provides protection for future residents. The to-be-considered guidance would be met for future residents. A deed notification will be added at the time that the land is transferred to non-federal ownership to inform future land owners that this area was used to manage hazardous material. Adding a soil cover and placing future deed notifications and restrictions are easily implementable at the FBRP. The cost for this alternative is relatively low.

\subsubsection{Alternative 4-Thermal Desorption/Incineration}

This alternative is very effective in reducing the risk from organic contaminants. The top four-foot layer of'soil in each of the pits would be excavated and treated. The PCBs and organic materials would be destroyed. The land would be available for restricted residential use in which excavation beyond four feet would be prohibited. 
This alternative is implementable at the FBRP. There are a limited number of contractors that can perform this remediation. The cost of this alternative is high.

\subsubsection{Alternative 5 - Offsite Soil Disposal}

This alternative effectively removes the contaminated soil from the BRPs/RPs. This alternative is readily implementable as the contaminated soil can be shipped to a licensed waste disposal facility. The BRPs/RPs would then be filled with clean soil and revegetated. The cost for this alternative is high.

\subsection{DETAILED ANALYSIS OF ALTERNATIVES}

Section 4.1 explains the nine CERCLA criteria and discusses what items should be included under each criteria. Section 4.2 gives a detailed analysis of each of the alternatives versus the nine CERCLA criteria. Section 4.3 discusses how well each of the alternatives addresses each particular criteria. Under each criteria, the alternatives are discussed in the relative order that they performed for that particular category.

\subsection{Discussion of the Nine CERCLA Criteria}

In the following sections, the alternatives that were selected are evaluated for the following criteria: 1) Overall protection of human health and the environment, 2) Compliance with ARARs, 3) Long-term effectiveness, 4) Reduction of toxicity, mobility, or volume, 5) Short-term effectiveness, 6) Implementability, 7) Cost, 8) State acceptance, and 9) Community acceptance. These criteria are explained in the following section.

\section{1) Overall Protection of Human Health and the Environment}

This criterion is used to determine how well the alternative, as a whole, achieves and maintains protection of human health and the environment. The overall assessment draws on the assessments conducted under other evaluation criteria, especially long-term effectiveness and permanence, short-term effectiveness, and compliance with ARARs.

Evaluation of the overall protectiveness of an alternative during the feasibility study focuses on whether a specific alternative achieves adequate protection and describes how site risks posed through each pathway are eliminated, reduced, or controlled through treatment, engineering, or institutional control. This evaluation also allows for consideration of whether an alternative poses any unacceptable short-term or cross-media impacts.

\section{2) Compliance with ARARs}

The assessment of this criterion is used to determine whether each alternative will meet all of its Federal and State ARARs. The ARARs that could apply here include chemical-specific ARARs for the Primary Drinking Water Standard, Clean Water Act (CWA) criteria, health-based risk levels, etc. Local-specific ARARs could also include restrictions on activities within floodplains, wetlands, historic sites, streams, etc. Action-specific ARARs would include methods for treating, storing, and disposing of hazardous material. It is assumed that local-specific and action-specific ARARs will be complied with.

\section{3) Long-Term Effectiveness}

Assessing this criterion addresses the results of a remedial action in terms of the risk remaining at the site after response objectives have been met. The primary focus of this evaluation is the extent and effectiveness of the controls that may be required to manage the risk posed by treatment residuals and/or untreated waste. The following components or the criterion are addressed:

- Magnitude of residual risk - This factor assesses the residual risk remaining from untreated waste or treatment residuals at the conclusion of remedial activities. The potential for this risk 
may be measured by numerical standards such as cancer risk levels or the volume or concentration of contaminants in waste, media, or treatment residuals remaining on the site. The characteristics of the residuals are considered to the degree that they remain hazardous, taking into account their volume, toxicity, mobility, and propensity to bioaccumulate.

- Adequacy and reliability of controls - This factor assesses the adequacy and reliability of controls, if any, that are used to manage treatment residuals or untreated wastes that remain at this site. It may include an assessment of containment systems and institutional controls to determine if they are sufficient to ensure that any exposure to human and environmental receptors is within protective levels. This factor also addresses the long-term reliability of management controls for providing continued protection from residuals. It includes the assessment of the potential need to replace technical components of the remedy (such as a treatment system), the potential exposure pathway, and the risks posed should components of the remedial action need replacement.

\section{4) Reduction or Toxicity, Mobility, or Volume}

The assessment of this criteria evaluates the anticipated performance of the specific treatment technologies employed. This evaluation criterion addresses the statutory preference for selecting remedial actions which employ treatment technologies that permanently and significantly reduce toxicity, mobility, or volume of the hazardous substances as their principal element. This preference is satisfied when treatment is used to reduce the principal threats at a site through destruction of toxic contaminants, reduction of the total mass of toxic contaminants, irreversible reduction on contaminant mobility, or reduction of the total volume of contaminated media. This evaluation focuses of the following specific factors:

- The treatment processes employed and the materials treated

- The amount of hazardous materials destroyed or treated, including how the principal threat(s) is addressed

- The degree of expected reduction in toxicity, mobility, or volume measured as a percentage of reduction (or order of magnitude)

- The degree to which the treatment is irreversible

- The type and quantity of treatment residuals that remain following treatment

\section{5) Short-Term Effectiveness}

The assessment of this criterion examines the effectiveness of the process option in protecting human health and the environment during the construction and implementation and until response objectives are met. The following factors are addressed as appropriate under this criterion:

- Protection of the community during remedial action - This aspect of short-term effectiveness addresses any risk that results from implementation of the proposed remedial action, such as transportation of hazardous materials, or air-quality impacts from a stripping tower operation, that may affect human health.

- $\quad$ Protection of workers during remedial actions - This factor assesses threats that may be posed to workers and the effectiveness and reliability of protective measures that would be taken! 
- Environmental impacts - This factor addresses the potential adverse environmental impacts that may result from the construction and implementation of the process or reducing the potential impacts.

- Time until remedial response objectives are achieved - This factor includes an estimate of the time required to achieve protection for either the entire site or individual elements associated with specific site areas or threats.

6) Implementability

This assessment evaluates the technical and administrative feasibility of process options and the availability of required goods and services. This criterion involves analysis of the following factors:

- Technical feasibility

- Construction and operation - This relates to the technical difficulties and unknowns associated with a technology.

- $\quad$ Reliability of technology - This focuses on the likelihood that technical problems associated with implementation will lead to schedule delays.

- Ease of undertaking additional remediation action - This includes a discussion of what, if any, future remedial actions may need to be undertaken and how difficult it would be to implement such additional actions.

- Monitoring considerations - This addresses the ability to monitor the effectiveness of the remedy and includes an evaluation of the risks of exposure should monitoring be insufficient to detect a system failure.

- Administrative feasibility

- Activities needed to coordinate with other offices and agencies (e.g., obtaining permits for offsite activities or rights-of-way for construction)

- Availability of services and materials

- Availability of adequate off-site treatment, storage, and disposal capacity and services

- $\quad$ Availability of necessary equipment and specialists, and provisions to ensure any necessary additional resources

- Availability of services and material, plus the potential for obtaining comparative bids, which may be particularly important for innovative technologies

- A vailability of prospective technologies

\section{7) $\underline{\text { Cost }}$}

This assessment evaluates the capital, and operation and maintenance $(O \& M)$ costs of each process option with estimates which are designed to be $+50 \%$ to $-30 \%$ of the actual costs. Relative costs of process options in the same technology type are provided. This is consistent with the Evaluation Process Option step of the "Guidance 
for Conduction Remedial Investigations and Feasibility Studies (RI/FSs) Under CERCLA" (EPA/540/G89/004).

\section{8) State Acceptance}

This assessment indicates whether the state is likely to concur with the alternative. This is typically based on previous decisions from the state on similar waste sites or from general discussions with the regulators.

\section{9) Community Acceptance}

This assessment indicates whether the community is likely to concur with the alternative. This is typically based on previous decisions from the community on similar waste sites or from pubic discussions with the citizens or the Citizens Advisory Board (CAB).

\subsection{Evaluation of the Alternatives Under the Nine CERCLA Criteria}

\subsection{Alternative $I$ - No Action}

The No Action alternative provides no action to remediate the FBRP.

\section{Overall Protection of Human Health and the Environment}

The No Action alternative will not reduce any of the risks to human health or the environment from those estimated in the BRA. The BRA reported that the FBRP does not pose any risks to the environment. There are no risks greater than $1 \times 10^{-4}$ for any of the scenarios from soil, however the risk is $2 \times 10^{-5}$ and the HI is 2.0 for ingestion of soil for future residents, attributable to PCB-1254 in RP 231-2F. There are several other risks between $1 \times 10^{-6}$ and $1 \times 10^{-4}$ in the pits (see Figure $1-5$ ).

\section{Compliance with ARARs}

The maximum concentration of PCB-1254 $(2.87 \mathrm{mg} / \mathrm{kg})$ is above the residential to-be-considered guidance of 1 $\mathrm{mg} / \mathrm{kg}$ in the soil in RP $231-2 \mathrm{~F}$. This value is below the ARAR of $10 \mathrm{mg} / \mathrm{kg}$.

\section{Long-Term Effectiveness}

No Action will not provide any long-term effectiveness.

\section{Reduction or Toxicity, Mobility, or Volume}

There is no reduction of toxicity, mobility, or volume of the contaminants for the No Action alternative.

\section{Short-Term Effectiveness}

There are no risks posed to remedial workers, the environment, or the community because this alternative does not provide any remediation.

Implementability

This alternative is readily implementable at the FBRP. 
$\underline{\text { Cost }}$

There are no costs for the No Action alternative.

\section{$\underline{\text { State Acceptance }}$}

This alternative would not likely be acceptable to the State because the maximum concentration of PCB-1254 in soil in RP $231-2 F$ is above the residential to-be-considered guidance level for residential land use.

\section{Community Acceptance}

The community would also not likely accept No Action for similar reasons as the State.

\subsubsection{Alternative 2 - Institutional Controls}

The Institutional Controls alternative places deed restrictions on the FBRP when the land is transferred to nonfederal ownership which set this area aside for future industrial use only Signs indicating that the land was used to manage hazardous materials would be installed. Five year ROD reviews would be provided to inform the State that the institutional controls were being enforced and the area was not being used for residential purposes.

\section{Overall Protection of Human Health and the Environment}

Institutional controls would prevent future residential use of this land. The BRA reported that the FBRP does not pose any risks to the environment. There are no risks greater than $1 \times 10^{-4}$ for any of the scenarios from soil. The risk to future workers is $4 \times 10^{-6}$ while the $\mathrm{HI}$ is 0.09 due to PCB-1254 from ingestion of the soil at RP 231$2 \mathrm{~F}$. The risk from ingestion of soil at the BRPs is $5 \times 10^{-6}$ due to arsenic, $\mathrm{HpCDD}$, and $\mathrm{B}[\mathrm{a}] \mathrm{P}$ in both the $0-2^{\prime}$ and $0-4^{\prime}$ layers of soil. The risk from dermal contact with the soil is $1 \times 10^{-6}$ from $B$ [a]P. The radioactive risk from direct exposure to the soil is $3 \times 10^{-6}$ at the BRPs and $2 \times 10^{-6}$ at RP $231-2 \mathrm{~F}$. These risks are due to the presence of $\mathrm{Cs}-137$ and $\mathrm{K}-40$.

\section{Compliance with ARARs}

All ARARs would be met. The maximum concentration of PCB-1254 found in RP 231-2F (2.87 mg/kg) is below the ARAR of $10 \mathrm{mg} / \mathrm{kg}$.

\section{Long-Term Effectiveness}

All ARARs would be met as long as the deed restrictions are enforced.

Reduction or Toxicity, Mobility, or Volume

There is no reduction of toxicity, mobility, or volume of the contaminants for the Institutional Controls alternative.

\section{Short-Term Effectiveness}

There are no risks posed to remedial workers, the environment, or the community because this alternative does not provide any remediation.

Implementability

This alternative is readily implementable at the FBRP. Deed restrictions can easily be placed. ROD reviews can be provided every five years. 
The total present value costs estimated for the Institutional Controls alternative are $\$ 10,346$. It is estimated that the survey plat and deed restrictions would cost about $\$ 2,000$. Five year ROD reviews were expected to cost $\$ 3,000$ each. The present value for the ROD reviews is $\$ 8,346$.

\section{$\underline{\text { State Acceptance }}$}

State acceptance of this alternative could possibly be obtained. The FBRP is located in an area that the Citizens Advisory Board has recommended be retained for future industrial use. The low levels of PCBs in the soil are only a threat to human health under a residential scenario. The State may decide that institutional controls provides sufficient protection to human health and the environment for the FBRP.

\section{Community Acceptance}

Community acceptance of this alternative could also possibly be obtained for the same reasons as State acceptance.

\subsubsection{Alternative 3 - Native Soil Cover (4').}

A four-foot native soil cover will be provided over all of the pits. This will be feathered into the surrounding area and revegetated to limit potential erosion. Minor maintenance will be provided to prevent erosion control of the cover for 30 years. This alternative provides deed notifications when the land is transferred to non-federal ownership to alert future land owners that this area was used to manage hazardous material. Five year ROD reviews would be provided to the State.

\section{Overall Protection of Human Health and the Environment}

The four-foot cover allows future residential use of this area by keeping the contaminated soil below the level that typicaliy can effect future residential receptors. The cover serves to also prevent soil contaminated with PCBs from becoming airborne where potential receptors could inhale the dust particles. All risks would be less than $1 \times 10^{-6}$.

\section{Compliance with ARARs}

This alternative meets all soil ARARs. It effectively reduces the level of PCBs in the top layer of soil which could affect future residents.

\section{Long-Term Effectiveness}

This alternative provides long-term effectiveness as long as the excavation restrictions are strictly enforced. As time goes on, residents may excavate without seeking building permits which could cause problems with spreading contaminated soil.

\section{Reduction or Toxicity, Mobility, or Volume}

PCBs are not readily mobile within the soil and do not tend to migrate to groundwater. The soil cover will help reduce any possible migration of metals or radionuclides to the groundwater by limiting water infiltration. The soil cover also reduces mobility by limiting the amount of airborne dust that may contain PCBs, metals, or radionuclides. No reduction in volume or toxicity is obtained from this alternative. 


\section{Short-Term Effectiveness}

The only risks expected for remediation workers are those involving working with heavy earthmoving equipment. Strict adherence to OSHA requirements should limit potential risks from this activity. There are no additional risks to the community while remediation is being done. Silt fences and other erosion prevention methods shall be employed during the construction of the cover to limit damage to the environment.

\section{Implementability}

This alternative is readily implementable at the FBRP. All necessary equipment can be easily obtained. Deed restrictions can be placed when ownership of the property is transferred.

\section{$\underline{\text { Cost }}$}

The total estimated present value cost for this alternative is $\$ 415,164$. The cost of installing a four-foot soil cover over each of the three pits is estimated to cost $\$ 347,132$. The cost to prepare a Remedial Design/Remedial Action (RD/RA) plan is estimated to be $\$ 50,000$. Deed restrictions and the survey plat would cost $\$ 2,000$. Maintenance is estimated to cost $\$ 500$ per year for 30 years. This present value cost is $\$ 7,686$. The cost of ROD reviews every five years for 30 years is estimated to be $\$ 3,000$ per year for a present value cost of $\$ 8,346$.

\section{State Acceptance}

State acceptance may possibly be obtained for this alternative if the State decides that they prefer to accommodate future residential use of this land.

\section{Community Acceptance}

Community acceptance would likely follow the State's lead on this alternative.

\subsubsection{Alternative 4- Thermal Desorption/Incineration}

This alternative would excavate the soil in all of the pits to four feet. This soil would then be fed to a thermal desorption unit which would vaporize the PCBs and other organic materials from the soil. The offgas would then be incinerated to destroy the PCBs and other organic materials. The treated soil would then be placed back into the pits and revegetated. This alternative would allow for restricted residential use of this land in which excavation beyond four feet would be prohibited.

\section{Overall Protection of Human Health and the Environment}

This alternative provides complete protection of human health and the environment.

\section{Compliance with ARARs}

All ARARs will be met.

\section{Long-Term Effectiveness}

This alternative provides long-term effectiveness as the PCBs and organic materials are removed from the soil and destroyed through incineration. Some risk will remain as this technology will not remediate metals or radionuclides in the soil. 
Reduction or Toxicity, Mobility, or Volume

Toxicity, mobility, and volume of the PCBs and organic materials will all be greatly reduced. This alternative is expected to remove virtually all of the PCBs and organic materials from the soil and will then degrade them during the incineration process. The risks from metals and radionuclides will remain as this technology has little effect of these contaminants.

\section{Short-Term Effectiveness}

There are risks to remedial workers from working with heavy earthmoving equipment, from potential contact with contaminated soil, and from the high temperature equipment used for desorption and incineration. All of these risks can be managed through strict adherence of OSHA regulations and wearing proper equipment.

\section{Implementability}

This alternative is implementable at FBRP, however, there are a limited number of contractors with equipment capable of treating PCBs in soil. NESHAPS air permits will be required for the incineration process.

\section{$\underline{\text { Cost }}$}

The total present value cost of this process has been estimated to be $\$ 6,879,536$. This is based on a turnkey contracted cost of $\$ 30 / \mathrm{ft}^{3}$ of soil to be remediated. RP $231-2 \mathrm{~F}$ covers an area of approximately $164 \mathrm{ft}$ by $33 \mathrm{ft}$. The soil depth required for residential use is four feet for a total soil volume of $21,648 \mathrm{ft}^{3}$. BRP 231-F covers an area measuring approximately $275 \mathrm{ft}$ by $62 \mathrm{ft}$. Excavating to four feet results in a volume of $68,200 \mathrm{ft}^{3}$. BRP 231 -1F measures $325 \mathrm{ft}$ by $89 \mathrm{ft}$ which results in a volume of $115,700 \mathrm{ft}^{3}$. The total volume of soil to be treated for all three pits is $205,548 \mathrm{ft}^{3}$. Deed restrictions and a survey plat were estimated to cost $\$ 2,000$. The estimated cost for preparing an RD/RA plan is $\$ 150,000$. The estimated cost of obtaining an air permit for PCB incineration is $\$ 150,000$.

\section{$\underline{\text { State Acceptance }}$}

This alternative would likely meet with the State's approval. The PCBs and other organic materials are totally removed and destroyed so that there is not residual risk from these contaminants. This alternative will not remediate the metals or the radionuclides. Some risks between $1 \times 10^{-6}$ and $1 \times 10^{-4}$ will remain.

\section{Community Acceptance}

The community would likely accept this alternative as well, however, it is likely that they would have reservations about this level of spending for the low level of risk reduction attained.

\subsubsection{Alternative 5 - Offsite Soil Disposal}

This alternative would excavate the soil in the pits to four feet. This soil would then be shipped to a licensed waste disposal facility. Clean soil would then be placed into the pit and revegetated. This alternative would allow for restricted future residential use of this land in which excavation beyond four feet would be prohibited.

\section{Overall Protection of Human Health and the Environment}

This alternative provides complete protection of human health and the environment.

Compliance with ARARs

All ARARs will be met. 


\section{Long-Term Effectiveness}

This alternative provides complete long-term effectiveness as the contaminants are removed from the rubble pits.

\section{Reduction or Toxicity, Mobility, or Volume}

This alternative is expected to remove virtually all of the contaminants from the pits. The mobility of the contaminants will be slightly decreased. The contaminants are not very mobile, however, licensed waste facilities are designed to minimize migration of the contaminants. The volume and toxicity of the contaminated soil remains the same.

\section{Short-Term Effectiveness}

There are risks to remedial workers from working with heavy earthmoving equipment, from potential contact with contaminated soil, and transportation of the soil to the waste facility. All of these risks can be managed through strict adherence of OSHA regulations and wearing proper equipment.

\section{Implementability}

This alternative is implementable at FBRP. There are waste facilities that can take PCB, metals, and radionuclide contaminated soil (low levels) within 400 miles of SRS.

\section{$\underline{\text { Cost }}$}

The total present value cost of this alternative is $\$ 4,674,817$. Deed restrictions and a survey plat were estimated to cost $\$ 2,000$. Exćavation costs were estimated to be $\$ 205,548$ based on a cost of $\$ 1 / \mathrm{ft}^{3}$ for $205,548 \mathrm{ft}^{3}$. BRP $231-\mathrm{F}$ has dimensions of $275 \mathrm{ft}$ by $62 \mathrm{ft}$ while BRP231-1F is $325 \mathrm{ft}$ by $89 \mathrm{ft}$. RP $231-2 \mathrm{~F}$ covers an area of approximately $164 \mathrm{ft}$ by $33 \mathrm{ft}$. The soil depth required for residential use is four feet. The cost of transportation was estimated to be $\$ 761,289$ based on a cost of $\$ 0.25 / \mathrm{yd}^{3} /$ loaded mile for 400 miles. The cost for refilling the pit with clean soil was estimated at $\$ 1 / \mathrm{ft}^{3}$ for a cost of $\$ 205,548$. The cost of disposal is $\$ 3,350,432$ based on a cost of $\$ 326 /$ ton and $100 \mathrm{lb} / \mathrm{ft}^{3}$ for the soil. The cost to prepare an RD/RA plan is estimated to be $\$ 150,000$.

\section{$\underline{\text { State Acceptance }}$}

This alternative would likely meet with the State's approval. The PCBs, metals, and radionuclides are totally removed from the top $4 \mathrm{ft}$ of soil so there is no residual risk.

\section{Community Acceptance}

The community would likely accept this alternative as well, however, it is likely that they would have reservations about this level of spending for the low level of risk reduction attained.

\subsubsection{Summary of the Evaluation of the Alternatives Under the 9 CERCLA Criteria}

Tables 4-1 through 4-5 give a brief summary of the evaluation of the five alternatives under the nine CERCLA criteria.

\subsection{Comparative Analysis of the Alternatives}

This section discusses how well each of the alternatives addresses each particular CERCLA criteria. Under each criteria, the alternatives are discussed in the relative order that they performed for that particular category. 


\subsubsection{Overall Protection of Human Health and the Environment}

Alternative 5 provides the greatest overall protection to human health and the environment. In this alternative, the contaminants have been completely removed from the pits. There is no chance that they will impact potential receptors at this unit. Alternative 4 provides the next highest level of protection as the PCBs and organic materials have been eliminated. These contaminants produced the highest levels of risk, however, some risk will still remain from the metals and radionuclides left in the soil. Alternative 2 provides the next best level of protection. Institutional controls prevent future residential land use. This effectively places the maximum PCB level at less than one-third of the ARAR. Risks from the other contaminants are-reduced from the residential land scenario to the values given for the industrial land use scenario. Alternative 3 adds a soil cover which acts as a barrier to the contaminated soil, however residential access to this land is allowed. It would be difficult to ensure that future residents did not excavate below the four-foot level. Alternative 1 provides no protection.

\subsubsection{Compliance with ARARs.}

All of the alternatives meet the PCB ARAR of $10 \mathrm{mg} / \mathrm{kg}$ (TSCA). Alternatives 4 and 5 provide the highest level of compliance as the PCBs are removed from RP 231-2F. Alternatives 2 and 3 both meet the to-be-considered guidance of $1 \mathrm{mg} / \mathrm{kg}$ PCB. Alternative 1 does not meet the to-be-considered guidance for residential use

\subsubsection{Long-Term Effectiveness}

Alternatives 4 and 5 provide complete long-term effectiveness as the contaminants are removed from the pits. Alternative 4, however, does not remove all of the contaminants. Alternative 2 relies on deed restrictions to provide long-term effectiveness. Alternative 3 relies on the integrity of the soil cover. Erosion control must be maintained and excavation limited. Alternative 1 provides no long-term effectiveness.

\subsubsection{Reduction of Toxicity, Mobility, or Volume}

Alternative 4 is the only alternative that reduces all of these items. While alternative 5 only reduces mobility to a small degree by shipping the soil to a designed waste facility, the contaminated soil is removed and is replaced with clean soil. Alternative 3 helps to reduce the mobility of the soil contaminates. The soil cover will effectively prevent contaminated dust from becoming airborne. Alternative 2 limits receptor access to the contaminated soil which lowers the likelihood of affecting potential receptors. Alternatives 1 and 2 will not reduce the toxicity, mobility, or volume of the contaminated soil.

\subsubsection{Short-Term Effectiveness}

Alternatives 1 and 2 provides the least risk to remedial workers because they involve no remediation work. Alternatives 3,4 , and 5 contribute risk to remedial workers from the use of heavy earthmoving equipment. Alternatives 4 and 5 contribute risk as potential contamination from excavated soils. Alternative 4 also presents a potential risk from contact with high temperature equipment. Alternatives 3,4 , and 5 all have the potential to cause impacts to the environment from erosion. None of the alternatives should affect the community during remediation.

\subsubsection{Implementability}

Alternative $I$ is the casiest to implement as it requires no further work. Alternative 2 requires only the addition of deed restrictions and the filing of ROD reviews every five years. Alternative 3 requires adding a four-foot soil cover, revegetating the area, and providing decd notifications. Alternative 5 requires excavating the soil, 
shipping it to a waste disposal facility, placing clean soil back in the pit, and revegetating it. Alternative 4 is the most difficult to implement as it requires excavating the contaminated soil, processing it through the desorption/incineration equipment, replacing the treated soil in the pit, and revegetating the surface.

\subsubsection{Cost}

Alternative 1 has no costs associated with it. Alternative 2 has an estimated present value cost of $\$ 10,346$. Alternative 3 has an estimated present value cost of $\$ 415,164$. Alternative 5 has a present value cost of $\$ 4,674,817$. Alternative 4 has an estimated present value of $\$ 6,879,536$.

\subsubsection{State Acceptance}

Alternative 5 would be acceptable to the State as it completely remediates the site. Alternative 4 would likely be acceptable to the regulators as the PCBs and organic materials are removed and destroyed. These contaminants produced the highest levels of risks calculated at the unit. The metals and radionuclides would still contribute risks between $1 \times 10^{-6}$ and $1 \times 10^{-4}$. Alternative 2 may be acceptable to the State if they accept the recommendation that this area should be retained for future industrial use only. Alternative 3 may be acceptable to the State as a low cost method of allowing the land to be used for residential purposes. Alternative 1 would not likely be acceptable to the State.

\subsubsection{Community Acceptance}

Alternative 2 would likely be the alternative most acceptable to the community. The CAB has recommended that the FBRP be designated for future industrial use only. This alternative is low cost and would provide protection to human health and the environment. Alternative 3 would possibly be acceptable to the community if they feel that deed restrictions are sufficient to prevent excavation in a residential area. Alternatives 4 and 5 would be acceptable to the community, however, it is likely that they will feel the significant expense for either of these alternatives does not justify the slight reduction in risk obtained. Alternative 1 would not likely be acceptable to the community. 


\begin{tabular}{|c|c|c|c|c|c|c|c|c|}
\hline $\begin{array}{l}\text { Overall Protection of } \\
\text { Hurman Health and } \\
\text { ixc Envirunment }\end{array}$ & $\begin{array}{l}\text { Compliance widh } \\
\text { ARARs }\end{array}$ & $\begin{array}{l}\text { Long-Term } \\
\text { Effectiveness }\end{array}$ & $\begin{array}{l}\text { Reduction of } \\
\text { Toxicity. Mobility, of } \\
\text { Volume }\end{array}$ & $\begin{array}{l}\text { Short-Term } \\
\text { Effectiveness }\end{array}$ & Implementability & $\operatorname{Cos} t$ & State Acceptance & $\begin{array}{l}\text { Community } \\
\text { Acceptance }\end{array}$ \\
\hline $\begin{array}{l}\text { - Prorectiveness } \\
\text { Yo action taken. } \\
\text { vill not redure risks } \\
\text { from those reported } \\
\text { in the } B R A \text {. }\end{array}$ & $\begin{array}{l}\text { - Compliance with } \\
\text { contaminant specific } \\
\text { ARARs } \\
\text { All ARARs met } \\
\text { PCB-1254 exceeds } \\
\text { tobe-considered } \\
\text { guiddance. } \\
\text { - Compliance with } \\
\text { Acrion-Specific } \\
\text { ARARs } \\
\text { No sction taken. } \\
\text { Not applicable } \\
\text { - Compliance with } \\
\text { Location.Specific } \\
\text { ARARs } \\
\text { The site is in } \\
\text { compliance with all } \\
\text { location-specific } \\
\text { ARARs. } \\
\text { - Compliance with } \\
\text { other criteria. } \\
\text { odvisories, and } \\
\text { guidance } \\
\text { No ation taken. } \\
\text { Not applicable }\end{array}$ & $\begin{array}{l}\text { - Magnitude of } \\
\text { residual risk } \\
\text { No risks above } 1 \times \\
10^{-1} \text { from soil, } \mathrm{HI}<1 \text {. } \\
\text { - Adequacy and } \\
\text { reliability of controls } \\
\text { Inadequate. No } \\
\text { control of future } \\
\text { land use provided. }\end{array}$ & 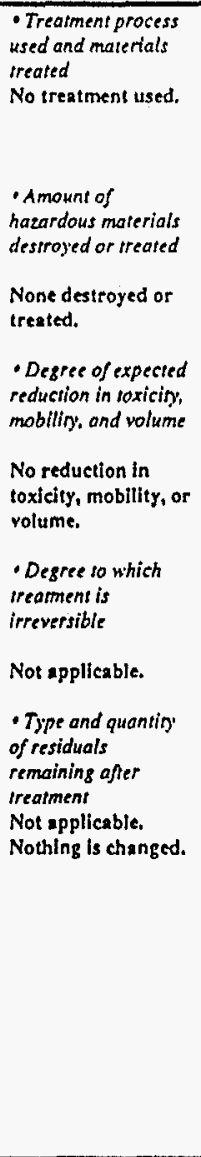 & $\begin{array}{l}\text { - Protection of } \\
\text { community during } \\
\text { remedial actions } \\
\text { Not appllcable. No } \\
\text { remediation } \\
\text { performed. } \\
\text { - Protection of } \\
\text { sorkers during } \\
\text { remedial action } \\
\text { Not applicable. No } \\
\text { remedistlon } \\
\text { pertormed. } \\
\text { Environmental } \\
\text { Impacts } \\
\text { None. }\end{array}$ & 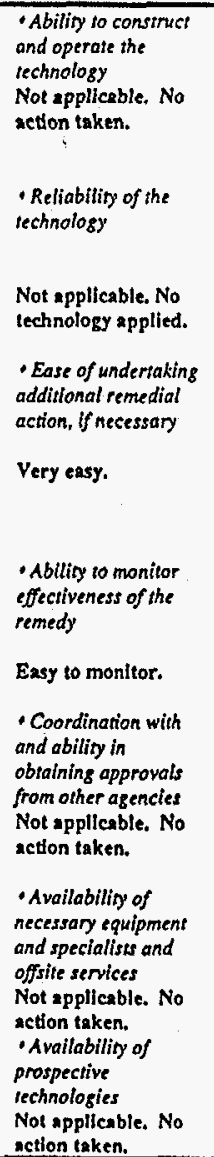 & $\begin{array}{l}\text { - Capisal costs } \\
\text { None. } \\
\text { - Operating and } \\
\text { maintenance cosss }\end{array}$ & $\begin{array}{l}\text { - Features of the } \\
\text { alternarive about } \\
\text { which the state has } \\
\text { reservarions } \\
\text { Not applicable. } \\
\text { - Elements of the } \\
\text { aliernative the stase } \\
\text { strongly opposes } \\
\text { Overall risks to } \\
\text { future residents are } \\
\text { grenter then } 1 \times 10^{-4} \text {. }\end{array}$ & 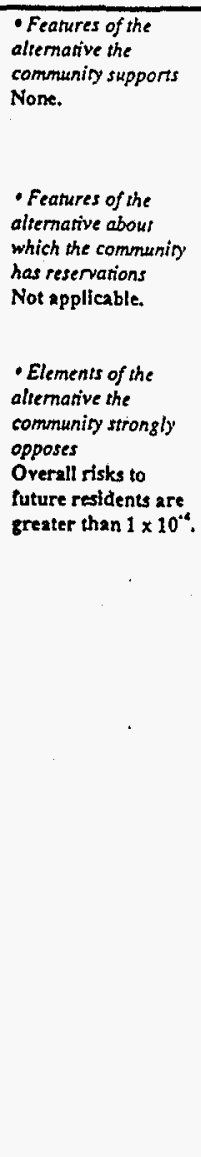 \\
\hline $\begin{array}{c}\text { Selectrd (Yes/No) } \\
Y_{e s}\end{array}$ & Rationalc & & ine for comparison. & & & & & \\
\hline
\end{tabular}


Table 4-2

Evaluation of Alternative 2 - Institutional Controls Under the Nine CERCLA Criteria

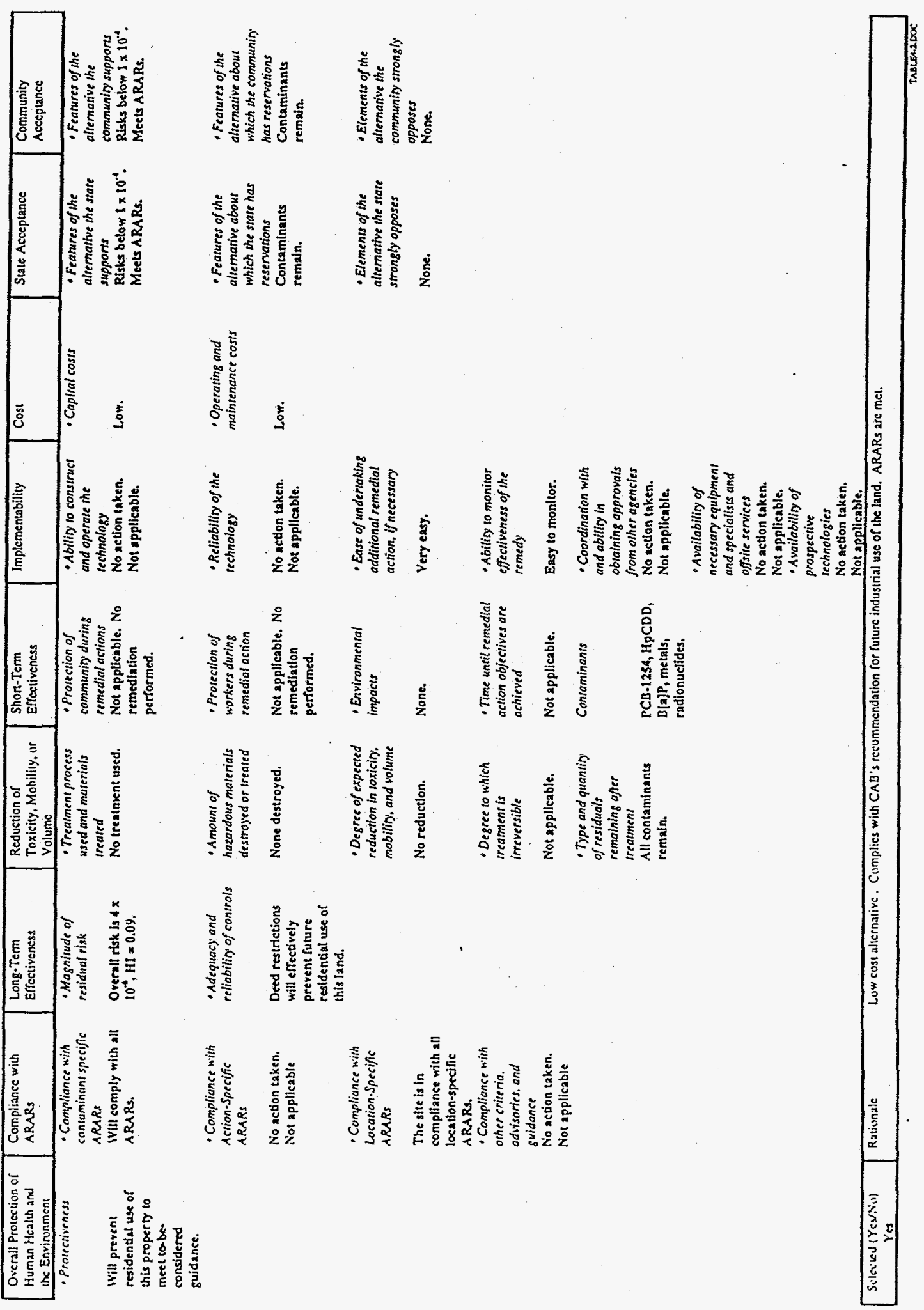


Table 4-3

Evaluation of Alternative 3 - Soil Cover $\left(4^{\prime}\right)$ Under the Nine CERCLA Criteria

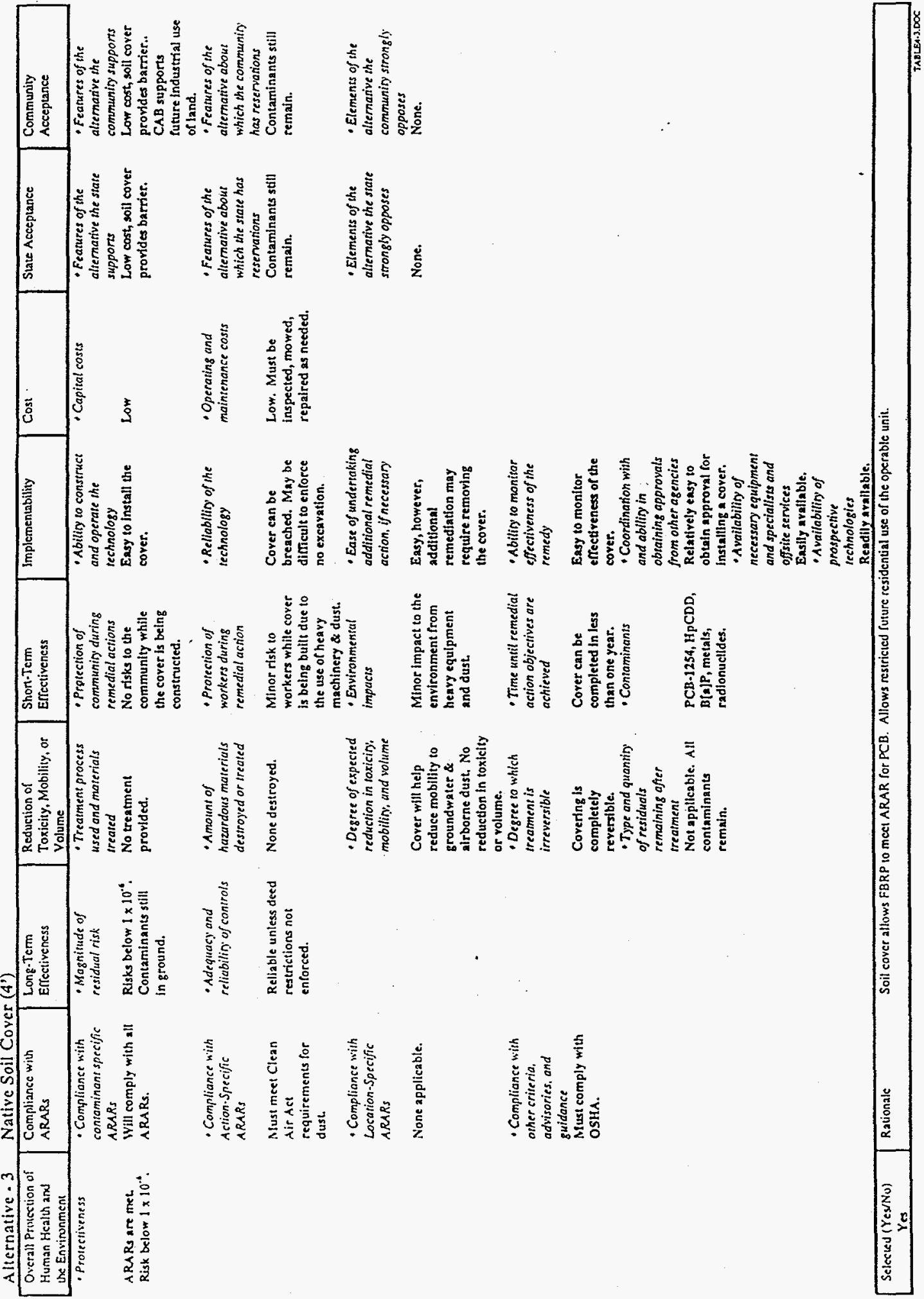




\begin{tabular}{|c|c|c|c|c|c|c|c|c|}
\hline $\begin{array}{l}\text { Overall Protection of } \\
\text { Human Heal th and } \\
\text { the Environment }\end{array}$ & $\begin{array}{l}\text { Complianec with } \\
\text { ARARs }\end{array}$ & $\begin{array}{l}\text { Long. Term } \\
\text { Efrectiveness }\end{array}$ & $\begin{array}{l}\text { Reduction of } \\
\text { Toxicity, Mobility, or } \\
\text { Volume }\end{array}$ & $\begin{array}{l}\text { Shorl-Term } \\
\text { Eftectiveness }\end{array}$ & Implementability & Cost & State Acceptance & $\begin{array}{l}\text { Community } \\
\text { Acceptance }\end{array}$ \\
\hline \multirow[t]{9}{*}{$\begin{array}{l}\text { Orers complets } \\
\text { protection of human } \\
\text { health \& the } \\
\text { environtrent. }\end{array}$} & $\begin{array}{l}\text { - Compliance with } \\
\text { contaminant specific } \\
\text { ARARs } \\
\text { will comply with all } \\
\text { ARARs. }\end{array}$ & $\begin{array}{l}\text { - Magnitude of } \\
\text { residual risk } \\
\text { Organic risks will be } \\
\text { reduced to below } 1 \mathrm{x} \\
10^{4} \text {. Risks from } \\
\text { metals \& } \\
\text { radionuclides } \\
\text { remain. }\end{array}$ & $\begin{array}{l}\text { - Treatment process } \\
\text { used and materials } \\
\text { treated } \\
\text { Organic } \\
\text { contaminants will be } \\
\text { volatilized and } \\
\text { incinerated. }\end{array}$ & $\begin{array}{l}\text { - Protocition of } \\
\text { communisy, during } \\
\text { remedial actions } \\
\text { Community will be } \\
\text { completely protected } \\
\text { whlle remediation is } \\
\text { ongolng. }\end{array}$ & $\begin{array}{l}\text { Ability to construct } \\
\text { ond operate the } \\
\text { lechnology } \\
\text { Implementable. } \\
\text { Somerhat limited } \\
\text { availabilty of equip. } \\
\text { Not a problem. }\end{array}$ & $\begin{array}{l}\text { Capisal costs } \\
\text { High. }\end{array}$ & $\begin{array}{l}\text { - Features of the } \\
\text { alternative the state } \\
\text { suppors } \\
\text { Destroys all organic } \\
\text { materials. }\end{array}$ & $\begin{array}{l}\text { - Features of the } \\
\text { aliernative the } \\
\text { community suppons } \\
\text { Destroys all organic } \\
\text { materials. }\end{array}$ \\
\hline & $\begin{array}{l}\text { - Compliance with } \\
\text { Action-Specific } \\
\text { ARARs }\end{array}$ & $\begin{array}{l}\text { Adequact and } \\
\text { reliabiling of controls }\end{array}$ & $\begin{array}{l}\text { Amount of } \\
\text { hazasdous materials } \\
\text { destroyed or treated }\end{array}$ & $\begin{array}{l}\text { - Protection of } \\
\text { workers during } \\
\text { remedial action }\end{array}$ & $\begin{array}{l}\text { - Relliability of the } \\
\text { technology }\end{array}$ & $\begin{array}{l}\text { - Operating and } \\
\text { maintenance costs }\end{array}$ & $\begin{array}{l}\text { - Fearures of the } \\
\text { alternative about } \\
\text { which the state has } \\
\text { reservations }\end{array}$ & $\begin{array}{l}\text { - Fearures of the } \\
\text { allermative about } \\
\text { which che community } \\
\text { has reservations }\end{array}$ \\
\hline & $\begin{array}{l}\text { Must meet Clean } \\
\text { Air Act } \\
\text { requirements for } \\
\text { dust \& emissions. }\end{array}$ & $\begin{array}{l}\text { Completely } \\
\text { adequate and } \\
\text { reliable. }\end{array}$ & $\begin{array}{l}\text { Yirtually all of the } \\
\text { organic } \\
\text { contaminants can be } \\
\text { remored end } \\
\text { destroyed. }\end{array}$ & $\begin{array}{l}\text { Protection from dust } \\
\text { inhalation, contact } \\
\text { with contamlnated } \\
\text { soll \& injurtes from } \\
\text { heary maachinery } \\
\text { needed. }\end{array}$ & Very reliable. & $\begin{array}{l}\text { High operating } \\
\text { costs, no } \\
\text { maintenance ster } \\
\text { remediation. }\end{array}$ & $\begin{array}{l}\text { No risk reduction to } \\
\text { metals or } \\
\text { radionuclides. }\end{array}$ & $\begin{array}{l}\text { CAB reeommends } \\
\text { industrial use. } \\
\text { Significant cost for } \\
\text { low risk reduction. }\end{array}$ \\
\hline & $\begin{array}{l}\text { - Compliance with } \\
\text { Location-Specific } \\
\text { ARARs }\end{array}$ & & $\begin{array}{l}\text { - Degrete of expected } \\
\text { reduction in roxicitis: } \\
\text { mobilly, and volume }\end{array}$ & $\begin{array}{l}\text { - Environmental } \\
\text { impacts }\end{array}$ & $\begin{array}{l}\text { - Ease of underraking } \\
\text { additional remedtial } \\
\text { action, if necessary }\end{array}$ & & $\begin{array}{l}\text { Elements of the } \\
\text { alternative the state } \\
\text { strongly opposes }\end{array}$ & $\begin{array}{l}\text { - Elements of the } \\
\text { allernative the } \\
\text { community strongly } \\
\text { opposes }\end{array}$ \\
\hline & $\begin{array}{l}\text { None applicable. } \\
\text { - Compliance with } \\
\text { other criteria. } \\
\text { advisories. and } \\
\text { suidance }\end{array}$ & - & $\begin{array}{l}\text { Virtually complete } \\
\text { tor organics only. } \\
\text { - Degree to which } \\
\text { treatment is } \\
\text { irreversible }\end{array}$ & $\begin{array}{l}\text { Erosion will be } \\
\text { controlled. } \\
\text { - Time until remedial } \\
\text { action objectives are } \\
\text { achieved }\end{array}$ & $\begin{array}{l}\text { Easy, but none } \\
\text { shoutd be required. } \\
\text {-Ability to monitor } \\
\text { effectiveness of the } \\
\text { remedy }\end{array}$ & & None. & None. \\
\hline & $\begin{array}{l}\text { OSHA must be } \\
\text { followed. }\end{array}$ & & Irreversible. & $\begin{array}{l}\text { Approximately one } \\
\text { year. }\end{array}$ & Easy to test & & & \\
\hline & & & $\begin{array}{l}\text { - Type and quantity } \\
\text { of restiduals } \\
\text { remaining affer } \\
\text { treasment }\end{array}$ & - Contaminants & $\begin{array}{l}\text { - Coordination with } \\
\text { and ability in } \\
\text { obtaining approvals } \\
\text { from other agencies }\end{array}$ & & & \\
\hline & & & None. & $\begin{array}{l}\text { PCB-1254, HpCDD, } \\
\text { B|a]P, metals, } \\
\text { radionuclides. }\end{array}$ & Need uir permits. & & & \\
\hline & & & . & & $\begin{array}{l}\text {-Availability of } \\
\text { necessary equipment } \\
\text { and specialiss and } \\
\text { offsite services } \\
\text { Somewhat itmited. } \\
\text { - Availability of } \\
\text { prospective } \\
\text { rechnologies } \\
\text { Someshat limited. }\end{array}$ & & & . \\
\hline $\begin{array}{c}\text { Selected }\left(Y_{e s} / N_{0}\right) \\
Y_{e}\end{array}$ & Racionale & & & tion. & & & & \\
\hline
\end{tabular}

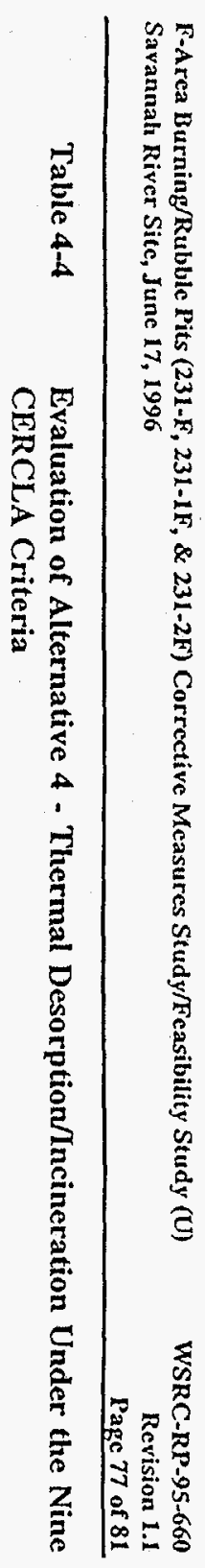


Table 4-5

Evaluation of Alternative 5 - Offsite Soil Disposal Under the Nine CERCLA Criteria

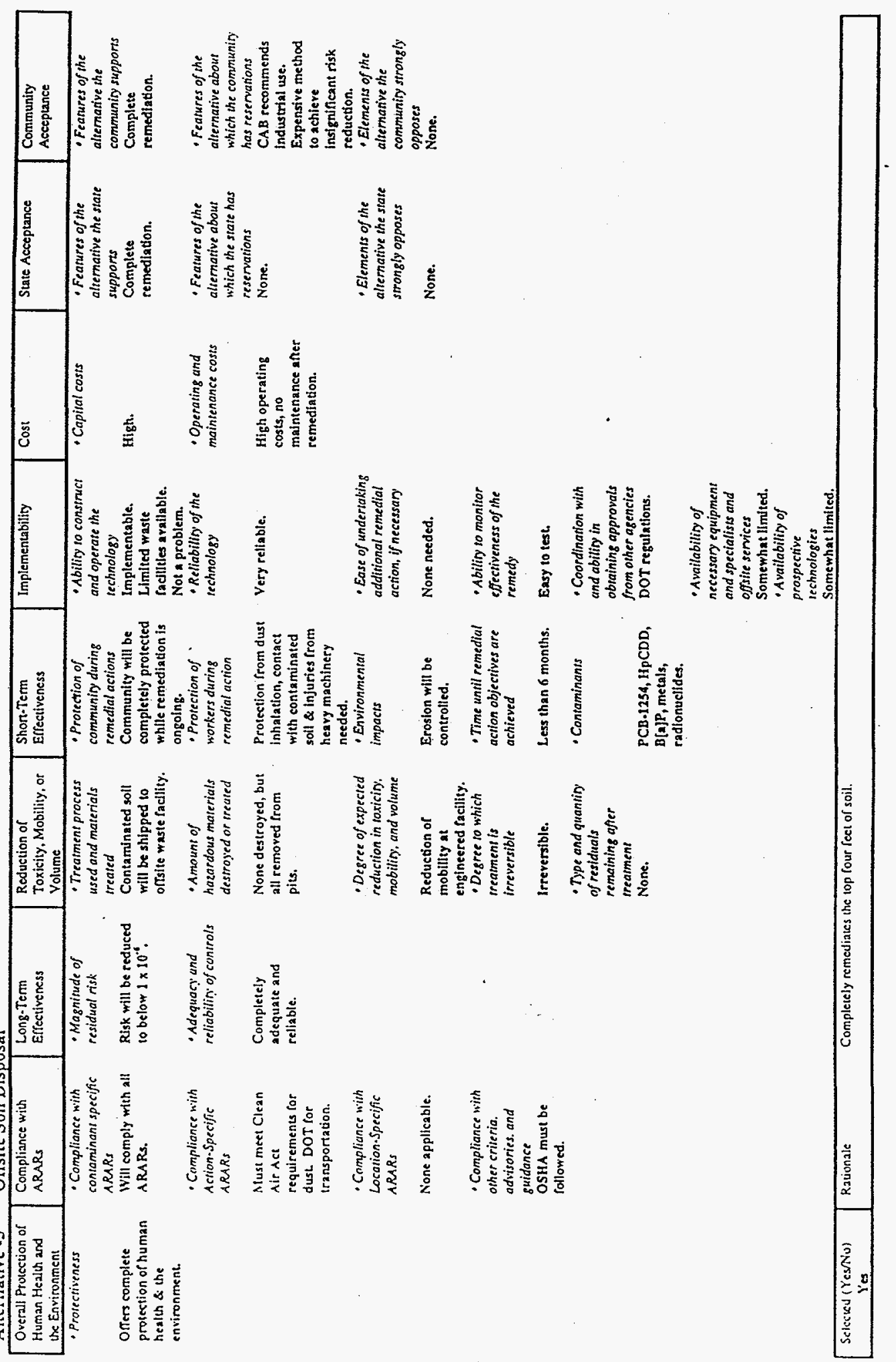


F-Area Burning/Rubble Pits (231-F, 231-1F, \& 231-2F) Corrective Measures Study/Feasibility Study (U)

WSRC-RP-95-660 Savannah River Site, June 17, 1996

Revision 1.1

Page 79 of 81

BIBLIOGRAPHY

Burbank, D. A., and Weingardt, K. M. Mixed Waste Solidification Testing on Thermosetting Polymer And Cement Based Waste Forms In Support Of Hanford's WRAP Module 2A Facility; Mixed Waste-Proceedings of the Second International Symposium; Baltimore, MD, August 17-20, 1993.

Chapman, C.C., and Robinson, R. A. Terra-Vit: A Low Cost Vitrification Technology For Site Cleanup. USDOE "ER'93-Meeting The Challenge Environmental Remediation Conference" (Proceedings Volume 2); October 24-28, 1993, Radisson Riverfront Hotel, Augusta, GA, 1993.

Conner, J. R. Hazardous Waste Site Soil Remediation-Theory and Application of Innovative Technologies (edited by Wilson, D. J. and Clarke, A. N.), Marcel Dekker, Inc., New York, NY, 1994.

DOE (U.S. Department of Energy). Implementation Plan-Environmental Restoration and Waste Management Programmatic Environmental Impact Statement. Prepared by the U.S. Department of Energy Environmental Restoration and Waste Management Program; Washington, DC, 1994;.

DOE (U. S. Department of Energy). Savannah River Site: Future Use Project Report. Stakeholder Recommendations for SRS Land and Facilities. January, 1996.

Dole, Leslie R. Case Studies of Solidification/Stabilization Remediation Technologies Applied to Mixed Wastes with Organics, Heavy Metals, and Radioactive lsotopes. Abstract presented at the Environmental Remediation Conference, Augusta, GA, 1993.

Dragun, J. The Fate of Hazardous Materials in Soils, Part 2, Hazardous Materials Control (HMC), May/June 1988.

England J. L., et al. Perspective Of Hazardous Waste And Mixed Waste Treatment Technology At The Savannah River Site. Mixed Waste-Proceedings of the First International Symposium; Baltimore, MD, August 26-29, 1991.

EPA (U. S. Environmental Protection Agency). Quality Criteria for Water, EPA/440/5-86/001, Office of Water Regulations and Standards., Washington, DC), 1986.

EPA (U. S. Environmental Protection Agency). Guidance for Conducting Remedial Investigations and Feasibility Studies Under CERCLA. EPA/540/G-89/004, OSWER Directive 9355.3-01, Office of Emergency and Remedial Response, USEPA, Washington, DC, October, 1988a.

EPA (U. S. Environmental Protection Agency). CERCLA Compliance with Other Laws Manual, Draft Guidance, OSWER Directive 9234.1-01, U.S. Environmental Protection Agency, Washington, DC, 1988b

EPA (U. S. Environmental Protection Agency). Technological Approaches to the Cleanup of Radiologically Contaminated Superfund Sites, EPA/540/2-90/00, U.S. Environmental Protection Agency, Washington, DC, $1988 \mathrm{c}$

EPA (U.S. Environmental Protection Agency). Interim Procedures for Estimating Risks Associated with Exposures to Mixtures of Chlorinated Dibenzo - p - Dioxins and -Dibenzofurans (CDDs and CDFs) and 1989 Update. EPA/625/3-89/016. Risk Assessment Forum, Washington, DC, 1989a.

EPA (U.S. Environmental Protection Agency). Stabilization/Solidification of CERCLA and RCRA WastesPhysical Tests, Chemical Testing Procedures, Technology Screening, and Field Activities, (EPA/625/6-89/022); Risk Reduction Engineering Laboratory, Cincinnati, OH), $1989 \mathrm{~b}$. 
EPA (U. S. Environmental Protection Agency). A Guide on Remedial Actions at Superfund Sites with PCB Contamination. Office of Emergency and Remedial Response. Directive 9355.4-01 FS. August, 1990.

EPA (U. S. Environmental Protection Agency). Handbook - Vitrification Technologies for Treatment of Hazardous and Radioactive Waste. EPA/625/R-92/002, 1992.

EPA (U. S. Environmental Protection Agency). Handbook-Approaches for the Remediation of Federal Facility Sites Contaminated with Explosive or Radioactive Wastes, (EPA/625/R-93/013); Office of Research and Development, Washington, DC, 1993.

EPA (U. S. Environmental Protection Agency, Region III). Selecting Exposure Routes and Contaminants of Concern by Risk Based Screening. EPA/903/R-93-001. Philadelphia, PA, 1994.

EPA (U. S. Environmental Protection Agency). Region IV, Supplemental Guidance to RAGS: Region 4 Bulletins. November, 1995a.

Fekete L. J., and Carnes W. S. Operational Control Design For A Low-Level Radioactive And Hazardous Waste Incinerator System. Mixed Waste-Proceedings of the First International Symposium; Baltimore, MD, August 26-29, 1991.

Freeman, H. M. Standard Handbook of Hazardous Waste Treatment and Disposal. McGraw-Hill Book Company, New York, 1989.

Gering K. L. Solidification Results From A Treatability Study Of Nonincinerable Low-Level Mixed Waste. Mixed Waste-Proceedings of the Second International Symposium; Baltimore, MD, ., August 1993

Loomis, G. G. and Thompson, D. N. Innovative Grout/Retrieval Demonstration Final Report, Idaho National Engineering Laboratory, Lockheed Idaho Technologies Company, Idaho Falls, Idaho. U.S. Department of Energy, Office of Environmental Management, DE-AC07-94ID13223, 1995.

Siegrist, R. L., et al. In situ Stabilization of Contaminated Soil, To be published in the Third International Symposium on Stabilization/Solidification of Hazardous, Radioactive and Mixed Wastes, ASTM STP 1240; Ed., American Society for Testing and Materials, Philadelphia, PA, 1995.

Tixier, J. S. Personal communication between Pacific Northwest Laboratories and RUST E \& I on February I, 1995.

Warren, R. W., et. al. Water Balance Relationships In Four Alternative Cover Designs For Radioactive And Mixed Waste Landfills, prepared for the USDOE Office of Technology Development/Office of Environmental Management and submitted to the American Nuclear Society for publication, August 1994.

Weidner, J. R., and Shaw, P. G. In situ Encapsulation Bench-Scale Demonstration Report FY-94 (for TTP-ID 142012), INEL-95/0039, Idaho Engineering Laboratory, Idaho Falls, ID, January 1995.

WSRC (Westinghouse Savannah River Company). Radioiodine in the Savannah River Site Environment (U). WSRC-RP-90-424-2. Aiken, SC., 1993a.

WSRC (Westinghouse Savannah River Company). Ecological Risk Assessors Guide for Evaluation of Waste Units on the Savannah River Site. WSRC-RP-92-232, Westinghouse Savannah River Company, Aiken, SC, $1993 b$.

WSRC (Westinghouse Savannah River Company). Feasibility Study Development for Environméntat Restoration Waste Units (U). ER-AP-068, Westinghouse Savannah River Company, Aiken, SC: 1/10/94. 
WSRC (Westinghouse Savannah River Company). RFI/RI Report for F-Area Burning/Rubble Pits (231-F, 231$I F$, and 23I-2F) (U). WSRC-RP-94-938, Rev. 1.1, Westinghouse Savannah River Company, Aiken, SC, March, 1996a.

WSRC (Westinghouse Savannah River Company). Baseline Risk Assessment for the F-Area Burning/Rubble Pits and Rubble Pit $(U)$. WSRC-TR-94-108, Rev. 1.2, Westinghouse Savannah River Company, Aiken, SC, March, 1996b.

WSRC (Westinghouse Savannah River Company). Phase II, RCRA Facility Investigation/Remedial Investigation Plan for the F-Area Burning/Rubble Pits (23I-F and 23I-IF) and Rubble Pit (23I-2F) (U). WSRC-RP-90-486, Rev.2.1, Westinghouse Savannah River Company, Aiken, South Carolina (May 1996c). 


\section{APPENDIX}

\section{Cost Estimates}

Cost estimates were designed to be within +50 percent and -30 percent of the actual values. Deed restrictions, ROD reviews, and site maintenance costs were best estimated values.

\section{Costs for No Action}

There are no costs associated with the No Action alternative

Total

Costs for Institutional Controls

Deed Restrictions

$\$ 2,000$

ROD Reviews, $\$ 3,000$ every 5 years for 30 years (factor 2.78 ), (see following page)

$\$ 8,346$

Total

\section{Costs for Native Soil Cover $\left(4^{\prime}\right)$}

Deed Restriction (Excavation) per CERCLA 120 (h)

$\$ 2,000$

Inspection, maintenance (present value), $\$ 500 / \mathrm{yr}, 30$ years (factor 15.375 )

$\$ 7,686$

ROD Reviews, $\$ 3,000$ every 5 years for 30 years (factor 2.78 ), (see following page)

$\$ 8,346$

Prepare RD/RA plan

$\$ 50,000$

Placing cover@ $\$ 1 / \mathrm{ft}^{3}, 347,132 \mathrm{ft}^{3}$ (4 feet thick), feathered to $40 \mathrm{ft}$

$\$ 347,132$

Total

$\$ 415,164$

\section{Costs for Thermal Desorption/Incineration}

Deed Restrictions (Excavation) per CERCLA $120(\mathrm{~h})$

$\$ 2,000$

Prepare RD/RA plan

$\$ 150,000$

Obtain air permit, administrative costs, etc.

$\$ 150,000$

Excavation

$\$ 205,548$

Thermal Desorption/Incineration turnkey contract

$\$ 6,166,440$

$205,548 \mathrm{ft}^{3}\left(@ \$ 30 / \mathrm{ft}^{3}\right)$

$\$ 205,548$

Refill Pit, revegetate

\section{Costs for Offsite Soil Disposal}

Deed Restrictions (Excavation) per CERCLA 120 (h)

Excavation

Prepare RD/RA plan

Transportation 


\section{Present Value Cost Calculation for ROD Reviews (Institutional Controls)}

For this calculation the following assumptions were made:

1) The cost of money is $5 \%$ per year.

2) The ROD reviews are relatively simple documents explaining any changes that have occurred to the site over the last five years that could possibly affect the protection of human health and the environment. The report would discuss any construction activities, land sale, or other changes that were made that might have an impact on the prescribed institutional control prohibiting residential use. The cost was estimated to be $\$ 3,000$ for each report. The first report would be due five years after the ROD is issued. Present value costs were calculated based on issuing additional reports every five years after this for 30 years. While the reports could be required well beyond 30 years, this time period was used to estimate costs.

3) The present value factors used are based on the following equation:

Present value $=$ Current $\operatorname{cost} x\left(\frac{1}{(1+i)}\right)^{y r}$

Where $\quad i=$ annual interest rate as a decimal (i.e., $5 \%$ is 0.05 )

$\mathrm{yr}=$ the number of years from the present

Reference: EPA, 1982. Economic Analysis: Methods, Procedures, Life Cycle Costing, and Cost Reviewing/Validating. DOE/MA-0063, Volume 1, January, 1982.

The following table summarizes the cost for the ROD review reports.

\begin{tabular}{|c|c|c|c|}
\hline Year & Initial Cost of ROD Review & Factor & Calculated Cost of ROD Review \\
\hline 5 & $\$ 3,000$ & 0.7835 & $\$ 2,351$ \\
\hline 10 & $\$ 3,000$ & 0.6139 & $\$ 1,842$ \\
\hline 15 & $\$ 3,000$ & 0.4810 & $\$ 1,443$ \\
\hline 20 & $\$ 3,000$ & 0.3769 & $\$ 1,131$ \\
\hline 25 & $\$ 3,000$ & 0.2953 & $\$ 886$ \\
\hline 30 & $\$ 3,000$ & 0.2314 & $\$ 694$ \\
\hline \hline Total & & $\mathbf{2 . 7 8 2 0}$ & $\$ 8,346$ \\
\hline
\end{tabular}

